UNIVERSIDADE DE SÃO PAULO - FFCLRP

DEPARTAMENTO DE FÍSICA

PROGRAMA DE PÓS-GRADUAÇÃO EM FÍSICA APLICADA À MEDICINA E BIOLOGIA

\title{
Avalanche neuronal em redes de neurônios estocásticos tipo integra-dispara com topologia Watts-Strogatz
}

\author{
Renata Pazzini Prado de Lima
}




\section{Renata Pazzini Prado de Lima}

\section{Avalanche neuronal em redes de neurônios estocásticos tipo integra-dispara com topologia Watts-Strogatz}

Dissertação apresentada à Faculdade de Filosofia, Ciências e Letras de Ribeirão Preto da Universidade de São Paulo, como parte das exigências para a obtenção do título de Mestre em Ciências.

Área : $\quad$ Física Aplicada à Medicina e Biologia

Orientador:

Prof. Dr. Ariadne Andrade Costa 
Lima, Renata Pazzini Prado de.

Avalanche neuronal em redes de neurônios estocásticos tipo integra-dispara com topologia Watts-Strogatz / Renata Pazzini Prado de Lima; Orientadora: Ariadne de Andrade Costa. Ribeirão Preto, 2021: 72p.

Dissertação (Mestrado - Programa de Pós-Graduação em Física Aplicada à Medicina e Biologia) - Faculdade de Filosofia, Ciências e Letras de Ribeirão Preto da Universidade de São Paulo.

1. avalanches neuronais 2.criticalidade auto-organizada 


\title{
FFCLRP \\ DEPARTAMENTO DE FÍSICA - UNIVERSIDADE DE SÃO PAULO \\ Universidade de São Paulo
}

\begin{abstract}
Dissertação apresentada á PROGRAMA DE PÓS-GRADUAÇÃO EM FÍSICA APLICADA À MEDICINA E BIOLOGIA intitulado Avalanche neuronal em redes de neurônios estocásticos tipo integra-dispara com topologia Watts-Strogatz de autoria de Renata Pazzini Prado de Lima, como parte das exigências para a obtenção do título de Mestre em Ciências:
\end{abstract}

Prof. Dra.: Ariadne de Andrade Costa

Instituição: Universidade Federal de Jataí (FFCLRP)

Prof. Dr.: Rodrigo Felipe de Oliveira Pena

Instituição: New Jersey Institute of Technology

Prof. Dr.: Pedro Valadão Carelli

Instituição: Universidade Federal de Pernambuco

Ribeirão Preto, 28 de Agosto de 2020 


\section{AGRADECIMENTOS}

Agradeço primeiramente à minha orientadora Ariadne de Andrade Costa pela paciência e disposição em me orientar mesmo à distância, agradeço por todo o ensinamento, dedicação, por todo o apoio que recebi nos momentos que mais precisava e por ter me oferecido a oportunidade de conduzir esta pesquisa, que é parte das atividades do CEPID-NEUROMAT -"Centro de Pesquisa e Inovação e Disseminação em Neuromatemática" (Grant No. 2013/07699-0, FAPESP).

- Agradeço aos membros da banca, por aceitarem o convite, pela disposição de acrescentar comentários construtivos que irão agregar no meu trabalho. Agradeço muitíssimo ao suporte financeiro oferecido pela agencia de fomento CAPES, por proporcionar vias financeiras para que meu projeto de mestrado pudesse ser desenvolvido.

Um agradecimento também à Nilza, Prof. Luciano Bachmann e Profa. Patricia Nicolucci por toda a paciência, disposição e praticidade nos momentos que foram necessários.

Um profundo agradecimento aos meus amigos : André, Gabi, Lucas e Sue, por estarem sempre presente e sendo o apoio que eu tanto precisava nos momentos mais difíceis e também por estarem presentes e me apoiarem nas minhas maiores loucuras e ideias aleatórias. Sem vocês eu certamente estaria lascada rs. Obrigada!

Agradeço também a meus pais e a minha família por estarem presentes sempre que possível. 


\section{RESUMO}

Redes de neurônios estocásticos do tipo integra-e-dispara com vazamento, seja em análise de campo médio ou para topologias de rede quadrada, ambas apresentam uma transição de fase de um estado absorvente para um estado ativo de maneira continua possuindo avalanches neuronais e uma correspondente lei de potência, quando analisados nos pontos críticos dessas transições. Neste projeto complementamos esses resultados para o caso de uma rede com topologia de mundo pequeno do tipo Watts-Strogatz, seja realizando comparações entre os métodos de estocasticidade tipo quenched ou tipo annealed e mostramos que possuem os mesmos expoentes de campo médio para qualquer probabilidade de rewriting $p>0$

Para uma rede com $p=0$, o expoente critico está relacionado com a dimensão critica $d=1$ da classe de universalidade, percolação direcionada. No modelo estudado, os disparos são estocásticos e ocorrem em instantes de tempo discretos, baseado em uma função de probabilidade dado por uma sigmoide. Cada neurônio do modelo possui um potencial de membrana que integraliza os sinais recebidos pelos neurônios vizinhos. O potencial de membrana este sujeito a um termo de vazamento (sendo $\mu$ a fração de potencial remanescente). Nós estudamos topologias com um variado número de conexões entre os vizinhos de cada de neurônio e diferentes valores para o termo de vazamento. Nossos resultados indicam que existe uma faixa dinâmica maior para o caso com $p=0$

O projeto aborda redes de neurônios integra-e-dispara estocásticos, para os quais a probabilidade de disparo neuronal depende do valor do potencial de membrana. Essa estocasticidade visa modelar as diferentes fontes de ruído biológico. Usando esse modelo de neurônio, simulamos redes de topologia de mundo pequeno tipo Watts-Strogatz.

Nos também estudamos o caso dos mecanismos homeostáticos com relação ao peso sináptico, força sináptica e limiar de disparo, que se auto organizam em direção da região critica. Essas oscilações estocásticas são uma característica do que denominamos na literatura como auto-organização na quasi-criticalidade.

Palavras-chave: Neurociência Computacional, Redes Neuronais, Rede de WattsStrogatz, Física Estatística, Neurônios Integra-e-Dispara Estocásticos. 


\begin{abstract}
Integral-fire-leakage stochastic neuron networks, whether in mean field analysis or for square lattice topologies, both present a phase transition from an absorbing state to an active state in a continuous manner, having neuronal avalanches and a corresponding law of potency, when analyzed at the critical points of these transitions. In this project, we complement these results for the case of a network with a Watts-Strogatz small world topology, either by making comparisons between the quenched or annealed type stochacity methods and we show that they have the same mean field exponents for any probability of rewriting $p>0$

For a network with $p=0$, the critical exponent is related to the critical dimension $d=1$ of the universality class, directed percolation. In the studied model, the triggers are stochastic and occur at discrete time instants, based on a probability function given by a sigmoid. Each neuron in the model has a membrane potential that integrates the signals received by neighboring neurons. The membrane potential is subject to a leakage term $\mu$. We study topologies with a varied number of connections between the neighbors of each neuron and different values for the leakage term. Our results indicate that there is a larger dynamic range for the case with $p=0$

The project addresses stochastic integrated-fire neuron networks, where the probability of neuronal firing depends on the value of the membrane potential. This stochasticity aims to model the different sources of biological noise. Using this neuron model, we simulate Watts-Strogatz small-world topology networks.

We also study the case of homeostatic mechanisms with respect to synaptic weight, synaptic strength and trigger threshold, which self-organize towards the critical region. These stochastic oscillations are a feature of what we call in the literature self-organization in quasi-criticality.
\end{abstract}

Keywords: Computational Neuroscience, Neuronal Networks, Watts-Strogatz Network, Statistical Physics,Stochastic Integrate-and-Fire Neurons 


\section{LISTA DE FIGURAS}

2.1 Representação de um neurônio biológico. . . . . . . . . . . . . . . . . . 15

2.2 Ilustração da comunicação sináptica entre neurônios. . . . . . . . . . . . . 17

2.3 Exemplo de uma religação aleatória com probabilidade $p$ para interpolar entre uma rede unidimensional com $K=4$ vizinhos e uma rede totalmente aleatória, permanecendo constante o número de nodos e ligações. . . . . . . 20

2.4 Comprimento do caminho característico $L(p)$ e coeficiente de agrupamento $C(p)$ em uma rede com $K=4$ vizinhos por nodo. . . . . . . . . . . . . . 21

2.5 Exemplo qualitativo de transições de fase. a) Transição de fase de primeira ordem e b) transição de fase de segunda ordem. . . . . . . . . . . . . . . . . 23

3.1 Exemplificação das propriedades do modelo neuronal e suas representações gráficas; Figura Adaptada de $[1]$. . . . . . . . . . . . . . . . . . . . 37

4.1 Simulação realizada para valores de $p \geqslant 0$ com uma rede de $N=10000$ neurônios, $K=4$ vizinhos e $\mu=0$ em redes a) quenched b) annealed. . . . 43

4.2 Curvas de $\rho(W \mid \mu)$ para o modelo com diferentes valores de probabilidade $p \operatorname{com} K=4$ e $N=10.000$, caso (a) quenched e (b) annealed. . . . . . . 45

4.3 Colapso de $\rho(W \mid \mu)$ para a) $p=0,0$ e b) $p=1,0 . N=10.000$ e $K=4$. . 46

4.5 Colapso de $\rho(W \mid K)$ para a) $p=0,0$ e b) $p=1,0 . N=10.000$ e $\mu=0 . \quad$. 46

4.4 Curvas de $\rho(W \mid K)$ para o modelo com diferentes valores de probabilidade $p$ com $\mu=0$ e $N=10.000$, caso quenched e annealed. . . . . . . . . . 47

4.6 Ajuste de curvas de redes com $N=10000$ neurônios, $K=4$ vizinhos e coeficiente de vazamento $\mu=0$, os valores obtidos para Wc foram compilados na tabela $4.2 \ldots \ldots \ldots \ldots \ldots \ldots$. . . . . . . . . . . . . . 5

4.7 Distribuição de avalanches de tamanhos $F(s)$ para vários valores de $N$, termo relacionado ao vazamento $\mu=0$ e número de vizinhos $K=4$. . . . 51

4.8 Colapso de dados da distribuição de tamanhos de avalanches $F(s)$ para $p=0,0 ; 0,3 ; 0,6$ e $p=1,0$. Termo relacionado ao vazamento: $\mu=0$ e número de vizinhos: $K=4 \ldots \ldots \ldots \ldots \ldots$

4.9 Distribuição de avalanches de duração $F(d)$ para vários valores de $N$, termo relacionado ao vazamento $\mu=0$ e número de vizinhos $K=4 \ldots \ldots$. . 54

4.10 Colapso de dados: Distribuição de duração de avalanches $F(d)$ para $p=$ $0,0,0,3,0,6$ e $p=1,0$. Termo relacionado ao vazamento : $\mu=0$ e numero de vizinhos: $K=4 \ldots \ldots \ldots \ldots \ldots \ldots$ 
4.11 Auto-organização com ganhos neuronais dinâmicos. Parâmetros: $W_{c}=$ $W_{c}(p)$ da Tabela 4.2, $\theta=0, K=4, \mu=0, I=0, u=0,1$ e $\tau$ variável. Para diferentes valores de $p$. (a) Simulação de rede do tipo quenched. (b) Simulação de rede do tipo annealed. . . . . . . . . . . . . . . . . . 58

4.12 Auto-organização com limiar de disparo dinâmicos. Parâmetros: $W_{c}=$ $W_{c}(p), \Gamma=1, K=4, \mu=0, I=0, u=0,1$ e $\tau$ variável. Para diferentes valores de $p$. (a) Simulação de rede do tipo quenched. (b) Simulação de rede do tipo annealed. . . . . . . . . . . . . . . . . . . . . . 60

4.13 Auto-organização com peso-sináptico dinâmicos. Parâmetros: $\theta=0, \Gamma=$ $1, K=4, \mu=0, I=0, u=0,1$ e $\tau$ variável. Para diferentes valores de p. (a) Simulação de rede do tipo quenched. (b) Simulação de rede do tipo

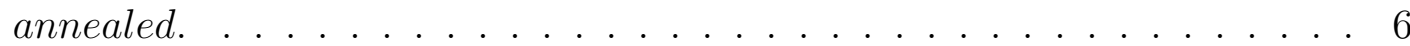




\section{LISTA DE TABELAS}

4.1 Expoentes críticos para percolação dirigida. O expoente do parâmetro de ordem na região crítica é $\beta$. Os expoentes $\tau_{s}$ e $\tau_{d}$ se referem às leis de potência para tamanho (size) e duração (duration) das avalanches. . . . . . 48

4.2 Coeficientes referentes à transição de fase de uma rede com $N=10000$ neurônios, $K=4$ vizinhos e termo relacionado ao vazamento $\mu=0$.$\} \quad . . . 49$ 


\section{Conteúdo}

1 Introdução 13

2 Referencial Teórico $\quad 14$

2.1 Atividade neuronal . . . . . . . . . . . . . . . . . . . 14

2.1.1 Neurônio biológico . . . . . . . . . . . . . . . . . . . . 14

2.1.2 Transmissão sináptica . . . . . . . . . . . . . . . . . . . 16

2.2 Neurociência teórica . . . . . . . . . . . . . . . . . . . . . . . . . 18

2.3 Redes com propriedades de mundo pequeno . . . . . . . . . . . . . . . 18

2.3.1 Redes de mundo pequeno em Neurociências . . . . . . . . . . . . 21

2.4 Transições de fase . . . . . . . . . . . . . . . . . . . . 22

2.4.1 Percolação direcionada . . . . . . . . . . . . . . . . . . . . . . 24

2.5 Avalanches neuronais . . . . . . . . . . . . . . . . . 25

2.6 Auto-organização . . . . . . . . . . . . . . . . . 26

2.6.1 Quasi-criticalidade Auto Organizada . . . . . . . . . . . 27

2.7 Annealed ou Quenched . . . . . . . . . . . . . . . . 27

3 Metodologia 29

3.1 Modelo neuronal . . . . . . . . . . . . . . . . . . . . . . . . 29

3.2 Aproximação de campo médio . . . . . . . . . . . . . . . . . . 31

3.3 Medidas de avalanches neuronais . . . . . . . . . . . . . . . . 32

3.3.1 Leis de potência . . . . . . . . . . . . . . . 32

3.4 Auto-organização . . . . . . . . . . . . . . . . . . . 33

4 Resultados e Discussão $\quad 38$

4.1 Cálculos de campo médio . . . . . . . . . . . . . . . . . . . . . . . 38

4.1.1 Resultados para $\mu=0 \ldots \ldots$. . . . . . . . . . . . 39

4.2 Elementos GGL em uma rede com topologia de Watts-Strogatz . . . . . . 41

4.2.1 Variação da probabilidade de religação $p \in[0,1] \ldots$. . . . . . . . 42

4.2.2 Variação do termo relacionado ao vazamento $\mu \in[0,1] \ldots 43$ 
4.2 .3 Variação do número de vizinhos $K \ldots \ldots$. . . . . . . . . . . . 44

4.3 Universalidade . . . . . . . . . . . . . . . . . . . . 46

4.4 Avalanches neuronais . . . . . . . . . . . . . . . . . . . . . . . . 49

4.5 Auto-organização à quasi-criticalidade . . . . . . . . . . . . . . . . 55

4.5.1 Auto-organização com ganhos neuronais dinâmicos . . . . . . . . . 55

4.5.2 Auto-organização com limiares de disparo dinâmicos . . . . . . . . 57

4.5.3 Auto-organização com pesos sinápticos dinâmicos . . . . . . . . . . 59

5 CONCLUSÕES E PERSPECTIVAS $\quad 63$

REFERÊNCIAS $\quad 64$ 


\section{Introdução}

A neurociência tem sido uma área de constante expansão e interesse dentre a comunidade cientifica. Tamanho interesse se dá pelo fato de que o objeto de estudo principal seja um dos mecanismos mais complexos do corpo humano: o cérebro. Visando sanar e compreender essa contemporânea área da pesquisa cientifica, a neurociência tornase um campo de constante interdisciplinaridade, envolvendo físicos, matemáticos, biólogos, dentre outros. Todos esses diferentes pesquisadores atuam na melhor compreensão das condições fisiológicas e anatômicas do cérebro.

A neurociência procura entender como diversos fatores externos, tais como a idade e as experiências, afetam direta e indiretamente os circuitos neurais e o desenvolvimento mental. $[2,3,4]$.

Nosso cérebro é o órgão responsável pela maioria das funções vitais e controle do nosso organismo, é o encarregado por integralizar a nossa percepção dos estímulos externos. Devido a essa capacidade de integralização, o cérebro precisa ser uma estrutura bastante flexível e dinâmica.

O cérebro é a estrutura mais importante e participativa do sistema nervoso, sendo o sistema nervoso responsável por inúmeros elementos interagentes que apresentam uma dinâmica em grupo. A célula neuronal é encarregada do processamento de toda a informação recebida pelos estímulos internos e externos. Esse processamento da informação consiste em integralizar e disparar potenciais de ação $[3,4]$. Devido a essas atividades, os neurônios apresentam grade complexidade (mais detalhes serão apresentados na Seção 2.1.

Os comportamentos coletivos exibidos por neurônios são descritos através de alguns modelos de física estatística. Um sistema composto de muitas partículas interagentes costuma apresentar eventos como transições de fase $[5,6,7]$. Com o auxílio da análise de classes de universalidade podemos obter mais informações a respeito desses eventos [6, 7]). Dada uma classe de universalidade, podemos fazer comparações do comportamento dos sistemas que pertencem a essa classe. Portanto podemos comparar sistemas complexos a sistemas mais simples, se ambos estiverem na mesma classe de universalidade.

Esta abordagem através das classes de universalidade será nossa premissa para tentar explicar os eventos a seguir. Para tanto, estudarmos transições de fase em redes de neurônios do tipo integra-e-dispara estocásticos, com topologias do tipo mundo pequeno (modelo de Watts-Strogatz [8, 9]). 


\section{Referencial Teórico}

\section{$2.1 \quad$ Atividade neuronal}

Alguns dos objetivos da neurociência são estudar a atividade e a representação de sistemas de neurônios e a comunicação neuronal [10, 11]. No entanto, tratar o cérebro humano a partir de um modelo de neurônios discretos, contabilizando seus 89 bilhões de neurônios, pode ser um tanto quanto custoso, dependendo da abordagem utilizada.

Apesar de defendida a ideia no capítulo introdutório de que estudaremos o comportamento coletivo da rede, o comportamento individual de cada um dos elementos dessa rede contendo $N$ neurônios individuais é influente para nosso modelo. Esses neurônios possuem características que atuam de maneira significativa para a atividade da rede como um todo. Algumas características como emissão de potenciais de ação, força de interação entre dois neurônios e ganhos neuronais são importantes para a compreensão do modelo.

A intenção ao se fazer essa breve revisão teórica é capacitar o leitor a compreender algumas variáveis do nosso modelo e a quais funções biológicas essas variáveis corresponde em condições experimentais. Estaremos tratando de neurônios piramidais, que são bastante presentes no córtex $[2,3,4]$.

\subsubsection{Neurônio biológico}

O trabalho de se compreender os estímulos e princípios da propagação de informação no cérebro parte da compreensão da sua célula básica mais abundante: o neurônio [12]. Existem diferentes tipos de neurônios biológicos e existem inúmeras características que os diferenciam, dentre elas, morfologia, localização no cérebro e função. Contudo daremos um enfoque para os neurônios piramidais, devido a este ser o mais abundante no cérebro dos mamíferos [13].

Os neurônios piramidais, como o próprio nome já diz, possuem um aspecto de piramide, com uma ramificação dupla de dendritos em sua extremidade. Neurônios piramidais são de nosso interesse devido a constantes observações desses neurônios em diversas espécies. Devido a essa abundancia, estima-se que tais neurônios executem um papel importante nas atividades cognitivas [14,3].

Um neurônio possui alguns segmentos principais: dendritos, soma e axônio. Vamos aqui dar uma breve introdução das funções principais de cada um desses componentes. Todas essas células possuem uma membrana formada por lipídeos e proteínas, em que os lipídeos estão dispostos em bicamadas, conforme um modelo mosaico fluído com proteínas imersas e glicídios marcadores. A permeabilidade de sua membrana a um dado íon depende de fatores elétricos, químicos e mecânicos. 


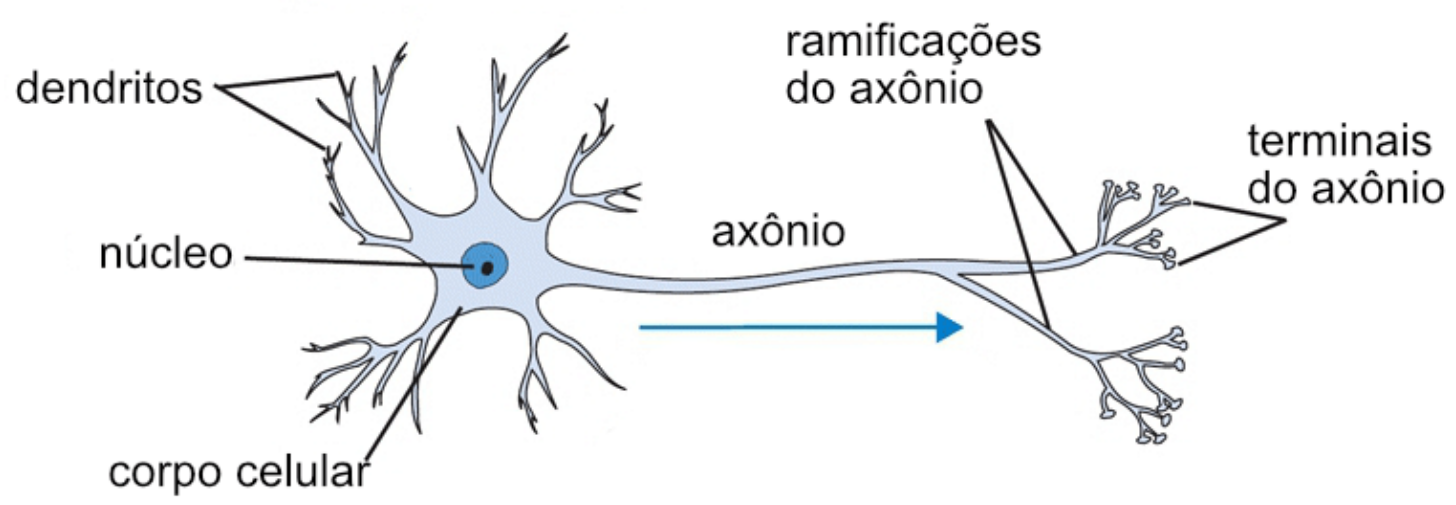

Figura 2.1: Representação de um neurônio biológico.

Figura adaptada de [15].

Primeiramente, o dendrito é a unidade responsável por interceptar um sinal emitido por um neurônio anterior e propagar esse sinal até o núcleo da célula neuronal. Uma curiosidade a respeito dos dendritos dos neurônios piramidais é sua abundancia. Uma vez que sua superfície de contato celular é vasta, o dendrito se torna mais eficiente em receptar os impulsos emitidos pelo axônio de outros neurônios anteriores [16].

O soma, também denominado núcleo, é a região responsável por integrar os sinais interceptados pelos dendritos e transmitir esse estímulo integralizado pelo terminal axônio do neurônio. O núcleo possui a função reguladora da célula, ditando sua frequência de disparos e atividade [17, 13].

E por fim, o axônio é o responsável por emitir um impulso nervoso para outras células neuronais. O axônio possui um corpo alongado e uma ramificação menos densa que os dendritos. Usualmente uma célula neuronal possui apenas um axônio, este mais longo que os dendritos, é envolvido em uma bainha, chamada de bainha de mielina, que garante isolamento elétrico. As bainhas de mielina são interrompidas regularmente e essas posições recebem o nome de nódulos de Ranvier.

Os três componentes acima descritos executam as funcionalidades principais de um neurônio, sendo a atividade principal a transmissão de informação por toda a rede complexa do cérebro. Esse processo de transmissão ocorre de forma que um impulso efetuado pelo axônio pré-sináptico e interceptado pelo dendrito pós-sináptico de outro neurônio é integralizado pelo núcleo e então posteriormente enviado para o axônio e assim transmite-se esse impulso nervoso por toda a rede de forma sucessiva pelas células [14]

A região onde ocorre a comunicação entre os dois neurônios é conhecida como sinapse. Essa região é repleta de mediadores tornando-a propícia para a propagação dos impulsos, sejam eles químicos ou elétricos dos neurônios. Alguns estudos apontam que 
uma única célula neuronal pode fazer até mil sinapses com outros neurônios. Para se compreender melhor as sinapses vide a seção seguinte.

Outras células que têm levantado interesse da comunidade cientifica são as glias (ou células gliais). Essas células estão presentes no cérebro em grande numero, cerca de 1 trilhão. As células gliais têm como função a manutenção e a nutrição da rede neuronal [18]. No entanto no presente trabalho não estudaremos as células gliais.

Em conclusão, os neurônios se diferenciam das outras células presentes no nosso corpo devido à capacidade de conduzir sinais bioelétricos por longas distancias.

\subsubsection{Transmissão sináptica}

Dando continuidade à breve introdução dos conceitos a respeito da atividade neuronal, precisamos explicitar os princípios básicos da transmissão sináptica, a qual possui papel fundamental no efeito de plasticidade sináptica, isto é, a capacidade de o cérebro se modificar. A plasticidade sináptica pode ser de curta ou longa duração (conhecida como plasticidade Hebbiana). O efeito de plasticidade sináptica modifica o cérebro através de algumas atividades biológicas, tais como: eficiência da transmissão sináptica, indução ou redução da atividade de novas conexões sinápticas e modulação das propriedades de excitabilidade dos neurônios [19].

A transmissão sináptica se resume, de forma simplificada, à comunicação entre dois neurônios. Ela ocorre na região denominada "fenda sináptica", região onde um impulso (seja químico ou elétrico) de um neurônio é transmitido ao posterior. Existem dois tipos de comunicação sináptica: sinapses elétricas e químicas.

As sinapses elétricas são encontradas em praticamente todos os sistemas nervosos. Esse tipo de sinapse ocorre devido ao deslocamento de corrente entre um neurônio présináptico e outro neurônio pós-sináptico. Porém, as sinapses elétricas foram descobertas no cérebro mais tarde que as químicas e não têm sido estudadas experimentalmente ou modeladas computacionalmente com tanta intensidade quanto as sinapses químicas [20], que compõem a forma mais expressiva de comunicação entre neurônios.

As sinapses químicas possuem como agente fundamental os neurotransmissores. Tais agentes realizam atividades importantes para o funcionamento do sistema nervoso, podendo-se destacar a sua função reguladora que ocorre entre as sinapses. Essa função possui como mecanismo principal a abertura e fechamento dos canais iônicos da membrana neuronal relacionada a permeabilidade do meio, sendo a regulação a base presumida dos fenômenos de plasticidade, adaptação e aprendizagem $[2,3,4,20]$. A Figura 2.2 esquematiza o mecanismo de transmissão de sinapses químicas.

Uma das diferenças entre as sinapses químicas e elétricas está no espaçamento 


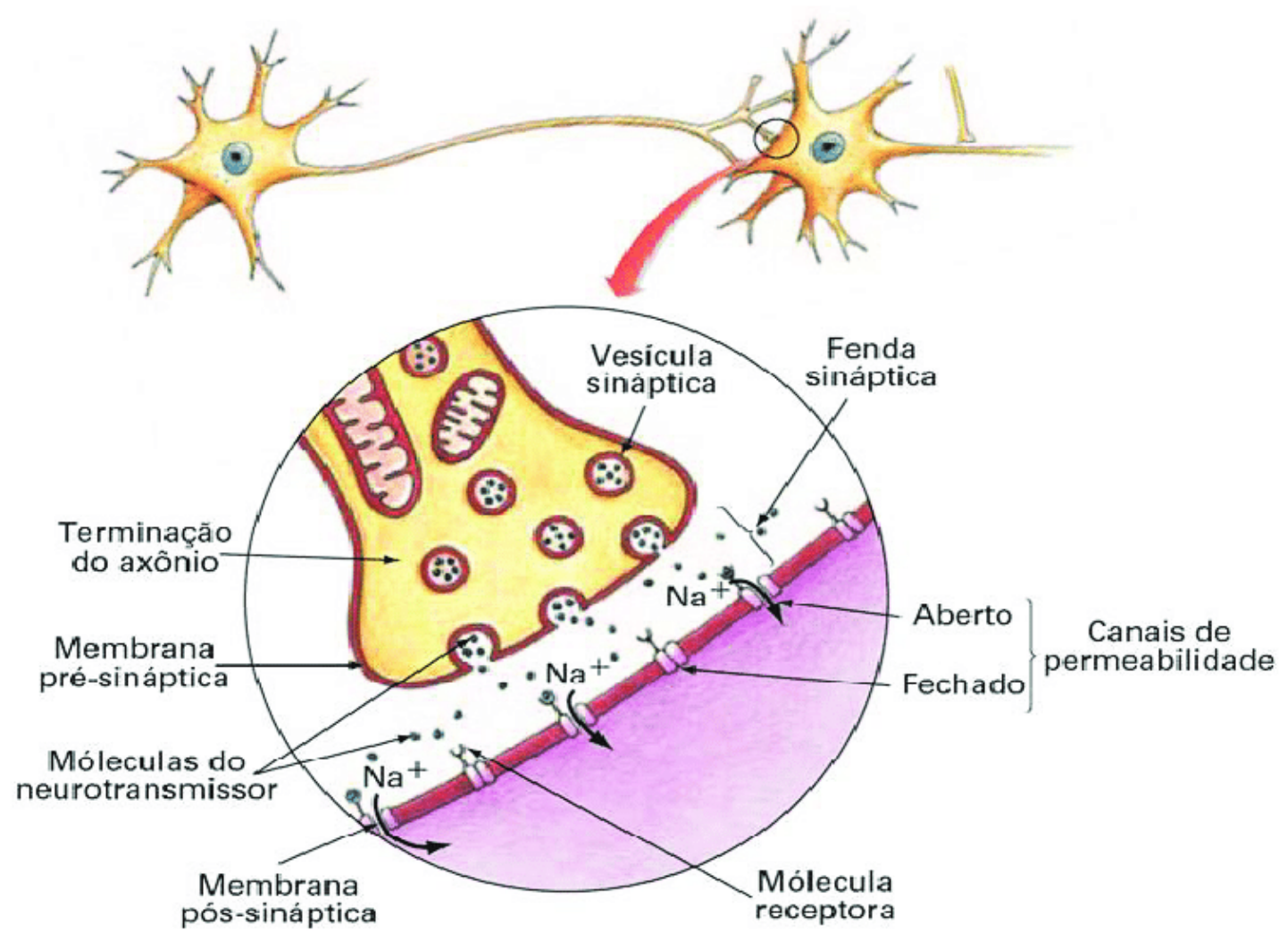

Figura 2.2: Ilustração da comunicação sináptica entre neurônios.

Figura adaptada de [21].

entre as fendas sinápticas. O espaçamento é maior na sinapse química do que na sinapse elétrica, com tamanho variando de 30 a 50 nanômetros. Na região dos terminais pré-sinápticos existem pequenas organelas esféricas membranosas chamadas de vesículas sinápticas, que possuem a função de armazenar e liberar os neurotransmissores até o neurônio pós-sináptico [2, 3, 4]. Existem inúmeras variantes de neurotransmissores, dentre eles os excitatórios como glutamato e aspartato, e os inibitórios como ácido gamaaminobutírico, glicina e taurina. Os excitatórios aumentam a probabilidade de o neurônio pós-sináptico disparar, enquanto que os inibitórios diminuem essa probabilidade. Outros neurotransmissores conhecidos são a serotonina, a dopamina e a acetilcolina. [22].

Neurotransmissores são liberados na fenda sináptica quando um impulso elétrico, também chamado de potencial de ação ou "spike", é gerado. O potencial de ação acontece por meio da difusão (transporte) de potássio $(\mathrm{K})$ e sódio $(\mathrm{Na})$, sendo disparado pelo neurônio pré-sináptico, quando algumas de suas vesículas são fundidas com a membrana celular, liberando neurotransmissores através de exocitose (excreção celular). Processo esse que corresponde ao transporte do material intercelular para o meio extracelular.

Os neurotransmissores liberados pelo neurônio pré-sináptico são recebidos pelo axônio e se ligam aos receptores pós-sinápticos. Isso causa uma abertura ou o fechamento 
do canal iônico. Dessa forma o potencial de membrana do neurônio pós-sináptico é alterado, aumentando ou diminuindo a probabilidade de esse neurônio emitir um potencial de ação $[2,3,4]$. Caso seja acionado um grupo de sinapses, seja de um ou mais neurônios pré-sinápticos, podem produzir uma mudança significativa no potencial de membrana do corpo celular ("soma") pós-sináptico. Em outras palavras, se a voltagem da célula atingir um certo limiar de disparo, o neurônio pode emitir um ou mais potenciais de ação, transmitindo o sinal para os neurônios posteriores.

Enquanto o neurônio pós-sináptico está transmitindo o sinal, o neurônio présináptico começa um processo de restauração das vesículas. Nesse processo, o neurônio as preenche com novas moléculas de neurotransmissores e também com moléculas recaptadas da fenda sináptica. Este processo não é instantâneo, a sinapse fica momentaneamente com sua eficácia diminuída, despolarizada[23, 13].

\subsection{Neurociência teórica}

Diante de um crescimento de profissionais interdisciplinares, a neurociência teórica obteve grande crescimento nos últimos vinte anos. Devido a essa pluralidade de áreas do conhecimento, novas abordagens foram sendo desenvolvidas por físicos, matemáticos e cientistas da computação, entre outros [24].

A modelagem dos neurônios biológicos não é trivial. No entanto, temos alguns modelos bastante fiéis em nível biofísico (modelos de condutância dependentes de voltagem) como o modelo de Hodking-Huxley [25, 26, 27]). Para uma abordagem mais matemática e computacional (menos realista em termos biológicos), podemos exemplificar os modelos baseados em automatas celulares [28], mapas[29], neurônios integra-e-dispara [30] e neurônios baseados em sistemas dinâmicos de tempo contínuo [31].

Nossa abordagem irá se basear em neurônios integra-e-dispara estocásticos com tempo discreto $[32,12,33,34,35,36,37]$, que serão descritos na Seção 3.1. Tais neurônios serão conectados conforme a topologia de uma rede de Watts-Strogatz (WS) [8]. A topologia de WS possui propriedades de uma rede de mundo pequeno.

\subsection{Redes com propriedades de mundo pequeno}

Inicialmente é necessário deixar claro que uma rede com propriedades de mundo pequeno não é necessariamente do tipo Watts-Strogatz [8]. Watts-Strogatz é a topologia da rede que iremos utilizar, a qual possui características específicas de uma rede de mundo pequeno, como a possibilidade de conexões de longa distancia [38].

A ideia a respeito de poucas conexões que abrangem longas distâncias até seu destino final foi proposta inicialmente como a teoria dos seis graus de separação pelo psicólogo 
Stanley Milgram em 1967 para caracterizar redes sociais. De acordo com Milgram [39], o número de contatos intermediários necessários para transmitir uma informação entre dois indivíduos em qualquer lugar do mundo é aproximadamente seis graus de separação.

Embora tenha passado por diversas variações, o experimento de Milgram consistiu em escolher indivíduos aleatórios da lista telefônica nas cidades de Omaha, Nebraska e Wichita como pontos iniciais e Boston como destino final. Cartas foram enviadas para pessoas escolhidas aleatoriamente nas cidades iniciais. As cartas continham informações básicas de contato de uma pessoa em Boston e pediam para a pessoa que recebesse o pacote assinasse o próprio nome e enviasse o pacote para algum contato próximo que possivelmente seria favorável para que o pacote chegasse ao seu destino final. Em conclusão parte dos pacotes não chegaram ao destinatário, no entanto cerca de $40 \%$ dos pacotes chegaram ao destinatário e dadas as assinaturas presentes no pacote que consideravam cada uma das pessoa que o tinha recebido foi contabilizado que o número médio de links necessários para que o pacote chegasse ao seu destino final: o resultado foi seis graus de separação.

Alguns anos após os estudos de Milgram, Watts e Strogatz [8] propuseram um modelo simples de grafo em formato de anel, que exibe a propriedade apresentada por Milgram. O modelo original de Watts-Strogatz pode ser visto na Fig. 2.3: parte-se de uma rede regular com topologia unidimensional onde cada um de seus nodos está conectado em média apenas aos seus $K$ vizinhos mais próximos. Watts e Strogatz então introduzem uma probabilidade $p$ de que cada ligação partindo de um nodo seja religada para um nodo aleatório da rede.

Vamos definir melhor a propriedade principal de mundo pequeno. A distância entre dois nodos é pequena em média: seja $l_{i j}$ como a distância mínima entre dois nodos $i$ e $j$ (contada em termos de número de ligações intermediárias). Em uma rede de mundo pequeno com $N$ nodos e $p>0$, a distância mínima média $L(p)=\frac{1}{N(N-1)} \sum l_{i} j$ é de ordem $L(p) \sim \mathcal{O}(\log N)$. Por outro lado, redes de mundo grande, por exemplo redes regulares d-dimensionais, têm $L(p=0) \sim \mathcal{O}(N)[9,38]$.

Sabendo que $l_{i j}$ é o número mínimo de ligações intermediárias entre dois nodos $i$ e $j$ e que $p$ é a probabilidade de religação, tem-se em uma rede de mundo pequeno com $N$ nodos e $p>0$ que a distância mínima média $L(p)=\frac{1}{N(N-1)} \sum l_{i} j$ é de ordem $L(p) \sim \mathcal{O}(\log N)$. Por outro lado, redes de mundo grande, por exemplo redes regulares d-dimensionais, têm $L(p=0) \sim \mathcal{O}(N)[9,38]$. 


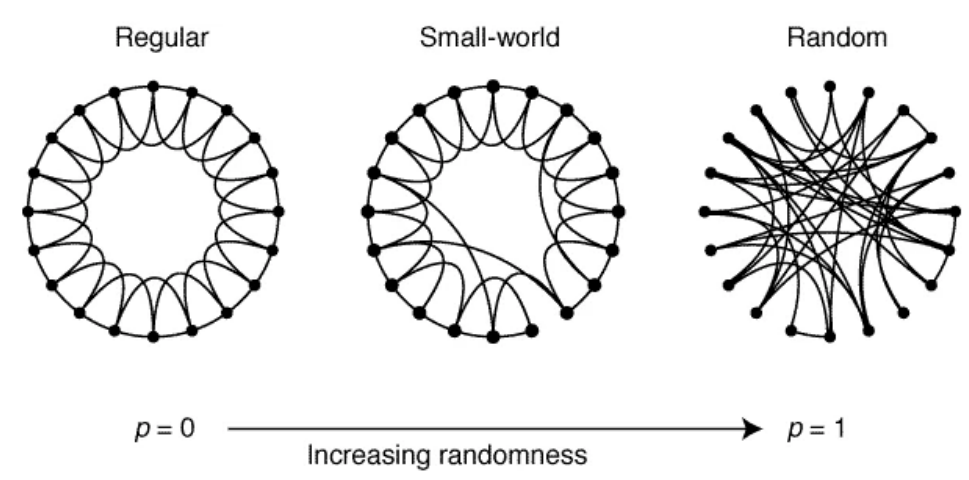

Figura 2.3: Exemplo de uma religação aleatória com probabilidade $p$ para interpolar entre uma rede unidimensional com $K=4$ vizinhos e uma rede totalmente aleatória, permanecendo constante o número de nodos e ligações.

Figura adaptada de [8].

Definimos o Coeficiente de Agrupamento (Clustering Coefficient) $C(p)$ do modelo WS como sendo uma medida da probabilidade de que dois vizinhos de um dado nodo também sejam vizinhos entre si. Vale ressaltar que uma rede de mundo pequeno existem algumas propriedades para classificar se estamos falando de uma rede de mundo pequeno ou não, conhecidas como $\sigma$ e $\omega$. A função sigma é dada por:

$$
\sigma=\frac{\left(C / C_{r}\right)}{\left(L / L_{r}\right)}
$$

Já a função $\omega$ é calculada como:

$$
\omega=\frac{L_{r}}{L}-\frac{C}{C_{r}}
$$

onde, $C$ e $L$ são respectivamente os coeficientes de agrupamento médio e comprimento médio do caminho mais curto entre os nodos da rede. Os coeficientes, $C_{r}$ e $L_{r}$ são conhecidos como coeficientes de referência, que são referenciados por uma rede aleatória equivalente.

Para o coeficiente $\sigma$, um grafo é eventualmente classificado como mundo pequeno se $\sigma>1$. O coeficiente $\omega$ relacionado a uma rede de mundo pequeno varia entre $[-1,1]$. Quando o valor de $\omega$ está próximo de zero, a rede apresenta características de mundo pequeno. Para valores próximos de -1 , temos uma rede organizada; e para valores próximos de 1 , temos uma rede do tipo aleatória[40, 41, 42, 43, 44, 45].

Dessa forma, as propriedades estruturais da rede WS podem ser definidas através da distância mínima média $L(p)$ e pelo coeficiente de agrupamento do sistema $C(p)$ e pelos coeficientes $\sigma$ e $\omega$, conforme pode ser visto na Fig. 2.4. 


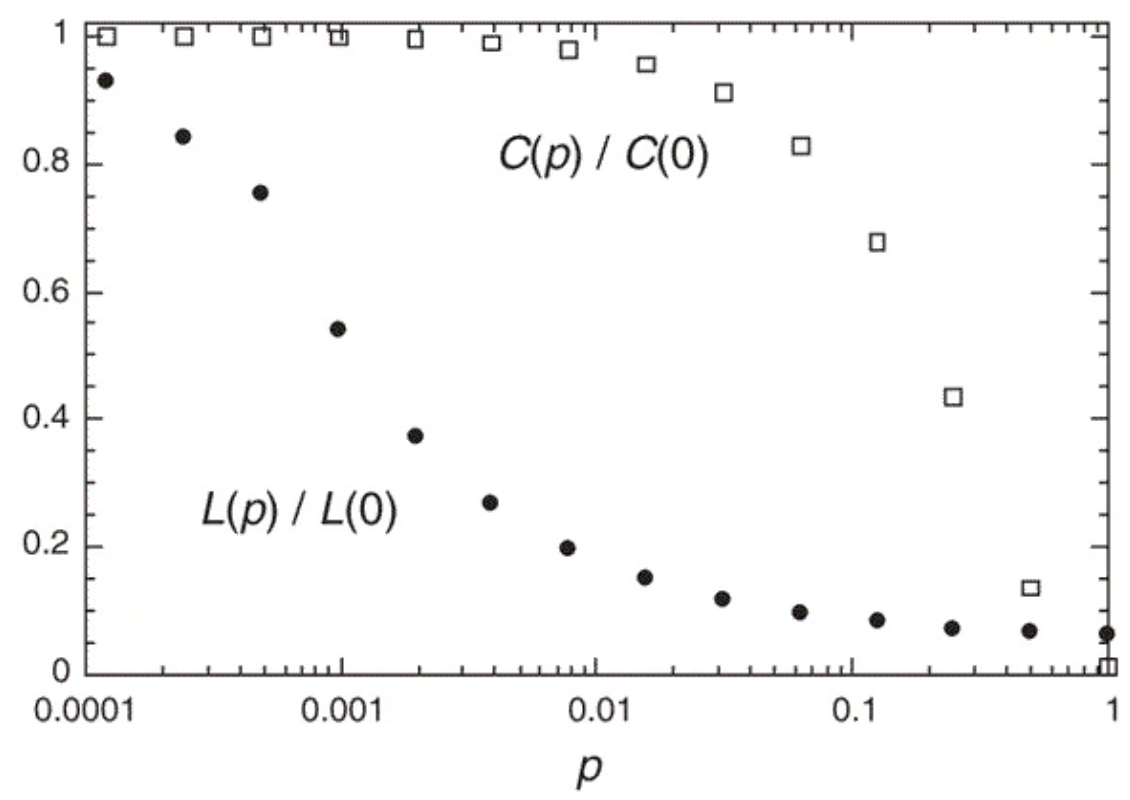

Figura 2.4: Comprimento do caminho característico $L(p)$ e coeficiente de agrupamento $C(p)$ em uma rede com $K=4$ vizinhos por nodo.

Figura adaptada de [8].

A rede regular com $p=0$ é uma rede usualmente denominada como mundo grande com alto coeficiente de agrupamento. Temos apenas conexões locais e $L(0)$ cresce linearmente com o número de nodos $N$. No outro extremo, temos uma rede aleatória com $p=1$, similar ao grafo conhecido na literatura como Erdős-Rényi (ER) [38], o qual é uma rede de mundo pequeno mal agrupado, ou seja, com $C \rightarrow 0$. O modelo de WS com $0<p<1$ se relaciona com os dois casos [8,38].

Vale ressaltar que a rede de WS possui número fixo de nodos, mas a quantidade de vizinhos por neurônio $(K)$ pode mudar para $p>0$. No entanto, a média de ligações entre eles, considerando a rede como um todo, é exatamente o valor estimulado $K$ [8].

\subsubsection{Redes de mundo pequeno em Neurociências}

A segregação funcional e a integração são dois princípios organizacionais principais do cérebro humano. Em outras palavras, um cérebro ideal requer um equilíbrio adequado entre a especialização local e a integração global da atividade funcional do cérebro [46]. Estudos demonstram que as redes funcionais (conectomas) do cérebro possuem propriedades de mundo pequeno, realizando experimentos em diferentes indivíduos afim de se obter um padrão de conectividade [46, 42].

Através desses experimentos, foi possível observar que indivíduos saudáveis possuem propriedades eficientes da rede de mundo pequeno, ou seja, eficiência na propagação de informação por meio da utilização de conexões de longa distância. Em contrapartida, 
em indivíduos com diagnóstico de esquizofrenia e de Alzheimer tais propriedades não apresentavam os mesmos valores de indivíduos controle, notando-se um menor número de ligações de longa distância [47, 42].

Vale ressaltar que em pacientes com esquizofrenia as propriedades da topologia de mundo pequeno são significativamente afetadas em inúmeras regiões do córtex préfrontal, parietal e temporal. Foi descoberto que essas medidas topológicas alteradas estão relacionadas à duração da doença degenerativa neuronal.

A detecção e a estimativa dessas alterações podem ser úteis para a compreensão do mecanismo fisiopatológico, bem como para a avaliação da gravidade da esquizofrenia [47]. De maneira geral, encontrou-se um número de conexões relativamente mais baixo, bem como força de conectividade e coeficiente de agrupamento absoluto mais baixos em comparação a indivíduos saudáveis. Por outro lado, observou-se comprimento mínimo médio absoluto mais longo em comparação com aqueles de sujeitos saudáveis. Todas essas evidências suportam a hipótese de que a esquizofrenia é um distúrbio de integração disfuncional entre regiões cerebrais [48].

A abordagem também pode ser usada em outros distúrbios, como a doença de Alzheimer, que pode ser tomada como uma síndrome de desconexão em que a conectividade funcional anormal desempenha um papel importante no córtex [42].

\subsection{Transições de fase}

De forma breve e sucinta, uma transição de fase ocorre quando um sistema passa de uma dada fase para outra, por exemplo: a transformação de água (fase líquida) em gelo (fase sólida) a temperaturas baixas (ou vapor - fase gasosa -, em altas temperaturas). O conceito de transição de fase é amplo e detém uma longa trajetória histórica e prática. A seguir iremos desenvolver alguns tópicos a fim de situar o leitor da relevância do tema. Transições de fases estão intimamente relacionadas com física estatística. As transições são caracterizadas por dois expoentes críticos independentes. Na década de 1950 e 1960, foi experimentalmente reconhecido que quantidades como a Temperatura crítica de um sistema dependem de detalhes que ocorrem ao longo das interações, de outro modo, entende-se que eles não dependem de detalhes microscópicos, mas apenas de um pequeno número de características gerais, como a dimensão ou as simetrias do sistema. Assim, devido a características macroscópicas, a transição de fase é percebida de acordo com o modelo adotado [49].

Modelos de redes neuronais são sistemas dinâmicos que podem apresentar diferentes comportamentos macroscópicos ou fases, caracterizadas por parâmetros de ordem. As regiões de separação entre as fases podem ser descritas como bifurcações nos parâmetros de ordem ou então como transições de fase. Em vários modelos de atividade neuronal, a 
mudança de fase relevante é uma transição contínua de um estado silencioso para um estado ativo [34], mas existem outras transições envolvendo descontinuidades no parâmetro de ordem e bifurcações para fases oscilatórias [37].

As fases dependem de certos parâmetros do sistema, conhecidos como parâmetros de controle. Por exemplo, importantes parâmetros de controle em sistemas físicos são a temperatura e a pressão. Ao modificar esses parâmetros de forma contínua os parâmetros de ordem de um sistema pode transitar entre diferentes fases. Um parâmetro de ordem de um sistema é a quantidade mensurável resultante da manipulação dos parâmetros de controle.

Transições de fase em outros materiais são descritos por outros tipos de parâmetros de ordem e controle: por exemplo, em materiais ferromagnéticos o parâmetro de ordem é a magnetização e o parâmetro de controle é a temperatura [50].

Uma transição de fase pode ser classificada como de primeira ou segunda ordem [50]: de modo geral, uma transição de primeira ordem possui uma descontinuidade no parâmetro de ordem, enquanto uma transição de segunda ordem possui uma variação contínua no parâmetro de ordem, ver Fig. 2.5.
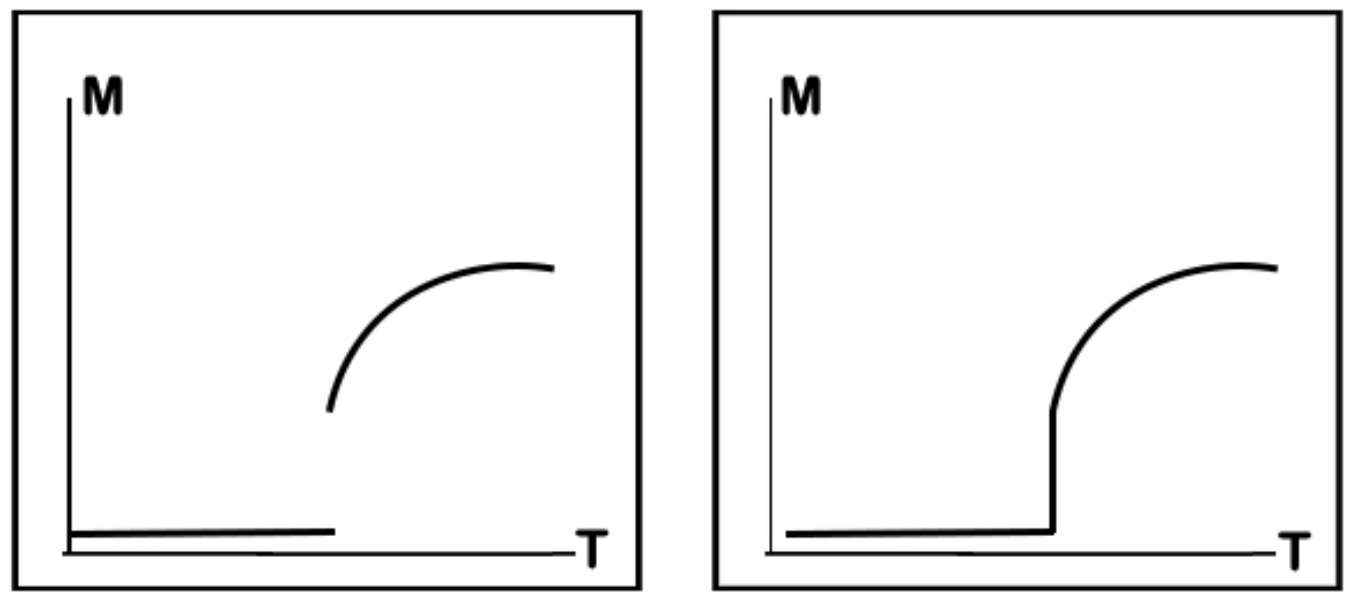

Figura 2.5: Exemplo qualitativo de transições de fase. a) Transição de fase de primeira ordem e b) transição de fase de segunda ordem.

No presente trabalho trataremos apenas de sistemas que apresentam transições de fase de segunda ordem, que ocorrem em redes neuronais com topologia do tipo WS sem inputs externos. Esse tipo de transição é especial devido aos eventos espontâneos aleatórios que ocorrem próximo ao ponto da transição, conhecidos na literatura como avalanches neuronais (ver Seção 2.5), cujas distribuições de tamanho e duração seguem leis de potência.

No ponto crítico das transições contínuas, o valor subsequente ao estado absorvente, 
ou estacionário, do parâmetro de ordem obedece a seguinte equação matemática:

$$
\rho \sim\left|\rho-\rho_{c}\right|^{\beta}
$$

onde $\left|\rho-\rho_{c}\right|$ é a distância relativa até o ponto crítico e $\beta$ é denominado o expoente crítico do parâmetro de ordem. Outros expoentes críticos podem ser definidos, tais como a susceptibilidade, o comprimento de correlação, etc. [5, 7].

Pode-se demonstrar que sistemas que possuem as mesmas características, por exemplo, dimensão espacial e simetrias, apresentam os mesmos expoentes críticos. Dessa forma, o conjunto de expoentes críticos nos auxilia a definir a qual classe de universalidade aquele evento ou sistema está inserido. Dessa forma, podemos descrever certos sistemas complexos utilizando modelos mais simples e fazer comparações, dado que pertence a uma mesma classe de universalidade. Assim, podemos estudar a transição de fase de sistemas complexos, como redes de neurônios, fazendo comparações de dados reais com os de modelos sucintos.

\subsubsection{Percolação direcionada}

Iniciamos a discussão na seção anterior a respeito de expoentes críticos de um sistema. Partindo desse conceito, temos as classes de universalidade. As classes de universalidade de um sistema representam um conjunto de características que são compartilhadas pelos indivíduos do grupo.

Existem inúmeras classes de universalidade, no entanto no presente trabalho daremos enfoque a uma classe em específico: a percolação direcionada. A vantagem de se conhecer a classe de um determinado sistema consiste no fato de que podemos fazer comparações entre sistemas muito complexos e sistemas mais simples, desde que eles estejam na mesma classe, sendo assim, o comportamento entre eles poderá ser comparado.

A classe de universalidade percolação direcionada, que será bastante mencionada nesse trabalho, é recorrentemente observada em determinados modelos de grande escala que possuem mesmo comportamento coletivo e transições de fase contínuas de um estado ativo para um estado inativo ou vice-versa. A percolação direcionada representa sistemas fora do equilíbrio. Como exemplo de sistemas fora do equilíbrio temos os modelos epidêmicos, nos quais podem não mais existir indivíduos suscetíveis (que possam ser infectados) na simulação e com isso a população acaba se mantendo em um estado absorvente, do qual não conseguem sair naturalmente (sem que haja uma perturbação externa no sistema). Assim, consideramos esse um sistema fora do equilíbrio.[51] 


\subsection{Avalanches neuronais}

No ano de 2003 foi encontrada a primeira evidência experimental de avalanches neuronais no cérebro. Os pesquisadores responsáveis pelo experimentos foram Beggz \& Plenz [52], mostrando que o cérebro é capaz de produzir cascatas de disparos neuronais consecutivos, denominadas avalanches neuronais [53]. Eles calcularam as distribuições de tamanho e duração das avalanches e observaram que seguem leis de potência.

Os resultados de Beggz \& Plenz foram obtidos através de medições nos potenciais de campo local, usualmente conhecidos na literatura como Local Field Potentials ou LFPs. LFPs são sinais eletrofisiológicos provocados pelo somatório das correntes elétricas emitidas por múltiplos neurônios em um pequeno espaço do tecido nervoso. O LFP foi obtido experimentalmente a partir de fatias do córtex cerebral de ratos, utilizando multieletrodos em matriz. No entanto, existe muito ruído biológico durante a obtenção dos resultados do potencial. Então, com o intuito de minimizar esse ruído, é definido um limiar. Desta forma, todo o sinal recebido que estiver abaixo de um valor estabelecido não acrescenta para os resultados, mas valores acima desse limiar são considerados como um disparo de um eletrodo.

Dadas algumas configurações do sistema, Beggs \& Plenz verificaram que muitos sinais apareciam nos eletrodos de forma consecutiva, formando uma aparente sincronia entre os disparos, seguidos por um período de total inatividade da rede. Os pesquisadores definiram tais eventos simultâneos como avalanches neuronais [52]. Desde então, outros estudos sobre avalanches neuronais foram trazidos à literatura e estabeleceram as experiências de Beggs \& Plenz como um evento natural e espontâneo presente no cérebro [54].

A partir das evidências apresentadas por Beggz \& Plenz, a hipótese conjecturada por Alan Turing sobre o cérebro atuar em um estado crítico [55] olta a ser colocada em pauta. Avalanches descritas por leis de potência começam ser observadas em várias condições experimentais e em diferentes modelos animais, tais como ratos anestesiados e macacos não anestesiados (porém em repouso) [56, 57], bem como em humanos saudáveis [58].

Os benefícios de um cérebro atuando no estado crítico vêm sendo estudados regularmente. Simulações computacionais mostraram que na criticalidade há uma máxima sensibilidade aos estímulos sensoriais, ou seja, uma maior variabilidade de estímulos que pode ser processada. [59]. Isso foi posteriormente confirmado em experimentos in vitro em fatias do córtex cerebral de ratos, por meio do qual, nas regiões onde existia um balanço entre as conexões sinápticas de excitação e inibição, a faixa dinâmica dessas regiões se mostrou maior, comprovando as hipóteses de auto-organização da atividade do cérebro em estados críticos. Foi possível concluir que existe um balanço entre excitação e inibição 
na criticalidade [60].

Estes resultados foram mais recentemente verificados em experiências in vivo com ratos anestesiados, mostrando que a faixa dinâmica sensorial é maximizada no estado crítico [61]. Também foi visto que a aprendizagem [62] e a destreza para o processamento de informações é otimizado na criticalidade [63]. Finalmente, foi demonstrado que o formalismo de redes excitatórias/inibitórias balanceadas [64] pode ser unificado com os modelos de criticalidade auto-organizada que apresentam avalanches neuronais [37].

\subsection{Auto-organização}

A criticalidade auto-organizada, usualmente chamada de SOC (do inglês selforganized criticality), é tida como a capacidade de regulação de sistemas para se manterem em torno da criticalidade. Os precursores da discussão a respeito de criticalidade auto-organizada foram os pesquisadores Bak, Tang e Wiesenfeld [56, 65], que tentaram descrever o comportamento de alguns sistemas, isto é, a maneira como tais sistemas evoluem para um estado crítico sem a necessidade de ajuste externo e sem dependência dos parâmetros iniciais do sistema.

Há diversos sistemas observados na natureza que exibem comportamento crítico, por exemplo: terremotos [66, 65], erupções solares [67], incêndios florestais [68, 69], dentre outros [70]. Esses eventos, mesmo que pareçam distintos, possuem propriedades em comum, existindo a hipótese de auto-organização na criticalidade também para o cérebro. No entanto, o princípio biológico por trás dessa hipótese ainda é desconhecido.

Mas o que define um sistema como crítico? Algumas condições são necessárias para se cogitar que um sistema se encontra na criticalidade. As leis de potência, que classificam um sistema como invariante de escala, costumam ser compreendidas como uma dessas condições. Contudo, o sistema pode apresentar variáveis distribuídas em leis de potência e não estar em regime crítico, de modo que esse tipo de distribuições não é suficiente para se estabelecer a criticalidade [71].

Leis de potência podem surgir mesmo longe do ponto crítico, no entanto a relação de escala obtida através dos expoentes é um forte argumento para classificar uma configuração do sistema como crítico.[64, 72, 73]

$$
\frac{1}{\sigma \nu z}=\frac{\tau_{t}-1}{\tau_{s}-1}
$$

O expoente de lei de potência indica uma ausência de um evento característico e reflete na existência de inúmeros eventos de tamanho reduzido e um número reduzido de eventos em grande escala [74]. 


\subsubsection{Quasi-criticalidade Auto Organizada}

Na seção anterior, demos uma breve introdução a respeito do conceito de criticalidade auto-organizada e mencionamos a existência de inúmeras aplicações em diversas áreas, inclusive em neurociências [73].

Tanto redes de neurônios quanto terremotos e incêndios florestais são considerados sistemas não conservativos, no entanto um sistema considerado SOC precisa ser conservativo, como as pioneiras pilhas de areia [70, 75]. Portanto, modelos como redes neuronais, terremotos e incêndios que são sistemas não conservativos foram denominados como criticalidade fraca[76, 77].

Partindo desse pressuposto de uma criticalidade diferente daquela discutida nas pilhas de areia, foi introduzido o conceito de quasi-criticalidade auto-organizada (selforganized quasi-criticality, $S O q C$ ) que seria sistemas que apresentam comportamento de auto-organização em regimes críticos, no entanto é necessário um ajuste fino de parâmetros para observar esses eventos.

Pensando no que foi discutido anteriormente, como a rede se auto organiza na região crítica/quasi-crítica e o que a mantém? Os sistemas possuem uma grande quantidade de parâmetros de controle. Parâmetros esses que podem levar o sistema a estados subcríticos, crítico e super críticos. Devido a essa variedade de estados, para se alcançar o estado crítico é necessário um ajuste fino de parâmetros do sistema, o que favorece a ideia de que esses sistemas possuem uma criticalidade fraca e por isso SOqC. [78, 79, 74, 80].

Uma interpretação é a de que existe uma região dos parâmetros de controle para os quais a rede se mantém em torno da criticalidade. Assim, podemos assumir que quanto maior essa região, mais robusta a criticalidade no sistema.

Outra questão também apresentada para SOqC é o fato de o sistema, ao se encontrar na região crítica, permanecer com flutuações ao redor de um ponto e não estático em um ponto fixo[76, 77, 81].

\subsection{Annealed ou Quenched}

Os termos annealed e quenched em tradução literal seriam "recozido" ou "temperado". Causando ligeira estranheza se levado ao seu sentido literal, mas estão relacionados a processos termodinâmicos de fortificação de materiais, em específico aços e vidros [82]. No entanto é comum tratar das desordens aleatórias annealed ou quenched em sistemas estatísticos [83].

Redes com desordem quenched são aquelas que possuem alguns de seus parâmetros aleatórios imutáveis ao decorrer do tempo. Tais variáveis se mantém as mesmas durante 
todo o intervalo de tempo. Já para o caso de redes com desordem annelead, temos variáveis aleatórias que mudam constantemente em cada passo de tempo. De forma análoga, para o caso annelead temos uma nova configuração de variáveis a cada instante de tempo. Visto que para o caso quenched elas se mantém fixas, essa é a diferença entre ambos [83, 84].

Mais especificamente, o que se faz no caso annealed é definir aleatoriamente as conexões da rede a cada passo de tempo, enquanto no caso quenched a rede é sorteada no início da simulação e inalterada durante todo o processo. Trabalharemos com redes neuronais do tipo WS tanto para o caso annealed quanto para o caso quenched e compararemos os resultados. 


\section{Metodologia}

\subsection{Modelo neuronal}

Conforme foi descrito na seção anterior a respeito das características de uma célula neuronal, podemos simplificar de forma objetiva um neurônio como sendo uma célula capaz de integrar sinais recebidos de outras células e disparar dependendo das condições presentes. É possível então simplificar essas condições específicas da célula por uma função potencial. A partir do potencial do neurônio, determina-se a capacidade dele disparar ou não, conforme o sinal recebido [85].

Após o neurônio realizar um disparo, ele entra em um período refratário, o qual podemos compreender como um período de recuperação das vesículas sinápticas. Ao longo desse período, o neurônio não é capaz de emitir outro potencial de ação independente do impulso recebido, esse efeito é conhecido como período refratário absoluto. Temos também o período refratário relativo, onde o neurônio tem a possibilidade de disparar diminuída durante esse evento.

O modelo de neurônio que iremos utilizar é uma variação do modelo integra-edispara com propriedade de vazamento, também conhecido como (leaky integrate-and-fire ou LIF). Este é um modelo simplificado de neurônio, no qual sempre que um neurônio atinge um determinado valor, um potencial de ação é gerado, e logo após o neurônio retorna seu potencial abaixo do limiar de disparo.

Dado o modelo integra-e-dispara, temos alguns modelos oriundos dessa abordagem. Neste trabalho usaremos o modelo que chamaremos de GGL. Essa ramificação do modelo LIF foi proposta inicialmente por Gerstner [32] e estendido posteriormente por Galves \& Löcherbach [33]. A particularidade do modelo GGL se dá pela unificação de todas as formas de ruído biológico de uma célula neuronal para uma função de disparo que descreve a probabilidade aleatória de efetuar um disparo de um neurônio.

O modelo GGL foi adaptado e simplificado de forma que cada neurônio possui um potencial de membrana que evolui em tempo discreto da seguinte forma [34, 35]:

$$
V_{i}[t+1]= \begin{cases}0 & \text { se } X_{i}[t]=1 \\ \mu V_{i}[t]+I_{i}[t]+\frac{1}{K_{i}} \sum_{j}^{K_{i}} W_{i j} X_{j}[t] & \text { se } X_{i}[t]=0 .\end{cases}
$$

Ou seja, caso haja um disparo de um neurônio $i\left(X_{i}[t]=1\right)$, o seu potencial $V_{i}[t+1]$ é redefinido para zero, representando o período refratário absoluto. Caso o neurônio não dispare $\left(X_{i}[t]=0\right)$, ele segue com a evolução do potencial de membrana conforme a equação (3.1), cujos parâmetros serão definidos a seguir.

A variável $\mu$ é o termo correspondente à parcela do potencial que permaneceu 
durante a interação (não sofreu vazamento). Como se trata de uma fração do potencial, $\mu$ possui um conjunto de valores válidos no intervalo $\mu \in[0,1]$, uma vez que a parcela de vazamento de um neurônio é representado por $(1-\mu)$.

O termo $I_{i}[t]$ corresponde aos possíveis estímulos externos que são interceptados pelo neurônio $i$. No entanto, no presente trabalho trataremos o estímulo externo igual a zero. Isso é uma implicação biologicamente plausível, dado que a atividade das avalanches neuronais pode ocorrer de forma espontânea, sem estímulos externos.

A grandeza $K_{i}$ representa o número de vizinhos de cada neurônio, ou seja, o número de vizinhos pré-sinápticos que emitem potencial ao neurônio $i$. Já $W_{i j}$ é um elemento da matriz que compõe a lista de vizinhos de cada neurônio. Ele está relacionado com o valor da força sináptica, ou peso, de interação entre o neurônio pós-sináptico $i$ e seu $j$-ésimo neurônio pré-sináptico.

Por fim, a variável $X_{i}[t]$ possui característica estocástica e ela torna o modelo GGL um diferencial, lembrando que a estocasticidade de $X_{i}[t]$ vem da função disparo que será apresentada a seguir.

Conforme mencionado, uma particularidade do modelo GGL é a não distinção dos tipos e das quantidades de fontes de ruído inseridas no sistema. Todo o comportamento proveniente de ruído e aleatoriedade do sistema é representado pela função de disparo $\Phi(V)$ :

$$
\Phi(V)=\frac{(V-\theta) \Gamma}{1+(V-\theta) \Gamma} \Theta(V-\theta)
$$

onde $\Gamma$ é o ganho da função de disparo e $\theta$ é a representação para o limiar de disparo. Inicialmente trataremos $\Gamma$ como um valor constante (que permanecerá inalterado ao longo das simulações). Uma possível representação biológica para a função $\Gamma$ é sua relação com o seguimento inicial do axônio [34]. Utilizaremos $\Gamma=1,0$ sem perda de generalização [86].

O limiar de disparo, $\theta$, inicialmente também terá um valor fixo assim como $\Gamma$, mas este igual a zero. Dessa forma, a equação $\Phi$ dependerá apenas da variação da função potencial, $V_{i}$, de cada neurônio.

$$
\Phi(V)=\frac{\Gamma V}{1+\Gamma V}
$$

A função 3.3 é monotonicamente crescente e possui limites definidos, de forma que $\Phi(-\infty)=0$ e $\Phi(+\infty)=1$.

Para determinar a atividade da rede, definiremos a função $\rho[t]$, que será responsável por contabilizar a fração ou densidade de $N$ neurônios que dispararam em cada instante de tempo $t$. A função $\rho[t]$ possui o seguinte aspecto: 


$$
\rho[t]=\frac{1}{N} \sum_{j=1}^{N} X_{j}[t]
$$

A função $\rho[t]$ será o parâmetro de ordem para este modelo que, embora estocástico, não possui mecanismo de adaptação para nenhuma das variáveis.

As simulações computacionais foram realizadas utilizando o cluster da Universidade de Jatai. O algoritmo utilizado pode ser acessado no link do Github https: //github.com/repazzini/msc_mallworld.git

\subsection{Aproximação de campo médio}

Os primeiros indícios da necessidade de resolver um problema de muitas partículas interagentes vem da Mecânica Estatística, na qual existe uma busca para somar a função partição do sistema. A solução para esse problema veio inicialmente por Van der Waals em 1883, com a equação de estado clássica, que posteriormente o concedeu o Prêmio Nobel em 1910[87, 88].

O princípio a respeito da aproximação de campo médio assume que os corpos (partículas, neurônios) estão distribuídos de forma homogênea e que não têm preferência de interação entre corpos específicos, ou seja, eles interagem igualmente entre si. No grafo, poderíamos assumir que todos os neurônios estão conectados com todos os demais. Assim, a interação de um corpo com cada outro poderia ser substituída por um campo efetivo [89, 90].

A aproximação de campo médio nos é útil como uma aproximação do sistema, uma vez que esta possui uma grande variedade de estudos na literatura. Fornecendo a segurança dos resultados analíticos e uma comparação para nossos resultados computacionais.

No modelo GGL temos o campo local $h_{i}[t]=\frac{1}{K_{i}} \sum_{j}^{K_{i}} W_{i j} X_{j}[t]$. Com a aproximação de campo médio, assumimos $K_{i}=N-1$ para qualquer neurônio $i$. Assumindo também que $W=<W_{i j}>$ é o valor médio da força de interação das sinapses, temos que, no limite termodinâmico $(N \rightarrow \infty)$, o campo pode ser aproximado: $h_{i}[t] \approx \frac{1}{N} \sum_{j}^{N} W X_{j}$. Assim temos $h[t] \approx W \rho[t]$.

Também usamos a aproximação $I=<I_{i}>$, de forma que a Eq. (3.1) resulta em:

$$
V_{i}[t+1]= \begin{cases}0 & \text { se } X_{i}[t]=1 \\ \mu V_{i}[t]+I+W \rho & \text { se } X_{i}[t]=0\end{cases}
$$

Que resulta em uma equação de tempo discreto que considera apenas a atividade média da rede naquele instante de tempo. Essa aproximação nos ajuda melhor compre- 
ender o comportamento de uma rede de neurônios com muitos elementos interagentes e como o potencial de membrana evolui considerando a atividade da rede.

\subsection{Medidas de avalanches neuronais}

Dada a topologia complexa das redes estudadas, não temos uma equação analítica para calcular os respectivos pontos críticos dos sistemas estudados, apenas temos uma aproximação de campo médio (que assume que as interações ocorrem em um grafo completo). Assim, estimaremos os respectivos pontos críticos $\left(W_{c}\right)$ a partir das simulações computacionais. Com o valor crítico obtido podemos encontrar as medidas de avalanches neuronais nesse ponto.

A definição de avalanche nas simulações é tal que uma avalanche termina quando o valor de $\rho[t]=0$. Quando a densidade atinge o zero, a rede tende a permanecer nesse valor a menos que algo a force a sair desse estado. Essa condição é conhecida como estado absorvente. Dessa forma, utilizamos um procedimento usual em que cada simulação é iniciada com uma pequena perturbação na rede, tal que um neurônio aleatoriamente selecionado dispara um potencial de ação, que atinge seus vizinhos pós-sinápticos. Toda vez que a atividade na rede é estagnada, uma nova perturbação é gerada no mesmo passo de tempo, de modo que uma nova avalanche é iniciada.

Temos então avalanches de tamanho $s$ variado. O qual é calculado pela soma da quantidade de neurônios que dispararam devido a uma perturbação até o próximo instante em que $\rho[t]=0$. A duração $d$ da avalanche é dada pelo intervalo de passos de tempo entre a perturbação e a próxima inatividade.

Apresentaremos no próximo capítulo as distribuições acumuladas de tamanho e duração de avalanches das simulações realizadas com diferentes conjuntos de parâmetros.

\subsubsection{Leis de potência}

Dada uma distribuição de avalanches em um determinado ponto crítico no limite termodinâmico, ou seja, com $N \rightarrow \infty$. Esse resultado é denominado lei de potência $P(s) \propto s^{-\tau_{s}}$ com um determinado expoente.

A maneira usual de obter uma lei de potência $P(s)$ é através da resultante do cálculo de distribuição acumulada complementar, que possui a seguinte expressão:

$$
F(s)=\sum_{x=s}^{\infty} P(x) \propto s^{-\tau_{s}+1} .
$$

No entanto antes de aplicar os resultados na expressão acima, é necessário fazer um tratamento prévio dos dados obtidos da simulação com $\rho[t]$. 
Após obter o tamanho das avalanches e área sob a curva de $\rho[t]$, primeiro precisamos reorganizar o conjunto de tamanhos, os quais definiremos como $s$, na forma de uma lista ordenada e decrescente. De forma que a maior avalanche tem ordem 1 e a última ordem $n$.

Feito a organização dos resultados, iremos calcular $F\left(s_{r}\right)$, que é a razão entre a ordem da avalanche pelo seu tamanho de elementos da amostra, algo do tipo $F\left(s_{r}\right)=r / n$. Essa operação nos informa a probabilidade acumulada, ou seja, a chance de se obter uma avalanche de tamanho mínimo é igual a 1,0. Isso equivale a $100 \%$ de chance de se ter um único neurônio disparando na rede. Por outro lado, a probabilidade de se obter uma avalanche de tamanho relativamente grande diminui a uma proporção $1 / n$.

Uma vez realizados os gráficos para a frequência acumulada, podemos fazer outro estudo com os mesmos resultados, mas agora para a distribuição com uma abordagem através de um escalonamento de tamanho finito. Na termodinâmica, o ponto crítico de uma lei de potência terá um limite relacionado ao tamanho do sistema, esse efeito possui nome de efeito de tamanho finito [91].

O escalonamento de tamanho finito é interessante para a construção do trabalho devido à confirmação do expoente de lei de potência, que também é usado nessa distribuição, lembrando que o expoente é necessário para classificar a qual classe de universalidade o sistema pertence.

A expressão para a curva de escalonamento de tamanho finito com um corte exponencial tem a seguinte forma:

$$
F(s ; N) \propto s^{-\tau_{s}+1} \exp \left(-s / s_{c}(N)\right)
$$

onde $s_{c}(N)$ é o tamanho característico do sistema a partir da qual a lei de potência não possui mais validade [75]. Sendo assim, o ajuste de curvas pode usar a função (3.7) para obter tanto $\tau_{s}$ como $s_{c}(N)$.

O mesmo procedimento pode ser feito para o coeficiente de duração das avalanches $d$. Obtendo as curvas de frequência acumulada e escalonamento de tamanho finito. Eventualmente os expoentes de tamanho $s$ e $d$ são diferentes.

\subsection{Auto-organização}

Partindo do conceito de plasticidade biológica, ação realizada pelos neurônios para regular seu nível de atividade. Existem mecanismos internos, ditos homeostáticos, para promover a estabilidade dos circuitos neuronais [92]. Aqui nos basearemos em tais mecanismos e proporemos possíveis dinâmicas regulatórias que podem ser utilizadas biologicamente para controle da atividade da rede. A regulação deve ser tal que o cérebro seja 
capaz de se adaptar aos estímulos ambientais, mantendo seu funcionamento robusto.

Primeiramente proporemos um mecanismo de depressão/recuperação que pode ser descrito pela equação abaixo. A grandeza adaptada é o peso sináptico e faz parte de um dos três mecanismos homeostáticos [1] que estudaremos e possui algumas modificações do modelo já descrito na Seção 3.1.

Inicialmente iremos apresentar o mecanismo sináptico conhecido como peso sináptico presente na Eq. 3.1 como um termo constante que influencia no potencial de membrana de cada neurônio. No entanto, o mesmo possui uma representação dinâmica que pode ser descrita como um mecanismo homeostático. Tal mecanismo possui algumas variáveis e uma dependência temporal, conforme pode ser visto na equação abaixo.

$$
W_{i j}[t+1]=W_{i j}[t]+\frac{1}{\tau}-u W_{i j}[t] X_{j}[t]
$$

Esse mecanismo sináptico possui uma variável $\tau$ que atua como o tempo de recuperação dos neurotransmissores do neurônio. Temos também a variável $u$ que possui um intervalo de valores possíveis entre $[0,1]$. Tal variável é responsável pela depressão sináptica. Cada vez que um neurônio pré-sináptico vizinho dispara, há uma redução de parte dos neurotransmissores na sinapse. Note que na Eq. 3.8 a fração $1 / \tau$ é responsável por aumentar o peso sináptico a cada passo de tempo $t+1$, porém dependendo da escolha do valor de $\tau$, nosso peso sináptico pode acabar divergindo com o tempo. Para que isso não ocorra, $\tau$ deve estar dentro de uma faixa (ampla) de valores compatíveis com a taxa de disparos no modelo.

Voltando à ideia dos resultados analíticos obtidos para uma aproximação de campo médio, fizemos algumas manipulações, as quais serão apresentadas no próximo capítulo. Essas manipulações foram feitas com o intuito de se obter equações analíticas que pudessem ser superficialmente comparadas com nosso modelo WS, afinal mostraremos na próxima seção que a nossa topologia WS se assemelha ao campo-médio à medida que os valores de $K$ aumentam.

Com isso temos que, após o equilíbrio, o produto do peso sináptico médio da rede e a densidade de neurônios ativos seria igual a uma razão das variáveis $\tau_{w}$ e $u_{w}$. E, portanto, a condição para o ponto fixo da equação (3.8) é:

$$
W^{*} \rho^{*}=\frac{1}{\tau_{w} u_{w}}
$$

Lembrando que $\rho^{*} \approx 1 / N$ e portanto tal igualdade nos fornece um valor aproximado de $W^{*}$, que podemos usar para comparar com os resultados das simulações. 
Uma avalanche neuronal ocorre no ponto crítico apenas se o campo externo por igual a zero [81]. Para isso, tal condição precisa ser satisfeita: $h_{c}=I-(1-\mu) \theta=0$. A condição de campo externo pode ser obtida através da seguinte equação:

$$
\rho=\frac{(W \rho+h)(1-\rho) \Gamma}{1+(W \rho+h) \Gamma} \Theta(W \rho+h)
$$

Essa equação será melhor discutida na seção de resultados, no entanto podemos ver que o termo correspondente ao campo externo $h$ precisa ser nulo em uma situação de equilíbrio e. Uma situação de equilíbrio corresponde, a condição $h=I-\theta$ para sistemas com vazamento completo, isto é, $\mu=0$.

Note que, de forma análoga, sistemas com spin possuem um campo externo igual a zero e, no caso, um campo magnético externo igual a zero é uma condição natural. Assim, precisamos encontrar um valor crítico $\theta_{c}$ que apresente equilíbrio com o campo externo $I$. Portanto, precisamos de algum mecanismo homeostático que configure o campo externo $h$ como zero para obter o comportamento SOqC [81].

Para isso, propomos uma condição para que nosso limiar $\theta$ se torne um mecanismo simplificado de adaptação, dessa forma temos:

$$
\theta_{i}[t+1]=\theta_{i}[t]-\frac{1}{\tau_{\theta}} \theta_{i}+u_{\theta} \theta_{i} X_{i}[t]
$$

Vale destacar que os sinais de $(1 / \tau) \theta$ e de $u_{\theta} X_{i}$ são opostos ao do caso anterior, onde temos um decaimento constante do limiar à medida que o tempo passa e um aumento no limiar após um disparo.

Através de uma aproximação de campo médio realizada na equação 3.11, chegamos na seguinte expressão:

$$
\rho^{*}=\frac{1}{\tau_{\theta} u_{\theta}}
$$

Temos aqui constantes análogas àquelas antes atribuídas ao peso sináptico. No entanto, mesmo que tenham funções semelhantes, os parâmetros $\tau$ e $u$ podem assumir valores diferentes em ambos os mecanismos, por isso os chamaremos de $\tau_{w}$ e $\tau_{\theta}$.

Dadas as equações 3.11 e 3.8, podemos após manipulação algébrica encontrar uma expressão aproximada para o ponto crítico dado por $\rho^{*}=1 /\left(\tau_{\theta} u_{\theta}\right)$. Combinando essa expressão a Eq. (3.9), temos:

$$
\begin{aligned}
W^{*} & =\frac{\tau_{\theta} u_{\theta}}{\tau u} . \\
W^{*} \rho^{*} & =\frac{1}{u_{w} \tau_{w}}
\end{aligned}
$$


Com essas equações também podemos obter uma outra abordagem para o campo externo $h$ que havíamos mencionado anteriormente, partindo do estado estacionário da equação $\rho[t]$, e algumas manipulações algébricas, obtemos:

$$
h^{*}=\frac{1}{\tau_{\theta} u_{\theta}-2}-\frac{1}{\tau u}, \quad \theta^{*}=I-h^{*}
$$

Foi possível encontrar uma uma dedução a respeito de uma atividade quasi-critica, onde $\rho^{*}=\mathcal{O}(1 /(\tau u) \approx 0$. Para qualquer condição inicial, após um transiente, as coordenadas $(W[t], h[t])$ apresentam uma espécie de flutuação ao redor de um ponto quasi-critico, usaremos essa notação para denominar um ponto quasi-critico $\left(W^{*}, h^{*}\right)$.

Vale ressaltar de que os cálculos de campo médio realizados anteriormente são válidos apenas para grafo completo e com infinitos vizinhos. Os resultados analíticos apresentados aqui são (novamente) apenas para nos fornecer uma intuição a respeito do processo de auto-organização em topologias do tipo WS.

Um ponto importante é que nesse modelo com adaptação no parâmetro $\theta$, desconsideramos a adaptação sináptica, isto é, estamos analisando o que ocorre devido a cada mecanismo homeostático independentemente. Assim, $W$ é constante no modelo. O mesmo será feito para o próximo mecanismo de adaptação proposto.

Por fim, e não menos importante, foi realizado o processo de homeostase no parâmetro de ganho neuronal para o qual estamos usando a notação $\Gamma$. Com isso, temos que:

$$
\Gamma_{i}[t+1]=\Gamma_{i}[t]+\frac{1}{\tau} \Gamma_{i}[t]-\Gamma_{i}[t] X_{i}[t]
$$

Para estudarmos a adaptação em $\Gamma$, mantivemos fixos os parâmetros $W$ e $\theta$. No caso vemos que quando um neurônio dispara $X_{i}[t]=1$, a recuperação do neurônio para o próximo disparo segue de maneira lenta, dependente do parâmetro $\tau$ como já discutido anteriormente. O intuito biológico proveniente do ganho vem da ideia da adaptação das frequências de pico do neurônio, fenômeno conhecido como a regulação (decaimento e recuperação) da densidade de disparos dos canais iônicos de sódio presentes na célula neuronal $[93,94]$.

Destaca-se que estudar a adaptação do ganho neural $\Gamma$ ou do limiar de disparo $\theta$ é bem mais rápido em termos computacionais. Nesses dois casos as dinâmicas homeostáticas são calculadas para cada neurônio $i$ (de uma rede de tamanho $N$ ). Já no caso da adaptação sináptica, a dinâmica é calculada para cada par de vizinhos ij. Assim, a cada passo de tempo $t$ são calculadas aproximadamente $N * K$ equações, onde $K$ é a média de neurônios 
pré-sinápticos para cada neurônio na rede.

$\mathrm{Na}$ imagem a seguir, pode-se ver uma exemplificação de todas essas funções apresentadas anteriormente. Na Fig. 3.1(a) observa-se uma representação de um neurônio biológico, onde cada uma das funções apresentadas atuam na célula neuronal. Na figura (b) representa nosso parâmetro de ordem vs alguma das funções representativas de energia do sistema e nota-se que existe uma região de atrator no ponto próximo à transição de fase. E por fim, temos a figura (c), que mostra a evolução temporal de $E$ e a sua flutuação ao redor de seu ponto crítico $E_{c}$. A faixa dinâmica dessas oscilações é uma função do tamanho $N$ do sistema.

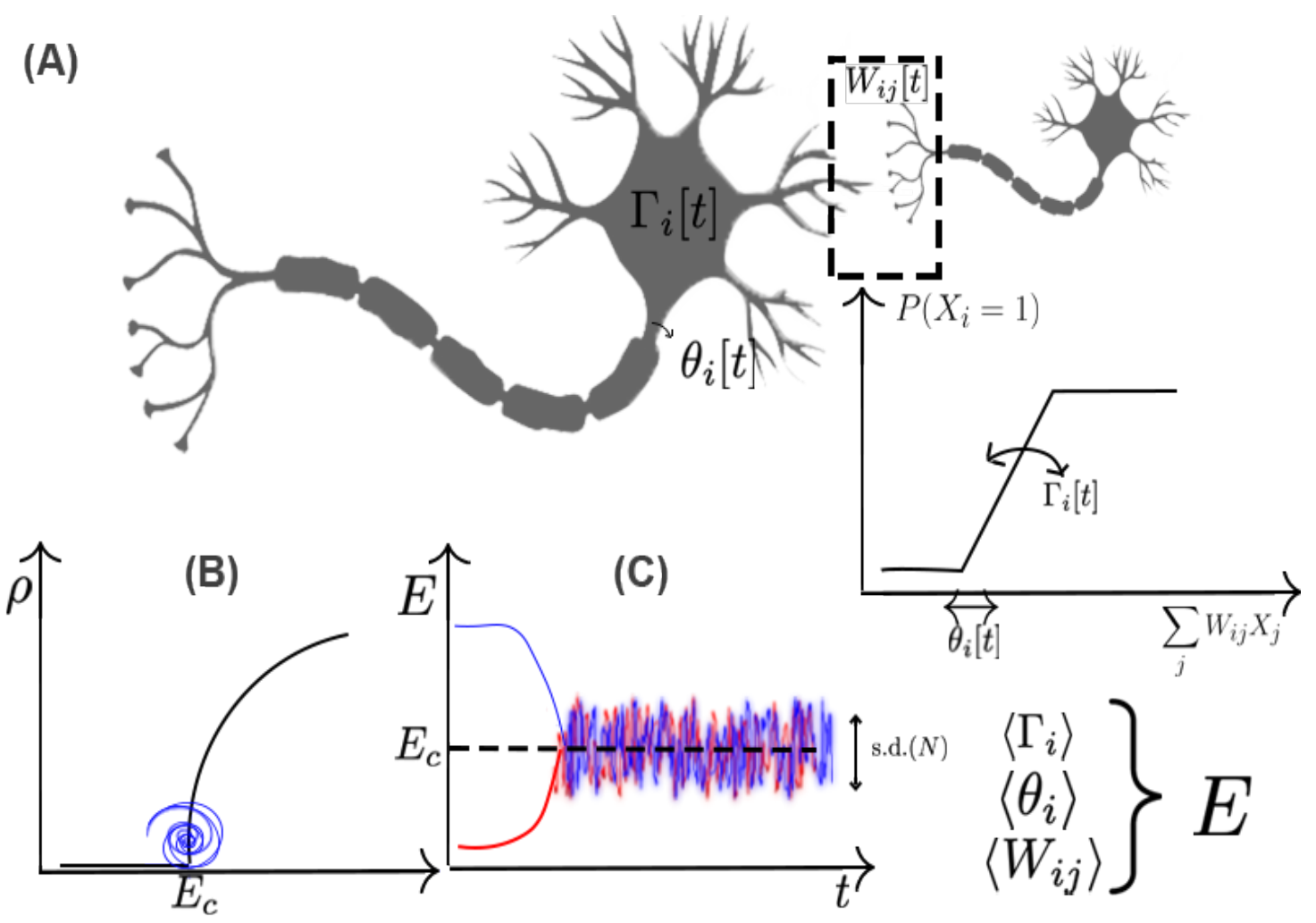

Figura 3.1: Exemplificação das propriedades do modelo neuronal e suas representações gráficas; Figura Adaptada de [1].

Na Fig. 3.1(b) vale ressaltar o seguinte caso: considerando um estado absorvente em uma transição de fase de segunda ordem para o qual a atividade da rede é aproximadamente zero $(\rho=0)$, podemos chegar a uma função a respeito desse evento da seguinte forma:

$$
\rho \approx C\left(\frac{E-E_{c}}{E}\right)^{\beta},
$$

onde $E_{c}$ é o ponto critico em que ocorre a transição de fase. 


\section{Resultados e Discussão}

Após uma introdução dos conceitos e métodos, mostraremos a seguir um estudo a respeito do comportamento das simulações em topologia WS, fazendo comparações entre as redes aleatórias do tipo annealed e quenched e os resultados analíticos de campo médio.

\subsection{Cálculos de campo médio}

Desenvolveremos aqui os cálculos da aproximação de campo médio para o modelo. Começaremos a partir da equação da densidade de disparos, Eq. (3.4), na qual a atividade média da rede é calculada. No entanto existe outra maneira de quantificar a atividade média da rede, que seria através da densidade de probabilidade do potencial de membrana, que pode ser expresso da seguinte forma $p(V)[t]$.

Assumindo que $p(V)[t]$ é a densidade de neurônios daquele instante de tempo $t$, se integrarmos essa função a respeito do potencial $V$, teremos uma expressão do tipo: $p(V)[t] d V$, que corresponde à fração de neurônios que possuem um potencial de membrana presente no intervalo $[V, V+d V]$ dado um instante de tempo $t$.

Essa relação, quando multiplicada pela função de probabilidade de disparo $\Phi(V)$ e integrada em função da variável $V$, nos fornece a densidade de disparos que foi apresentada anteriormente. Essa relação pode ser melhor visualizada a seguir:

$$
\rho[t]=\int_{-\infty}^{\infty} \Phi(V) p(V)[t] d V
$$

Para darmos continuidade ao desenvolvimento analítico das equações, é necessário ressaltar que quando temos uma aproximação de campo médio, podemos substituir o peso sináptico $W_{i j}$, introduzido no capítulo anterior, pelo seu valor médio $W=\left\langle W_{i j}\right\rangle$. Nesta situação temos que o campo local de cada neurônio é dado pela seguinte equação:

$$
h_{i}=\frac{W}{N-1} \sum_{j=1}^{N-1} X_{j}[t]=W \rho[t] .
$$

Utilizando da equação (4.2), isolando os termos e substituindo na equação (3.1), temos a seguinte equação:

$$
V_{i}[t+1]=\mu V_{i}[t]+I+W \rho[t]
$$

Note que o input externo, $I[t]$, é sempre o mesmo para todo os neurônios e por isso assume-se que $I_{i}=I$ conforme apresentado na equação acima. 
Lembremos que a densidade de probabilidade $p(V)[t]$ tem um impulso (ou delta) de Dirac no potencial $U_{0}=0$ que corresponde ao potencial da população de neurônios que no passo anterior disparou. Diferentemente do potencial $V_{i}$ que tínhamos anteriormente que era o potencial de cada neurônio, $U_{k}$ representa o potencial de um grupo de neurônios que não disparou nos últimos $k$ passos de tempo. Segue-se que, uma vez que todos os neurônios tenham disparado pelo menos uma vez, a densidade $p(V)[t]$ será uma combinação de impulsos de Dirac discretos com amplitudes $\eta_{0}[t], \eta_{1}[t], \eta_{2}[t], \ldots$, situados em correspondentes potenciais $U_{0}[t], U_{1}[t], U_{2}[t], \ldots$, tal que $\sum_{k=0}^{\infty} \eta_{k}[t]=1$ (normalização das probabilidades).

Situado em $U_{0}=0$, o termo $\eta_{0}[t]$ é a fração $\rho[t-1]$ dos neurônios que dispararam no intervalo de tempo anterior. Como $\Phi\left(U_{0}=0\right)=0$, a integral da Eq. (4.1) se torna uma soma discreta para este tipo de distribuição:

$$
\rho[t]=\sum_{k=1}^{\infty} \Phi\left(U_{k}[t]\right) \eta_{k}[t]
$$

De acordo com a equação (4.3), os valores $\eta_{k}[t]$ e $U_{k}[t]$ evoluem na forma:

$$
\begin{aligned}
U_{0}[t+1] & =0 \\
\eta_{0}[t=1] & =\rho[t] \\
U_{k}[t+1] & =\mu U_{k-1}[t]+I+W \rho[t] \\
\eta_{k}[t+1] & =\left(1-\Phi\left(U_{k-1}[t]\right)\right) \eta_{k-1}[t]
\end{aligned}
$$

para $k \geq 1$.

\subsubsection{Resultados para $\mu=0$}

Vale mencionar que tais resultados analíticos já foram discutidos na literatura considerando também o caso com vazamento completo $\mu=0$ [95]. Esse caso correspondente à situação em que o neurônio $i$ esquece o potencial de membrana do instante anterior e assim a equação do potencial $V_{i}[t]$ depende apenas das variáveis $I$ e $W \rho[t]$.

Aqui vale salientar que nossa variável $I$, que representa o campo externo de cada neurônio da rede, é uma variável que representa informações a respeito do limiar de disparo dos neurônios e inputs externo. Como $h=\theta-I$, usaremos nas equações a seguir a notação $h$ para representar essas informações.

A motivação por trás dessa simplificação com $\mu=0$ é devido à aplicabilidade de soluções analíticas,quando $\mu=0$ e $I_{i}[t]=I$ (entrada constante uniforme), a densidade $p(V)[t]$ consiste em apenas dois picos de Dirac nos potenciais $U_{0}=0$ e $U_{1}[t+1]=I+W \rho[t]$, 
com os termos de $\eta_{0}[t]$ e $\eta_{1}[t]$ que evoluem como:

$$
\begin{aligned}
\rho[t+1] & =\eta_{0}[t+1]=\Phi\left(I+W \eta_{0}[t]\right)\left(1-\eta_{0}[t]\right) \\
\eta_{1}[t+1] & =1-\eta_{0}[t+1] .
\end{aligned}
$$

Considerando o regime estacionário, a Eq. (4.9) se torna:

$$
\rho=(1-\rho) \Phi(h+W \rho)
$$

Usando a Eq. (3.3) temos:

$$
\rho=\frac{(1-\rho) \Gamma(W \rho+h)}{1+\Gamma(W \rho+h)}
$$

Isolando os termos e igualando a zero, encontramos a seguinte a equação de segundo grau:

$$
2 \Gamma W \rho^{2}-(\Gamma W-2 \Gamma h-1) \rho-\Gamma h=0,
$$

cuja solução, após algumas manipulações algébricas é:

$$
\begin{aligned}
\rho^{ \pm} & =\frac{\Gamma(W-h)-1 \pm \sqrt{\Delta}}{4 \Gamma W}, \\
\Delta & =(\Gamma(W-2 h)-1)^{2}+8 \Gamma^{2} W h
\end{aligned}
$$

vemos que para $\Delta=0$ temos uma descontinuidade de primeira ordem

$$
(\Gamma W+2 \Gamma h-1)^{2}=8 \Gamma^{2} W h
$$

isolando os termos, depois de algumas manipulações de álgebra temos:

$$
\begin{aligned}
W & =-\frac{2 \sqrt{2 h}}{\Gamma}+\frac{1}{\Gamma}+2 h: \\
W & =\frac{2 \sqrt{2 h \Gamma^{2}}+\sqrt{\Gamma}+2 h \Gamma \sqrt{\Gamma}}{\Gamma \sqrt{\Gamma}} \\
\Gamma W & =2 \sqrt{2 \Gamma h}+1+2 h \Gamma \\
\Gamma W & =(1+\sqrt{2 h \Gamma})^{2}
\end{aligned}
$$

De acordo com essas equações podemos ver que para o caso com $I>0$ teremos uma condição com $\Delta=0$ e portanto isso resultaria em uma transição de fase de primeira ordem considerando o ponto crítico $W_{c}$ [36].

Considerando uma rede com inputs externos, nosso parâmetro de ordem, ver 
equação 4.14, assume a seguinte expressão :

$$
\rho=\frac{1}{2}\left(\frac{\sqrt{2 \Gamma h}}{1+\sqrt{2 \Gamma h}}\right) .
$$

Neste caso teremos um valor de $\Delta$ diferente do caso onde o campo externo é nulo, devido a isso temos uma equação diferente para cada um dos casos.

Consequentemente, na ausência de um campo externo $(h=0)$, a partir da equação 4.14, temos uma transição de segunda ordem:

$$
\begin{aligned}
\rho(W) & =\frac{1}{2}\left(\frac{W-W_{c}}{W}\right)^{\beta}=\frac{1}{2}\left(\frac{\Gamma-\Gamma_{c}}{\Gamma}\right)^{\beta}, \\
W_{c} & =\frac{1}{\Gamma_{c}}
\end{aligned}
$$

O expoente crítico de campo médio $\beta=1$ é típico da classe de universalidade de Percolação Direcionada [7, 34, 35, 36, 37]. Relembramos que estes resultados analíticos apresentados nessa seção valem somente para o caso de campo médio, que é equivalente a uma topologia de grafo completo com infinitos vizinhos.

Esta aproximação de campo médio nos conjectura um possível ponto crítico da rede de uma transição de segunda ordem. A aproximação de campo médio nos fornece a seguinte equação para o ponto crítico: $W_{c}=(1-\mu) / \Gamma$ com expoente crítico $\beta=1$, que pertence à classe de universalidade DP, ver Eq. (4.22).

No entanto, como estamos falando sobre percolação direcionada, DP, vale lembrar que existem divisões dentro da classe a respeito da sua dimensão crítica. Para o caso de $p>0$ temos a dimensão $d=4$ e para o caso $p=0$ temos a dimensão $d=1$, com

dimensões diferentes, temos diferentes expoentes críticos. Portanto para $p=0$ nosso coeficiente deverá ser $\beta \neq 1$.

Entretanto, mesmo com todo o rigor que a aproximação de campo médio nos fornece, vale ressaltar que para a aproximação temos um valor de $K \rightarrow \infty$ e nosso trabalho irá tratar de no máximo $K=32$ como veremos nas seções a seguir. Apesar dessa discrepância a respeito de $K$, a aproximação é uma boa escolha para consulta e comparação.

\subsection{Elementos GGL em uma rede com topologia de Watts-Strogatz}

Nas seções seguintes apresentaremos e discutiremos os resultados obtidos com o modelo de neurônios GGL $[32,33]$ conectados com topologia do tipo mundo pequeno de Watts-Strogatz [8]. 


\subsubsection{Variação da probabilidade de religação $p \in[0,1]$}

A princípio iniciamos nossos resultados com uma comparação entre uma transição de fase para valores diferentes de $p$. Na Fig. 4.1 podemos observar que o valor correspondente ao ponto crítico $W_{c}$ varia à medida que o $p$ muda. Podemos ver que a diferença no valor de $W_{c}$ tende a estreitar a partir de $p>0.6$ e a transição de fase ocorre em valores muito próximos.

Nota-se que para o caso com $p=0$ a curva possui um comportamento diferente das demais, o que é aceitável uma vez que $p=0$ é considerado uma rede de "mundo grande" com dimensão crítica $d=1$ e portanto o coeficiente $\beta$ seria diferente, conforme podemos consultar na Tabela 4.1. Vale relembrar que para redes do tipo mundo grande as conexões ocorrem apenas entre vizinhos mais próximos, o que justifica a necessidade de um peso sináptico ou força sináptica $(W)$, maior para que haja uma transição de fase [34].

Na Figura 4.1 temos duas imagens, uma para uma rede aleatória do tipo quenched e outra para o tipo annealed. Nossa motivação por trás dessa comparação parte do princípio que o modelo quenched é biologicamente plausível, no entanto as redes estudadas pela literatura para o modelo GGL são do tipo annealed, então temos uma dualidade: a rede annealed possui resultados factíveis de comparação com a literatura e a rede quenched é uma rede mais próxima de um modelo biológico do cérebro. Devido a isso apresentaremos sempre os dois resultados e discutiremos as aparentes diferenças entre eles.

Quando se analisa os dois resultados da Figura 4.1 com relação a sua diferença entre quenched e annealed, vemos que não existe diferença qualitativa entre elas, a respeito do comportamento da transição de fase presente na rede, existe apenas uma diferença quantitativa. Em relação ao ponto crítico de ambas as figuras, a rede quenched apresenta um ponto crítico na ordem de \pm 0.1 inferior da rede annealed, no entanto nota-se que o coeficiente crítico é o mesmo. Na seção seguinte deixaremos essa afirmação mais evidente.

A hipótese para que a rede quenched possua essa pequena diferença no ponto crítico se dá pelo fato de que a rede possui correlações temporais mais fortes do que as do caso annealed, uma vez que a rede é criada apenas uma vez durante as simulações, enquanto que para rede annealed a rede é sorteada novamente a cada passo de tempo. Essas correlações renovadas a cada instante de tempo na rede annealed trazem uma justificativa a respeito da maior energia que o sistema demanda para atingir o ponto crítico.

Para se obter o ponto critico dessas simulações é realizado uma media de 15 simulações e obtido a media desses valores, esses valores serão apresentados a seguir na seção de Universalidade. No entanto é possível notar através dos resultados obtidos, que existem flutuações no ponto critico da rede, dado que temos uma rede com um parâmetro de aleatoriedade característico do modelo. 
a)

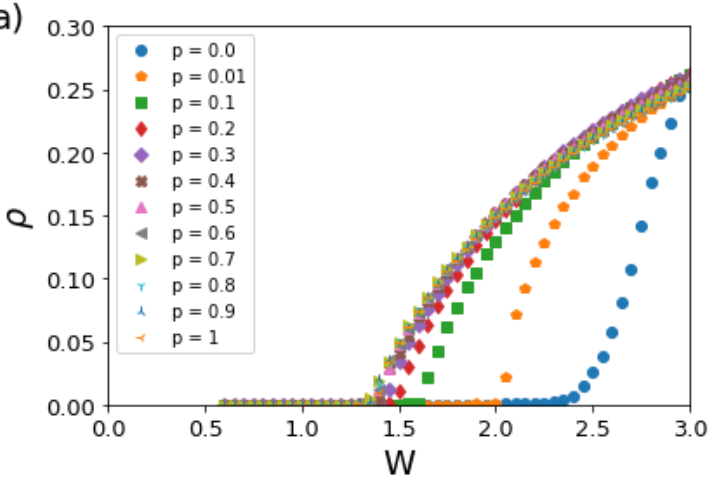

b)

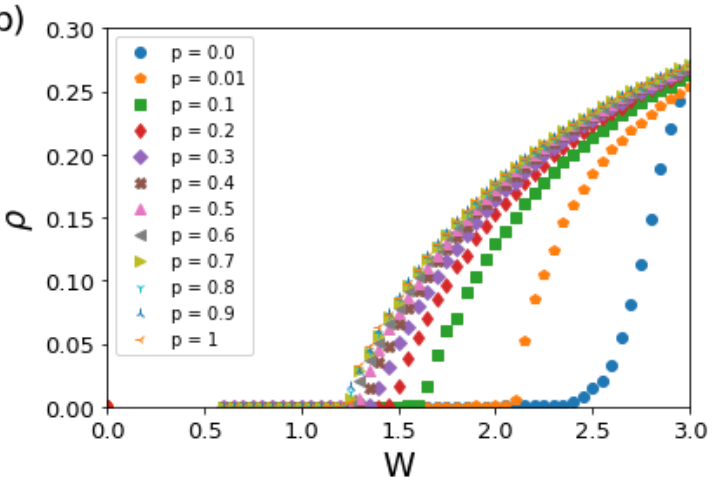

Figura 4.1: Simulação realizada para valores de $p \geqslant 0$ com uma rede de $N=$ 10000 neurônios, $K=4$ vizinhos e $\mu=0$ em redes a) quenched b) annealed.

\subsubsection{Variação do termo relacionado ao vazamento $\mu \in[0,1]$}

Nesta seção, mostramos resultados devido a alterações nos valores de $\mu$, o qual está relacionado ao vazamento do potencial de membrana devido à difusão de íons. Da forma como foi proposta a Eq. (3.1), $\mu$ mostra quanto do potencial de membrana permanece de um passo de tempo $t$ para o passo seguinte $t+1$.

É possível observar na Fig. 4.2 que à medida que a variável $\mu$ aumenta, a transição de fase tende a ocorrer para valores menores do peso sináptico $W$. Vale ressaltar que a constante $\mu$ é equivalente a quantidade de potencial que permanece na sinapse. Para $\mu=$ 0 não permanece nenhum potencial e por isso não temos a memoria do instante anterior. Por outro lado, para $\mu=1$ não ocorre vazamento dos neurotransmissores, havendo total "memória" do potencial de membrana do instante anterior $V_{i}[t]$, que influencia cada vez mais no potencial de membrana do neurônio seguinte, exigindo cada vez menos força sináptica entre os neurônios para que ocorra uma transição de fase. O mesmo efeito se aplica aos casos quenched annealed. Vemos apenas a diferença quantitativa do ponto correspondente ao ponto crítico da transição de fase $W_{c}$. Evento igualmente observado para o caso com diferentes valores de $p$, A diferença se mantém na ordem de $10 \%$.

Existem resultados analíticos que foram apresentados na literatura a respeito do cálculo de campo médio com respeito à variável $\mu$, de forma que temos a seguinte relação de $W_{c}, \Gamma$ e $\mu$ :

$$
W_{c}(\Gamma, \mu)=\frac{(1-\mu)}{\Gamma} .
$$

Como estamos considerando $\Gamma=1.0$, se temos $\mu \approx 1.0$ o ponto crítico da transição de fase acontece próximo de zero. Isso corrobora nossos resultados obtidos por simulações computacionais do modelo.

Na Figura 4.3, realizamos o colapso das curvas com diferentes valores de $\mu$ para o caso com $p=0$ e $p=1$, e podemos ver que as curvas possuem o mesmo comportamento a 
partir de um valor $W_{c}$. Como a curva necessária para o colapso no eixo x é $x=\left(W-W_{c}\right)$, ver a Eq. 4.22, vemos que as curvas da rede com $p=0$ quando colapsadas também possuem o mesmo coeficiente crítico $\beta$ para essa configuração e o mesmo pode ser visto para a rede $\operatorname{com} p=1$.

No entanto, ao analisar as redes com $p=0$ e $p=1$ separadamente, observamos que elas possuem comportamento da curva colapsada diferente. O que justifica que para $p=0$ a curva possui um coeficiente crítico $\beta=0,245$ e para $p=1$ temos $\beta=1$. Esses colapsos foram realizados para uma rede do tipo annealed e se mostrou válido dentro do que se esperava na literatura para essa configuração considerando o expoente crítico $\beta$.

\subsubsection{Variação do número de vizinhos $K$}

Estudaremos a seguir a relação das transições de fase com o número de vizinhos pós-sinápticos $K$. É possível observar que à medida que o número de vizinhos aumenta, a transição de fase tende a acontecer para um valor cada vez menor de $W$.

Lembrando que o número de vizinhos influencia no parâmetro $\frac{1}{K_{i}}$ no potencial de membrana atuando com o intuito de normalizar o somatório de pesos sinápticos recebidos dos neurônios pré-sinápticos.

À medida que o número de vizinhos aumenta, os resultados mostram que é necessário cada vez menos peso sináptico entre eles para que haja uma transição de fase, o que pode ser justificado pela ideia de que teremos uma função potencial que aumenta muito mais rápido a cada passo de tempo. Além disso, o fato de ter mais vizinhos aumenta a chance de que algum neurônio pré-sináptico emita um potencial para um neurônio $i$, aumentando seu potencial de membrana, o que, em média, torna os neurônios da rede mais ativos. Com isso, um valor de $\mathrm{W}$ menor é suficiente para aumentar a densidade da rede, retirando o sistema do estado absorvente.

Podemos notar um comportamento não usual para $p=0$ se comparado com as demais imagens. Vemos que para $p=0$ é necessário um valor em torno de $150 \%$ maior de $W$ para que ocorra uma transição de fase. Esse resultado pode ser justificado se lembrarmos que em uma rede com $p=0$ os neurônios se conectam apenas a vizinhos mais próximos e não efetua links de longa distância como o caso $p>0$.

Um dos benefícios dos links de longa distância é a otimização da informação. Devido a isso, para uma rede com $N$ neurônios que propaga informação a diferentes lugares da rede é necessário muito mais "força" para que isso ocorra do que seria para o caso com links de longa de distância. Essa informação é compatível com os resultados obtidos, seja para $K$, que é o objetivo dessa seção, como para $\mu$, que foi mostrado na seção anterior. 

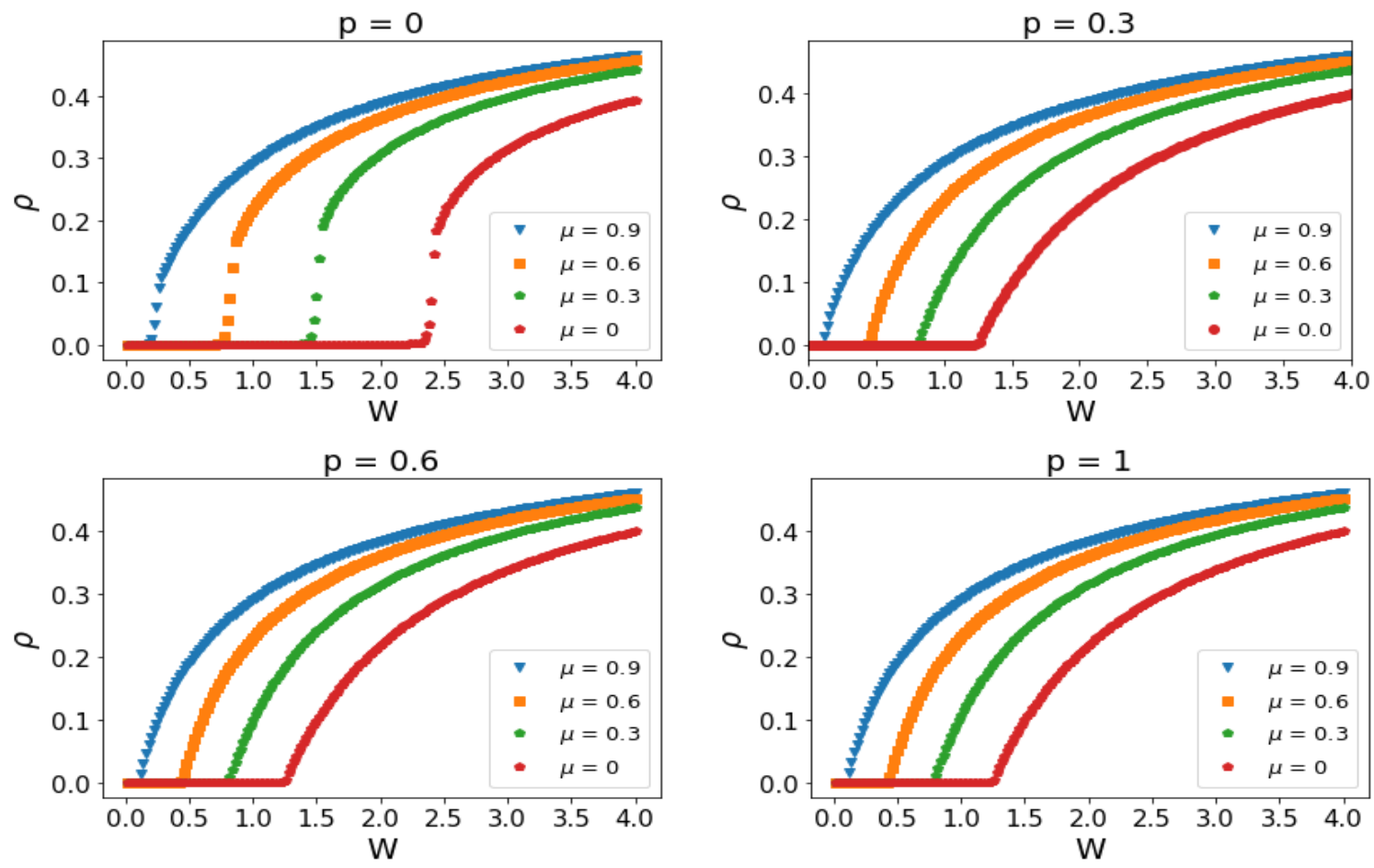

(a) Caso quenched
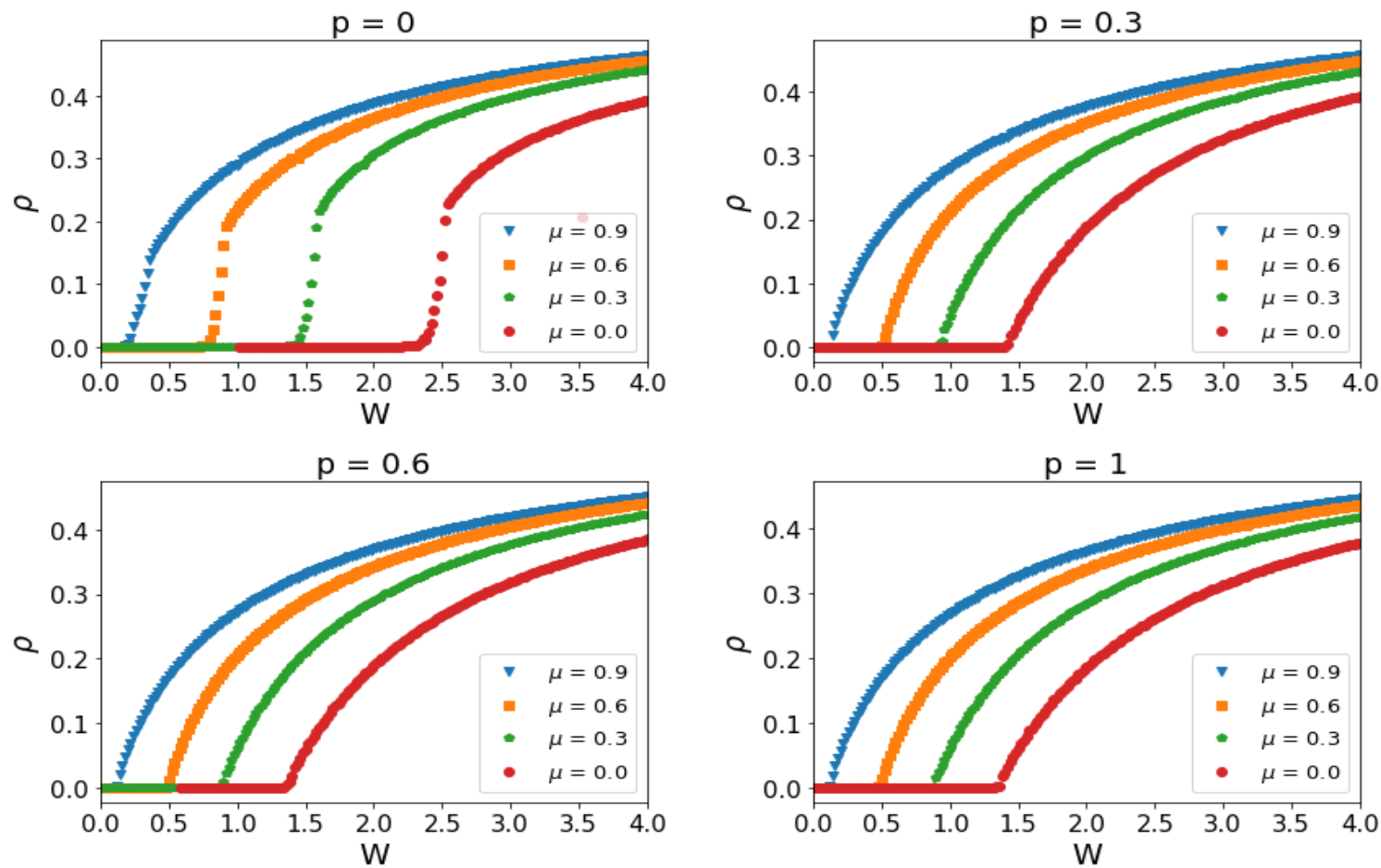

(b) Caso annealed

Figura 4.2: Curvas de $\rho(W \mid \mu)$ para o modelo com diferentes valores de probabilidade $p \operatorname{com} K=4$ e $N=10.000$, caso (a) quenched e (b) annealed. 

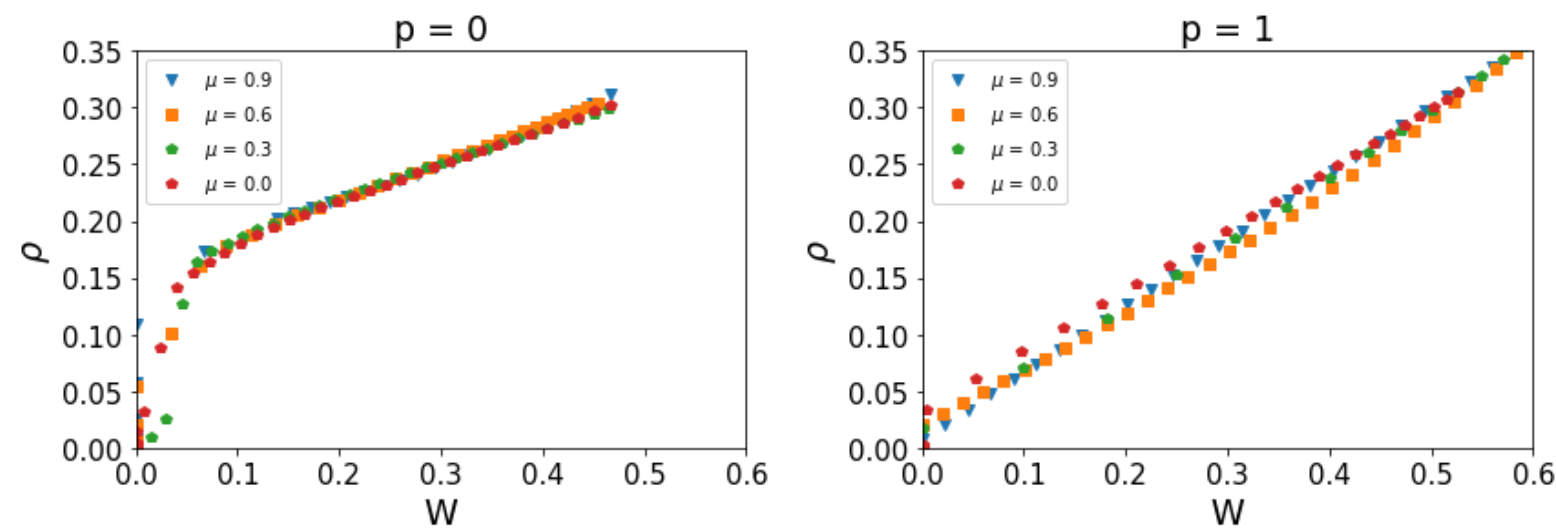

Figura 4.3: Colapso de $\rho(W \mid \mu)$ para a) $p=0,0$ e b) $p=1,0 . N=10.000$ e $K=4$.

O mesmo observado anteriormente em comparação ao caso quenched e annealed, com relação a transição de fase do sistema, é verificado na variação de $K$ vizinhos: uma pequena variação quantitativa quanto ao ponto crítico correspondente de cada configuração.

No caso com diferentes quantidades de vizinhos também efetuamos o colapso das curvas. Com o intuito de exemplificar a independência do ponto crítico $W_{c}$, vemos que as curvas colapsam quando feito o eixo $x=W-W_{c}$. Temos que as curvas para $p=0$ colapsam em uma curva diferente das colapsadas para $p=1$, reforçando a ideia de que temos expoentes diferentes dada a dimensão crítica dos sistemas.
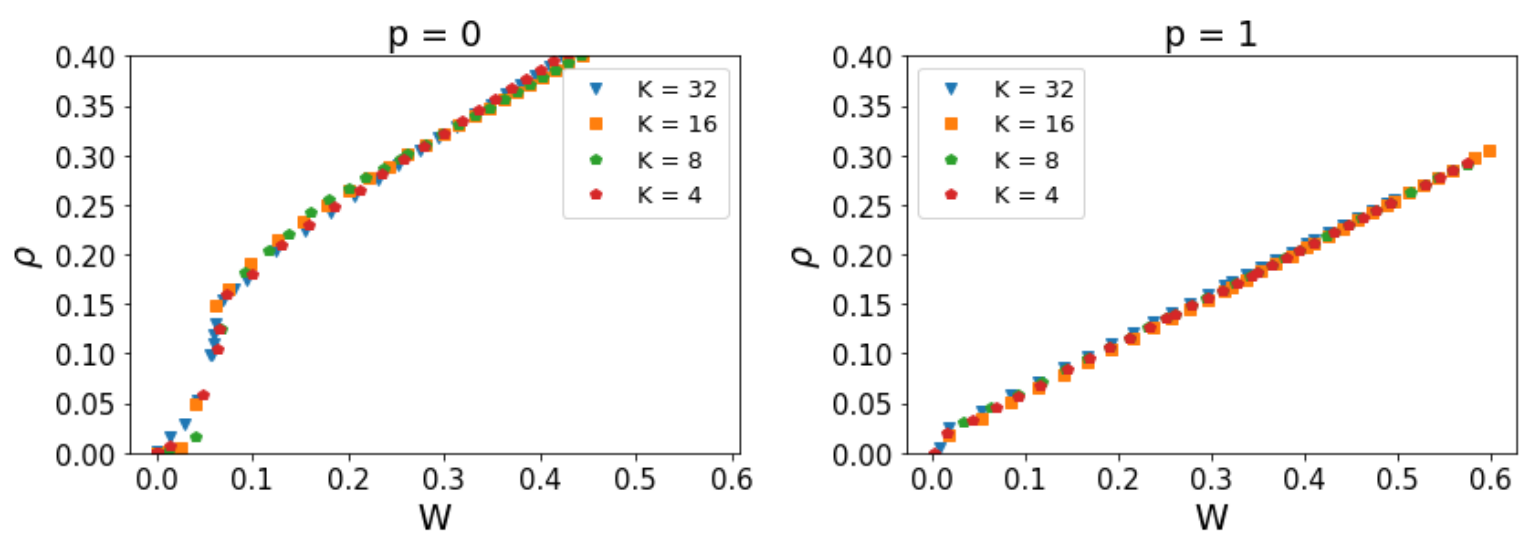

Figura 4.5: Colapso de $\rho(W \mid K)$ para a) $p=0,0$ e b) $p=1,0 . N=10.000$ e $\mu=0$.

\subsection{Universalidade}

A ideia de universalidade decorre da Física Estatística a partir da necessidade de relacionar grupos de sistemas, que em primeiro momento parecem não possuir relação alguma, mas que apresentam mesmo comportamento no ponto crítico [96].

Uma vez que dois modelos possuem a mesma classe de universalidade, podemos 

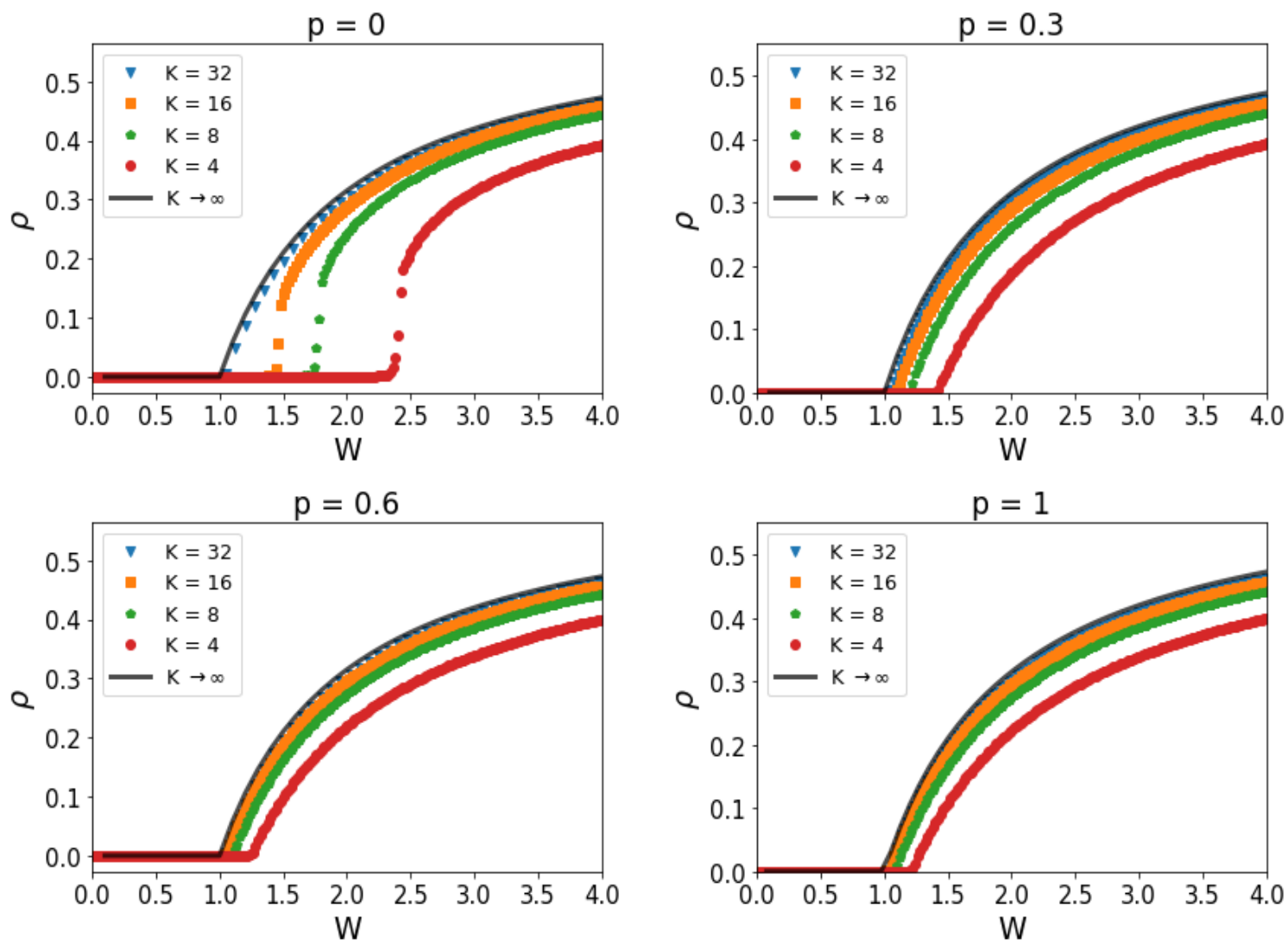

(a) Caso quenched
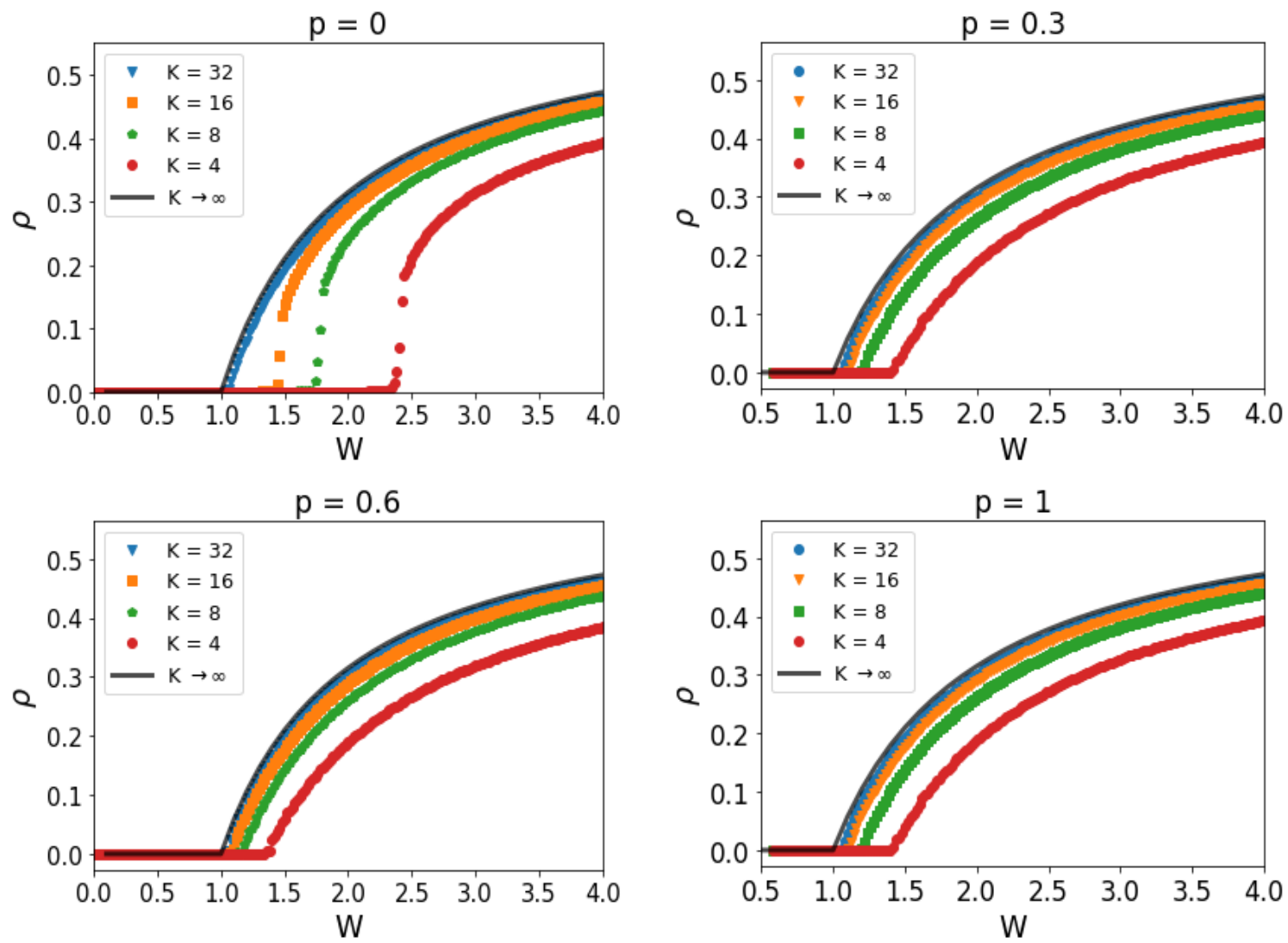

(b) Caso annealed

Figura 4.4: Curvas de $\rho(W \mid K)$ para o modelo com diferentes valores de probabilidade $p$ com $\mu=0$ e $N=10.000$, caso quenched e annealed. 
fazer considerações a respeito supondo que temos dois modelos: um complexo e outro mais simples. O modelo mais simples irá assumir o mesmo comportamento que o modelo complexo próximo ao ponto crítico, conforme já discutido em seção anterior [97].

Na Tabela 4.1 apresentamos os expoentes críticos para a classe de universalidade de Percolação Dirigida (PD).

Mostraremos que nossas redes WS apresentam um estado silencioso (absorvente) e que essa condição está assegurada pela classe de universalidade Percolação Direcionada (PD). Para $p=0$ temos uma rede de mundo grande equivalente à $\mathrm{PD}$ em $d=1$. No caso $d=4$, diz-se que é a dimensão crítica superior, pois acima desta as correlações são muito fracas e vale a aproximação de campo médio. Veremos que nossas redes WS com $p>0$ basicamente serão redes onde ocorrem expoentes críticos de campo médio.

\begin{tabular}{|c|c|c|c|c|}
\hline Expoente & $\mathrm{d}=1$ & $\mathrm{~d}=2$ & $\mathrm{~d}=3$ & $\mathrm{~d}=4$ \\
\hline$\beta$ & 0,276 & 0,583 & 0,805 & 1 \\
\hline$\tau_{s}$ & 1,108 & 1,268 & 1,395 & $3 / 2$ \\
\hline$\tau_{d}$ & 1,159 & 1,450 & 1,730 & 2 \\
\hline
\end{tabular}

Tabela 4.1: Expoentes críticos para percolação dirigida. O expoente do parâmetro de ordem na região crítica é $\beta$. Os expoentes $\tau_{s}$ e $\tau_{d}$ se referem às leis de potência para tamanho (size) e duração (duration) das avalanches.

Adaptado de [98].

No entanto, no presente trabalho estudaremos apenas os expoentes críticos que estão presentes na Tabela 4.1, $\left(\beta, \tau_{s}\right.$ e $\left.\tau_{d}\right)$, relacionados à classe de universalidade de percolação direcionada. Esta classe é bastante comum para casos de transição de fase de segunda ordem.

Em primeiro momento, vamos solucionar o respectivo expoente $\beta$ desse sistema através do ajuste das curvas. Em secções anteriores, iniciamos a discussão a respeito de expoentes diferentes, porém nesta seção iremos apresentar resultados que validem nossa argumentação do ponto crítico mencionado anteriormente.

Em uma rede com $K=4$ vizinhos e com uma curva de ajuste proporcional à:

$$
\rho=C\left(\frac{W-W_{c}}{W}\right)^{\beta}
$$

A equação de ajuste utilizada é análoga na Eq. (4.22), no entanto aqui temos estimativas a respeito de $W_{c}, \beta$ e $C$. Os valores encontrados não são necessariamente iguais aos valores da Tabela 4.1, mas apresentam boa aproximação [34, 35, 37].

Sem mais delongas, vamos analisar as figuras e encontrar o expoente crítico $\beta(p)$ do sistema com $K=4$ vizinhos. Utilizamos de um ajuste nas curvas nos dados simulados 
computacionalmente e podemos ver o resultado do ajuste na Fig 4.6.

Os parâmetros de ajuste obtidos podem ser visualizados na Tabela 4.2. Podemos observar de acordo com os valores que temos um valor de $\beta$ bem próximo do valor teórico tanto para o caso com $p>0$ e para $p=0$. Os demais valores, de $C$ igualmente se aproximam do valor teórico de 1/2, como pode ser visto na equação 4.22.

Vale ressaltar o resultado obtido para $p=0$, com valor de $\beta$ correspondente a 0.28 , valor esse que possui muita proximidade com o coeficiente para a dimensão critica $d=1$ da classe de universalidade PD. Isso reforça a consideração de que redes com $p=0$ são de "mundo grande", apenas com conexões entre vizinhos mais próximos.

\begin{tabular}{|c|c|c|c|}
\hline \multicolumn{4}{|c|}{ Annealed } \\
\hline & $W_{c} \pm 0,02$ & $\beta$ & $C$ \\
\hline$p=0.0$ & 2.37 & 0.30 & 0.51 \\
\hline$p=0.3$ & 1.42 & 0.99 & 0.56 \\
\hline$p=0.6$ & 1.36 & 0.99 & 0.56 \\
\hline$p=1.0$ & 1.34 & 0.99 & 0.56 \\
\hline
\end{tabular}

\begin{tabular}{|c|c|c|c|}
\hline \multicolumn{4}{|c|}{ Quenched } \\
\hline & $W_{c} \pm 0,02$ & $\beta$ & $C$ \\
\hline$p=0.0$ & 2.37 & 0.30 & 0.51 \\
\hline$p=0.3$ & 1.40 & 0.97 & 0.48 \\
\hline$p=0.6$ & 1.26 & 0.97 & 0.48 \\
\hline$p=1.0$ & 1.24 & 0.97 & 0.57 \\
\hline
\end{tabular}

Tabela 4.2: Coeficientes referentes à transição de fase de uma rede com $N=$ 10000 neurônios, $K=4$ vizinhos e termo relacionado ao vazamento $\mu=0$. $\}$

\subsection{Avalanches neuronais}

Discutimos anteriormente que avalanches com duração e tamanho distribuídos em leis de potência são eventos naturais que ocorrem de forma espontânea nas proximidades do ponto critico. Assim, utilizamos os valores obtidos na Tabela 4.2 e verificamos se apresentam leis de potência com os expoentes críticos determinados na Tabela 4.1.

As Figuras a seguir comprovam os expoentes presentes na tabela e, a respeito da dimensão critica do sistema, para $p=0$ temos $d=1$, enquanto $p>0$ corresponde a $d=4$.

É relevante salientar que os resultados foram obtidos através de um ajuste de parâmetros a cerca do ponto critico $W_{c}$. Para um valor de $W$ escolhido erroneamente a avalanche apresenta comportamento subcrítico ou supercrítico. Contudo, o valor utilizado para produzir os resultados de avalanches foram em alguns casos $\pm 0,02$ diferentes dos valores da Tabela 4.1.

Podemos observar nas figuras de avalanches para o caso quenched que algumas curvas das redes menores estão levemente subcríticas, embora os valores que utilizamos tenham sido os obtidos na Tabela 4.2, isso fornece uma argumentação a respeito do ponto critico ser uma função também do tamanho da rede, $\mathrm{N}$ neurônios, como na Figura 4.7a para $p=1$ que mostra que apenas a curva de $N=32000$ se encontra subcrítica. Os valores que encontramos de ponto critico na Tabela 4.2 são para uma rede de tamanho $N=10000$. 

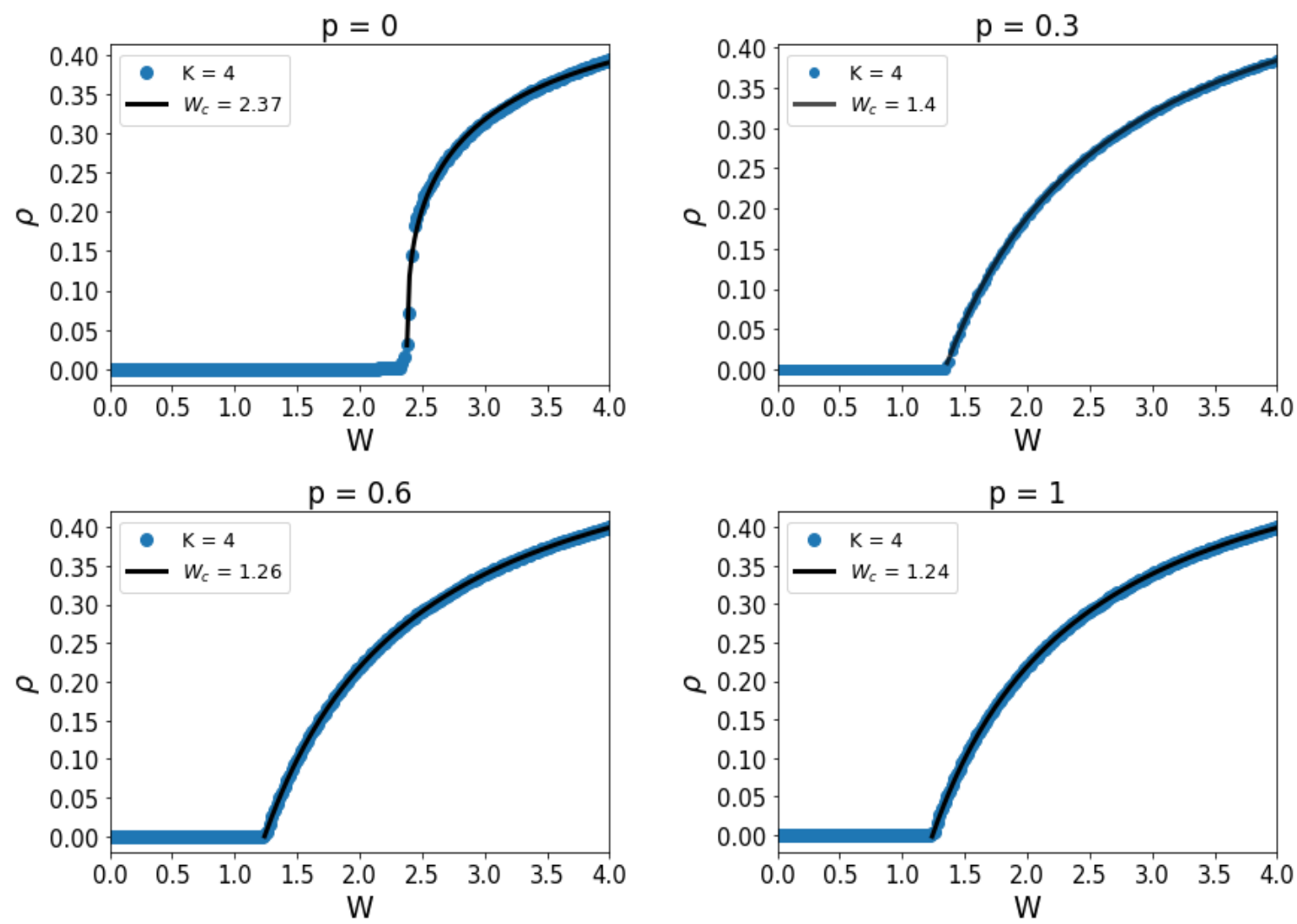

(a) Quenched
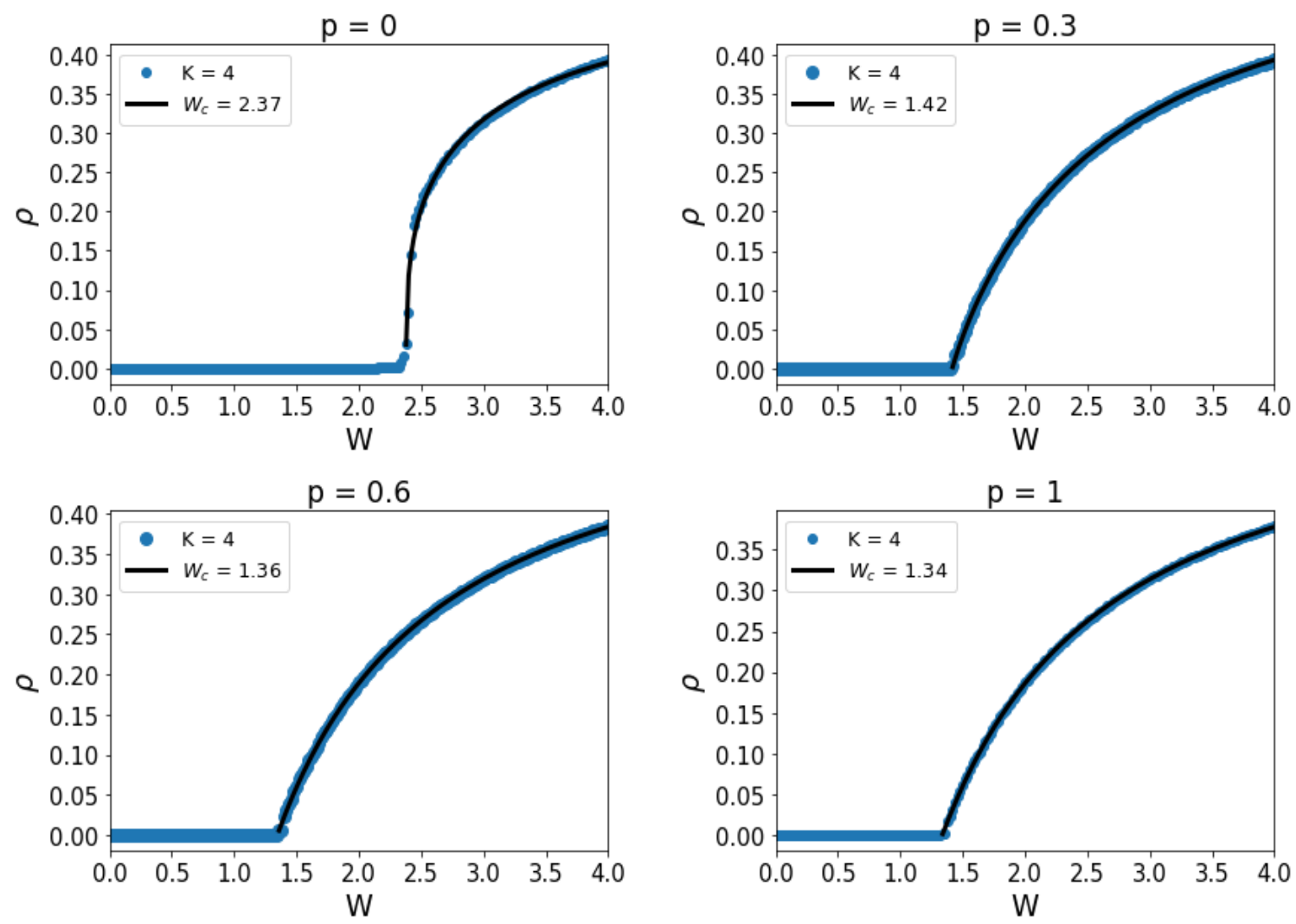

(b) Annealed

Figura 4.6: Ajuste de curvas de redes com $N=10000$ neurônios, $K=4$ vizinhos e coeficiente de vazamento $\mu=0$, os valores obtidos para Wc foram compilados na tabela 4.2 . 

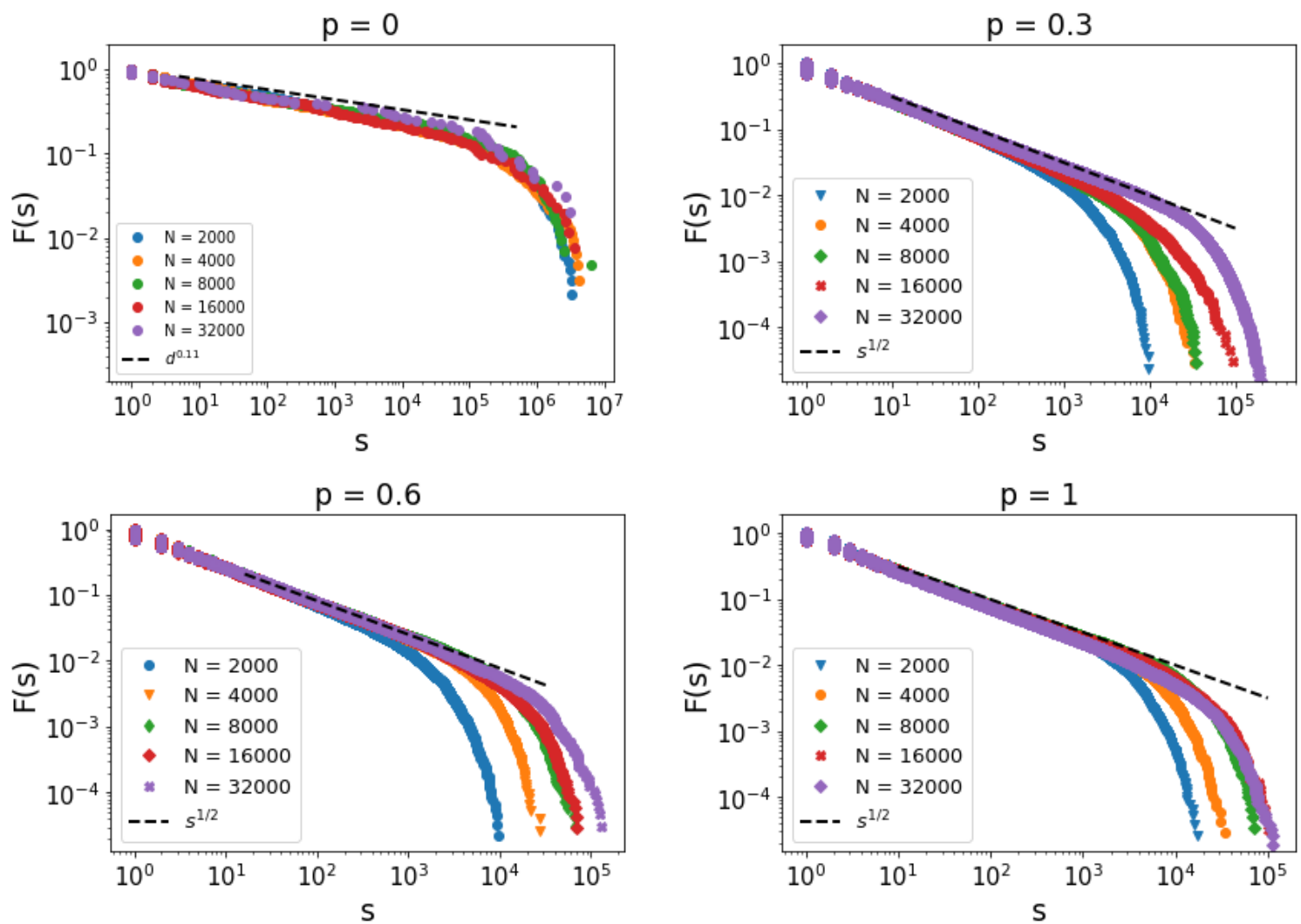

(a) Quenched
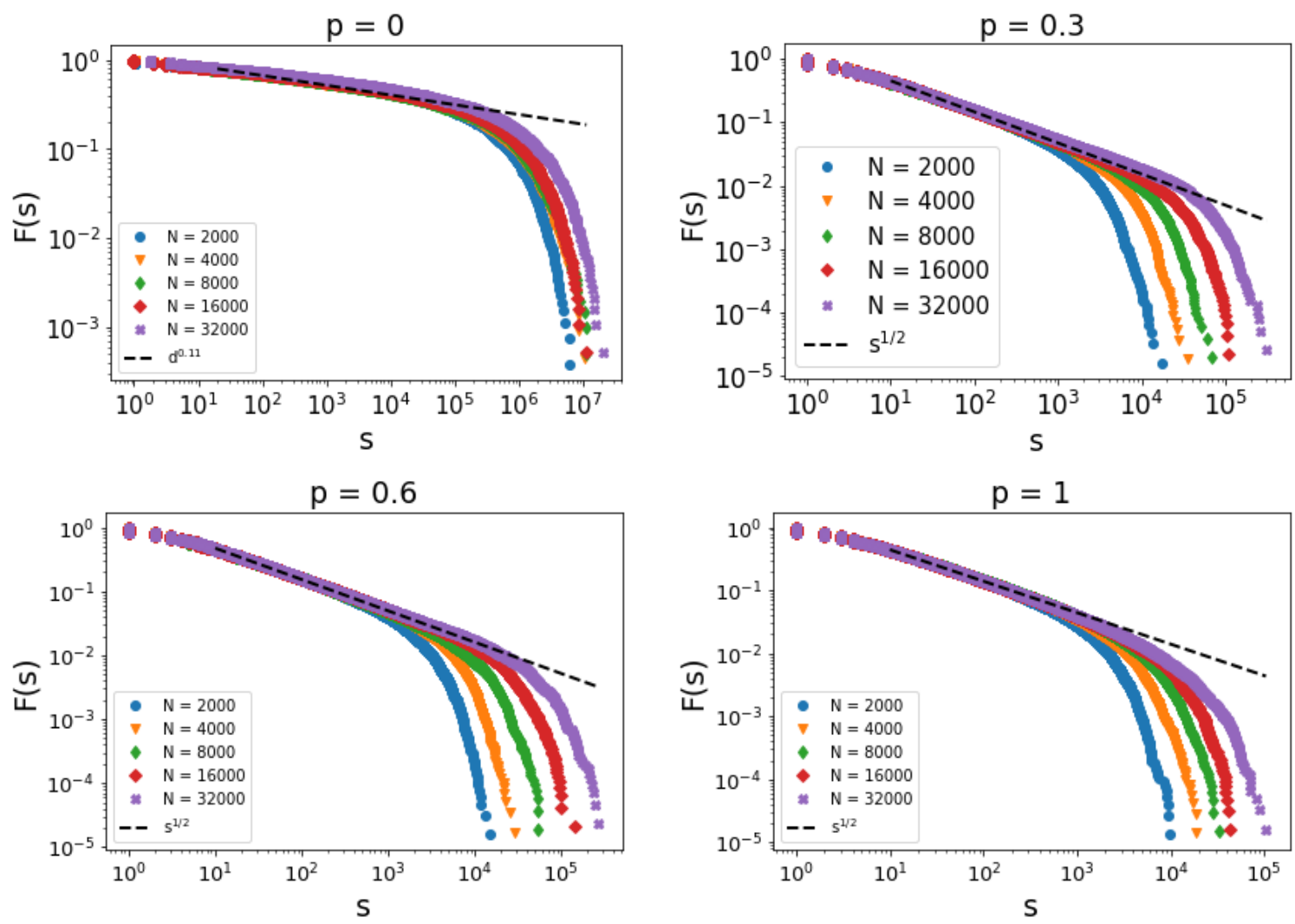

(b) Annealed

Figura 4.7: Distribuição de avalanches de tamanhos $F(s)$ para vários valores de $N$, termo relacionado ao vazamento $\mu=0$ e número de vizinhos $K=4$. 
Podemos ver na Fig. 4.7 e 4.9, para os casos com $p>0$, que a distribuição acumulada é dada por $F(s) \propto s^{-a}$, onde $a=\tau_{s}-1 \approx 0,5$. Portanto, $\tau_{s} \approx 3 / 2$, o que corresponde ao expoente de uma aproximação de campo médio. Para o caso de $p=0$, encontramos o $\tau_{s} \approx 1,11$, coerente com o valor $\tau_{s}(d=1) \approx 1,108$ da Tabela 1.1. Assim, podemos concluir que temos fortes evidências de que nossas redes Watts-Strogatz estão na mesma classe de universalidade de PD com $d=1$ para $p=0$ e $d=4$ para $p>0$.

Na Fig. 4.8a, fizemos a análise de tamanho finito para o nosso sistema. Obtivemos uma curva colapsada universal com $a=0,5$ e $b=1$. Podemos ver que, independente do tamanho de nossa rede, temos $\tau_{s} \approx 3 / 2$ e a função de corte depende de $s / N$. No caso de rede regular $p=0$ obtivemos $a=0,11$, o que fornece $\tau_{s}=1,11$. 

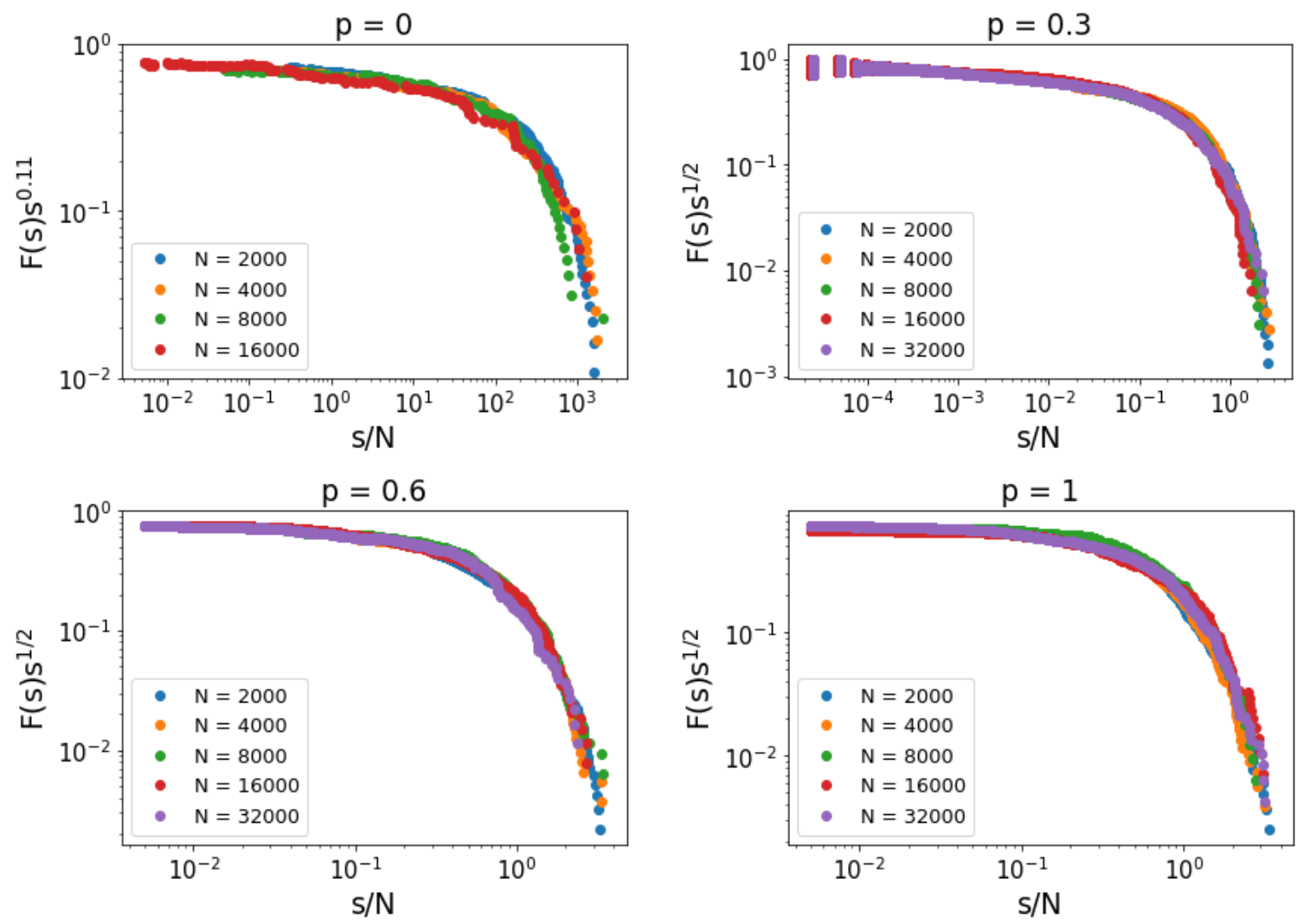

(a) Quenched
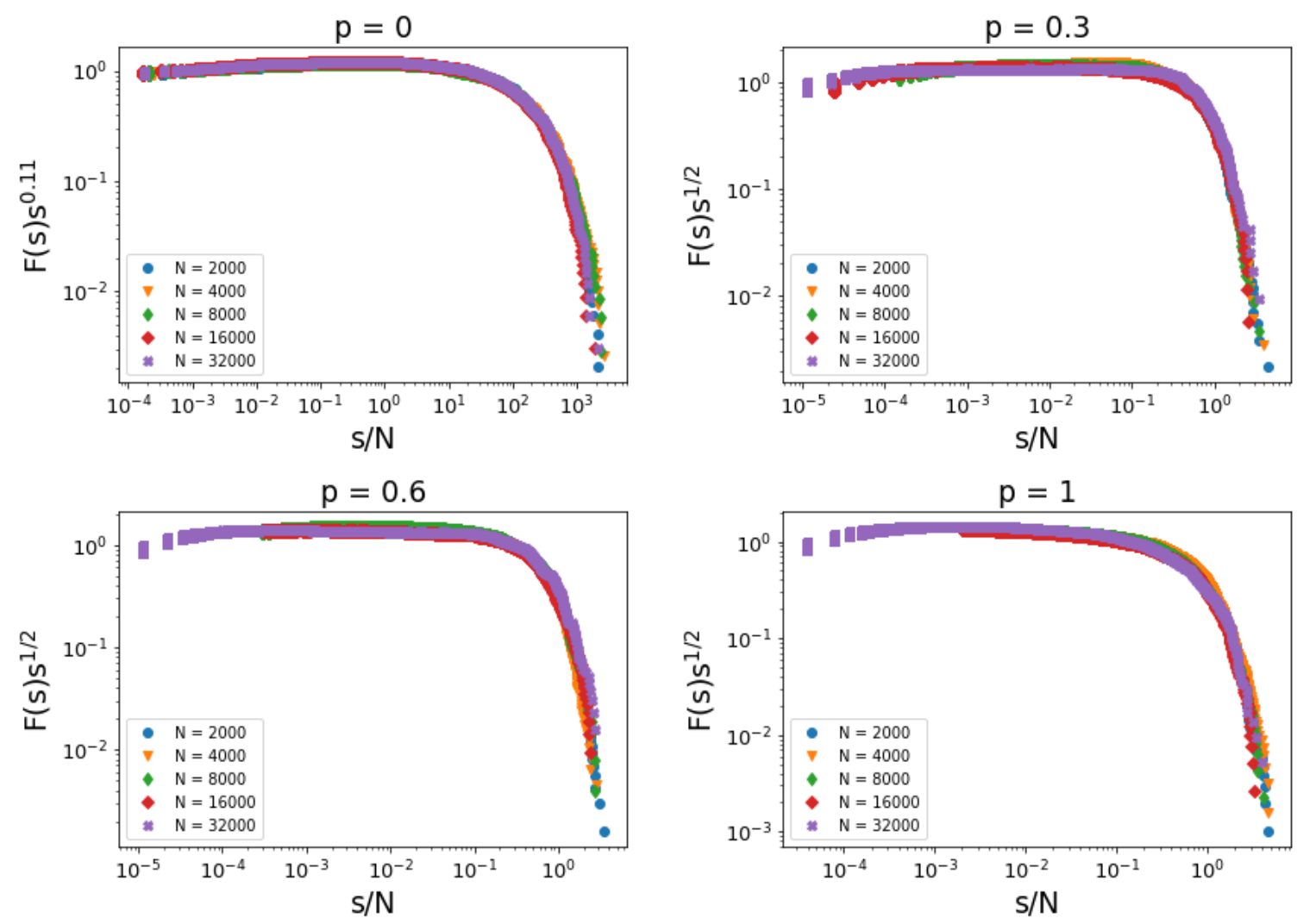

(b) Annealed

Figura 4.8: Colapso de dados da distribuição de tamanhos de avalanches $F(s)$ para $p=0,0 ; 0,3 ; 0,6$ e $p=1,0$. Termo relacionado ao vazamento: $\mu=0$ e número de vizinhos: $K=4$. 

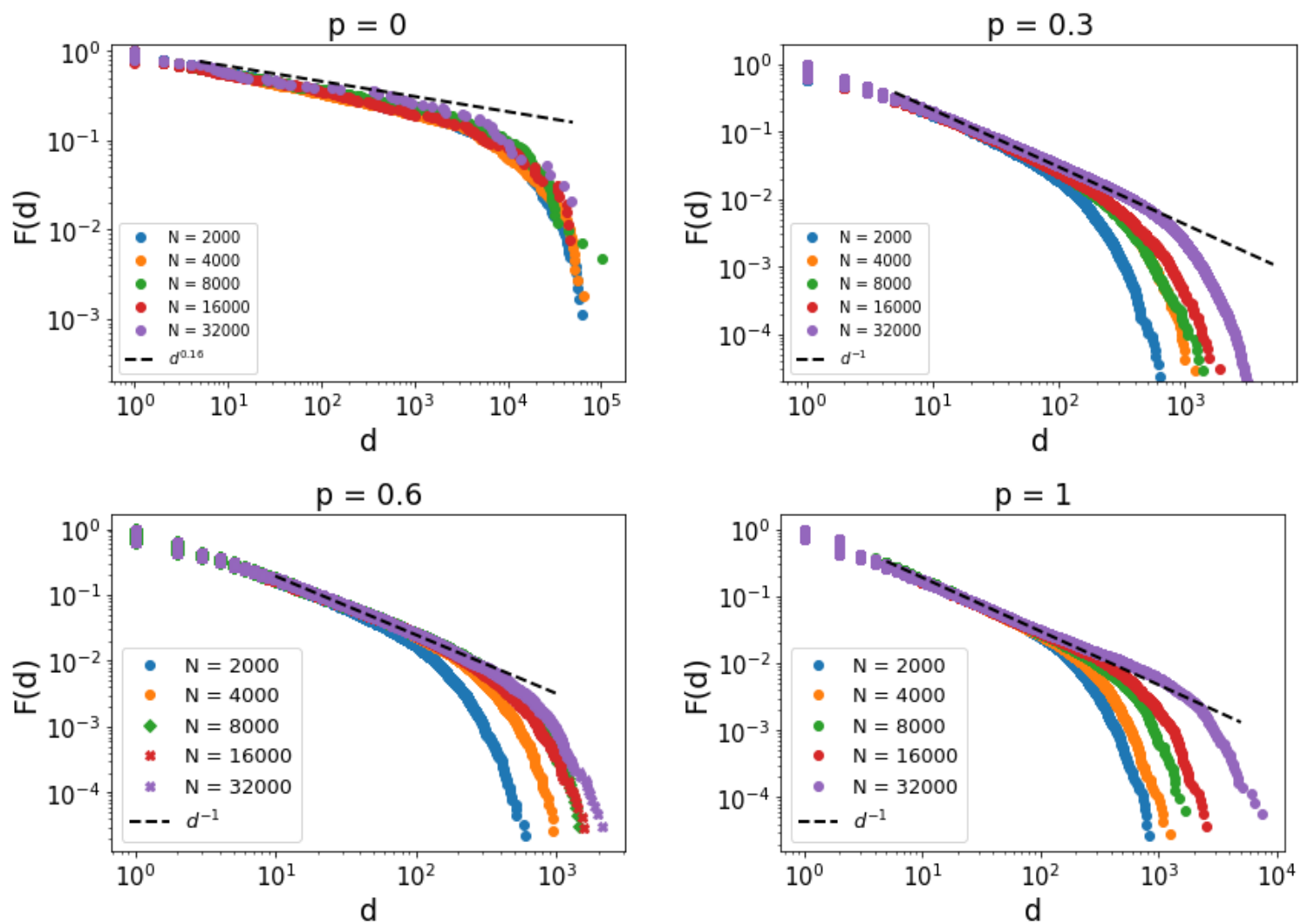

(a) Quenched
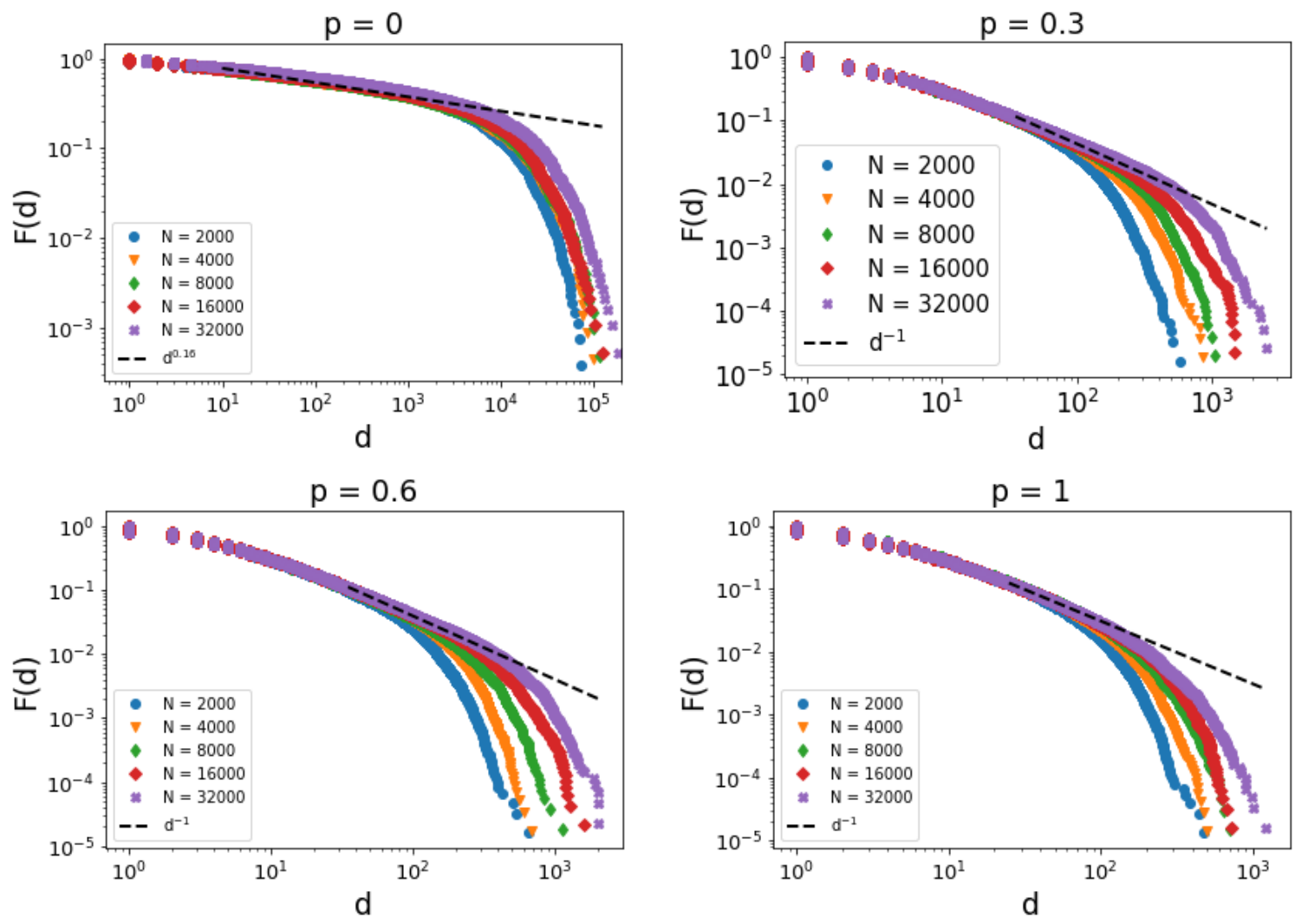

(b) Annealed

Figura 4.9: Distribuição de avalanches de duração $F(d)$ para vários valores de $N$, termo relacionado ao vazamento $\mu=0$ e número de vizinhos $K=4$ 
Na Fig. 4.9b, estudamos a duração das avalanches em função de $p$ : encontramos, para $p>0$, um expoente $\tau_{d} \approx 2$ que é o valor de campo médio esperado pela Tabela 4.1 . Para $p=0$ temos $\tau_{d}=1,16$, compatível com o valor 1, 159 o que corrobora nossa hipótese que a classe de universalidade de nosso modelo é DP.

Pode ser observado na Fig.4.10a,onde fizemos a análise do escalonamento de tamanho finito para a duração de avalanches. Observamos o mesmo comportamento na forma de uma curva universal $F\left(d / N^{b}\right)$ mas agora com expoente de corte $b=1 / 2$.

Vemos que as curvas possuem uma dependência com $N$, o que pode ser exemplificado pelo escalonamento de tamanho finito. O comportamento referente ao decaimento longo das leis de potência Fig. 4.7 e 4.9b, é um indicativo de que o sistema propaga suas flutuações através não só de grandes distâncias mas também por longos períodos de tempo. Ou seja, cada configuração do sistema armazena uma memória correspondente aos instantes anteriores [70].

\subsection{Auto-organização à quasi-criticalidade}

Aqui apresentaremos resultados a respeito de três mecanismos que conduzem a rede de neurônios, por meio de homeostase, para uma região critica. Essa condução da rede por mecanismos internos é usualmente denominada na literatura como auto-organização à quasi-criticalicidade $(\mathrm{SOqC})[99,74,80,95,86,36,81,1]$.

Os resultados analíticos obtidos anteriormente, como já dito, partiram de uma aproximação de campo médio; no entanto, tais resultados oferecem uma boa aproximação para nossa rede WS para resultados de $p>0$, especialmente para $p \approx 1$, que seria a rede aleatória com $K$ vizinhos.

\subsubsection{Auto-organização com ganhos neuronais dinâmicos}

A partir das discussões realizadas a respeito da auto-organização na criticalidade, nosso primeiro mecanismo homeostático estudado será $\Gamma$, que representa a média dos ganhos neuronais de cada neurônio $i$ da rede. Com o intuito de deixar o máximo de parâmetros livres, fizemos um estudo da variação de $\tau$ e mantendo $u=0,1$ que corresponde a fração de neurotransmissores recebidos pelo neurônio pós sináptico. Podemos ver na Figura 4.11 que o mecanismo é satisfatório em se auto-organizar em direção do regime critico para diferentes valores iniciais do ganho médio dos neurônios na rede. Esse valor vem de um parâmetro de entrada nas simulações, de modo que um número aleatório com distribuição de Poisson no intervalo $\left[0, \Gamma_{m} a x\right]$ é recebido para cada neurônio. Contudo, é possível observar que um parâmetro relevante para alcançar a criticalidade do modelo é o conhecido limite critico,no entanto, no modelo há um número médio de vizinhos $\mathrm{K}$ e o 

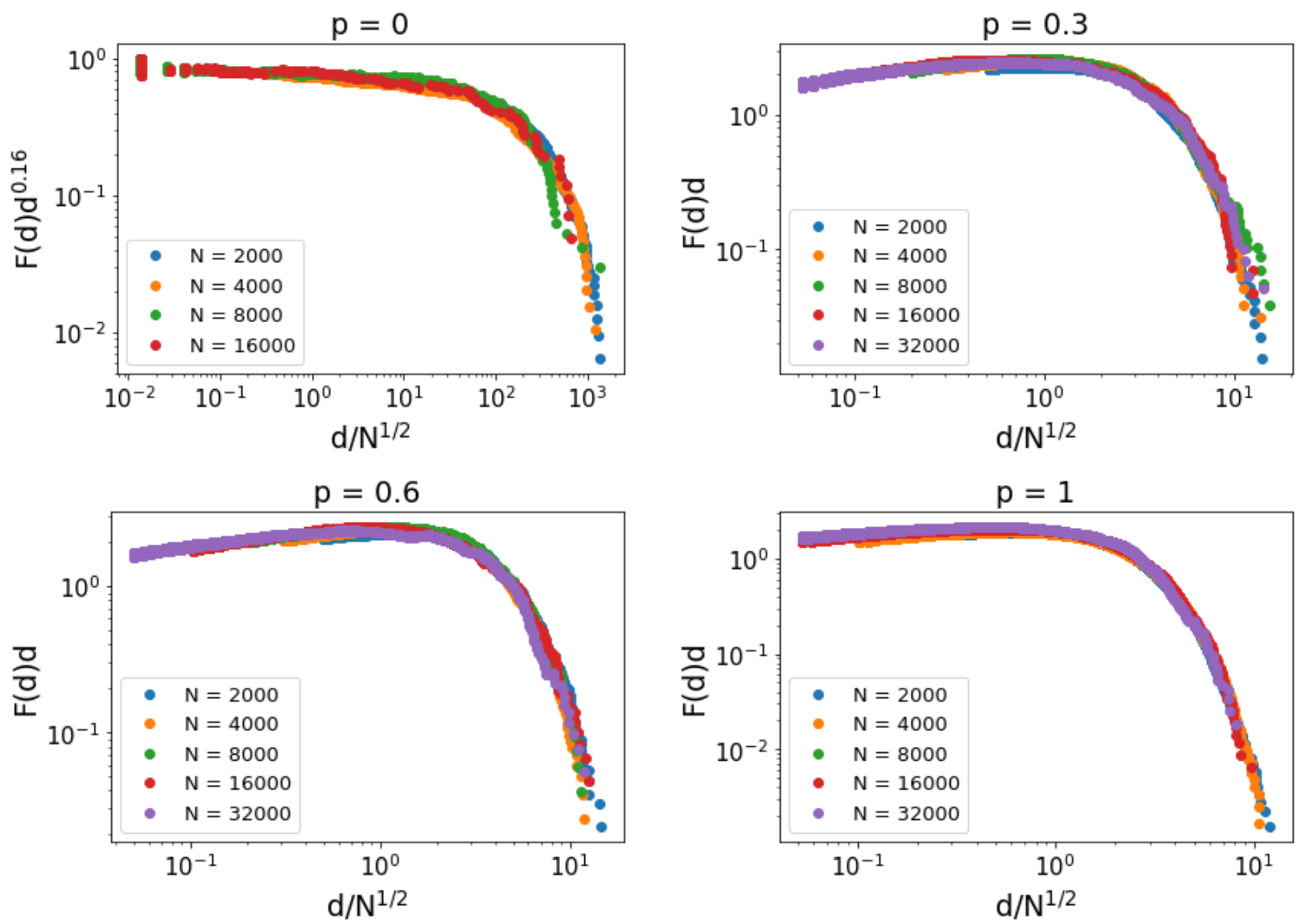

(a) Quenched
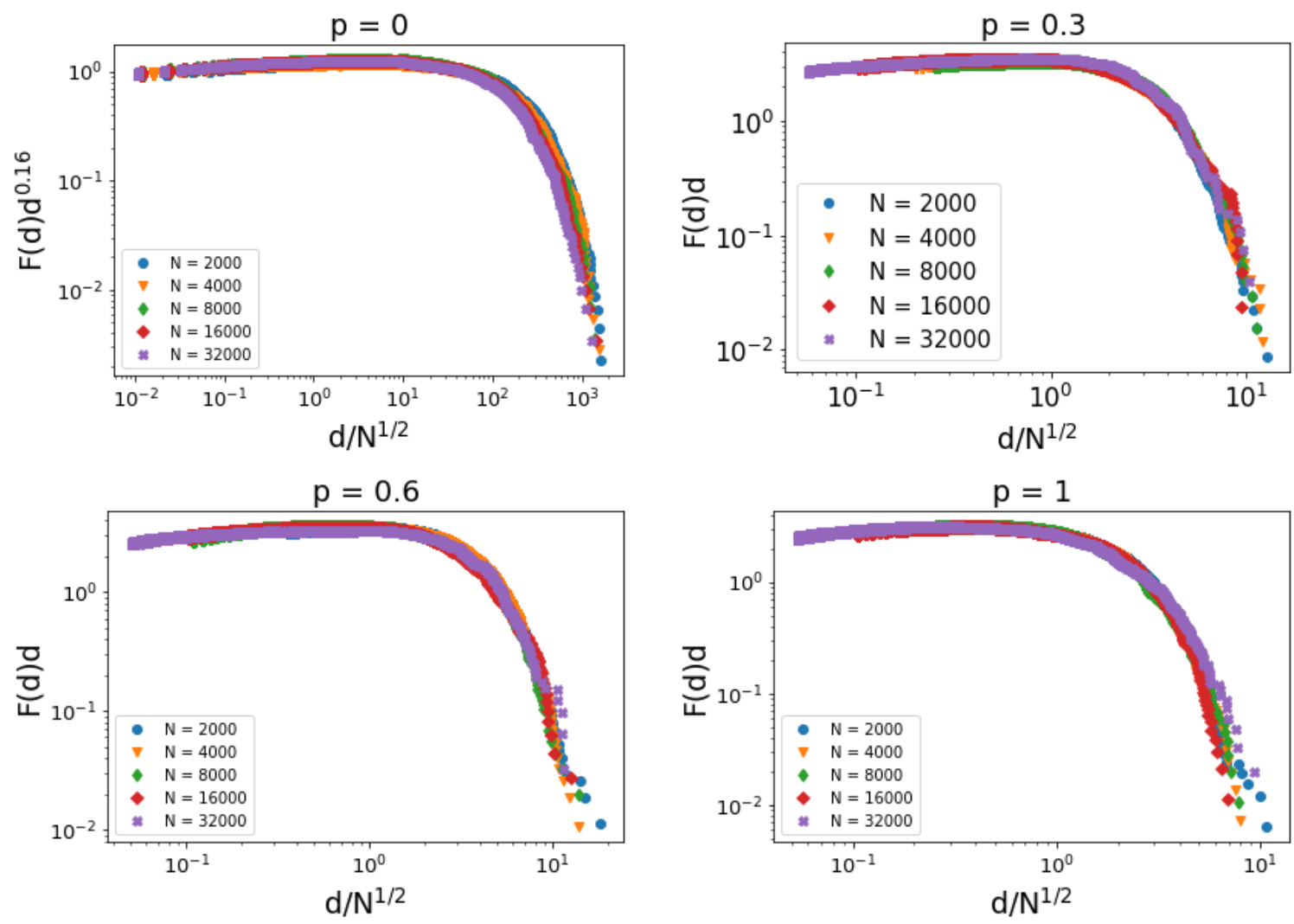

(b) Annealed

Figura 4.10: Colapso de dados: Distribuição de duração de avalanches $F(d)$ para $p=0,0,0,3,0,6$ e $p=1,0$. Termo relacionado ao vazamento : $\mu=0$ e numero de vizinhos: $K=4$. 
modo como os vizinhos são definidos é determinado pela probabilidade p, diferentemente do caso analítico (grafo completo). Com isso, há a dependência de uma constante de proporcionalidade $C(p)$, de forma que:

$$
\Gamma=C(p) W_{c}
$$

Diferentemente da Eq. 4.23, apresentada na seção de resultados analíticos do campo médio, para a qual temos uma distribuição do tipo grafo completo, nas simulações temos um numero limitado de vizinhos $K$, devido a isso a equação possui o ponto critico em 1 , e portanto uma constante de proporcionalidade que depende do parâmetro $p$ é incluída.

O valor de $W$ para cada $p$ usado na Figura 4.11 é aquele obtido no caso das simulações sem auto-organização (caso "estático") com os mesmos parâmetros (para cada p) no ponto crítico. As figuras apresentadas anteriormente sem auto-organização foram obtidas com $\Gamma=1$; sendo assim, o valor crítico teórico esperado para $\Gamma$ na próxima figura é $\Gamma=1$.

Podemos observar a partir das imagens presentes na Figura 4.11 um estudo para diferentes valores de $p$, em simulações do tipo quenched e annealed. Nota-se que $p=0$ demanda mais tempo para que ocorra a auto-organização e um valor de $\tau$ maior para que ocorra uma estabilidade. Esse valor de $\tau$ maior para $p=0$ pode ser explicado analisandose o tamanho das avalanches na Figura 4.7 onde podemos ver que $p=0$ possui avalanches da ordem de $10^{2}$ maiores que para os demais valores de $p$. Nos casos onde temos um $\tau$ igual ao valor utilizado nas figuras para $p>0$, nossa dinâmica em $\Gamma$ se auto-organiza em um valor muito acima do esperado que seria igual a 1.

Vale destacar também que as flutuações para a rede com $p=0$, fechada em formato de anel, são significativamente menores do que para as redes aleatórias $(p>0)$. Isso evidencia que a taxa de disparos na rede regular é mais equilibrada com a taxa de crescimento do ganho neuronal (definida pela variável $\tau$ ). Para $p=0$, os casos quenched e annealed são equivalentes entre si, pois as redes re-sorteadas no caso annealed sempre corresponderão ao mesmo "anel" da rede quenched.

Nota-se que existe pequena diferença para os casos quenched e annealed para diferentes valores de $\tau$ nas imagens de $\mathrm{SOqC}$ para o $\Gamma$; no entanto, existem valores críticos $W_{c}$ para cada um dos conjuntos de (a) e (b).

\subsubsection{Auto-organização com limiares de disparo dinâmicos}

Temos aqui algumas observações realizadas para o mecanismo de homeostase no limiar de disparo $\theta$. Os resultados são explicitados da mesma forma que os demais, havendo um painel de figuras com duas partes, uma para o caso quenched e outra para o 

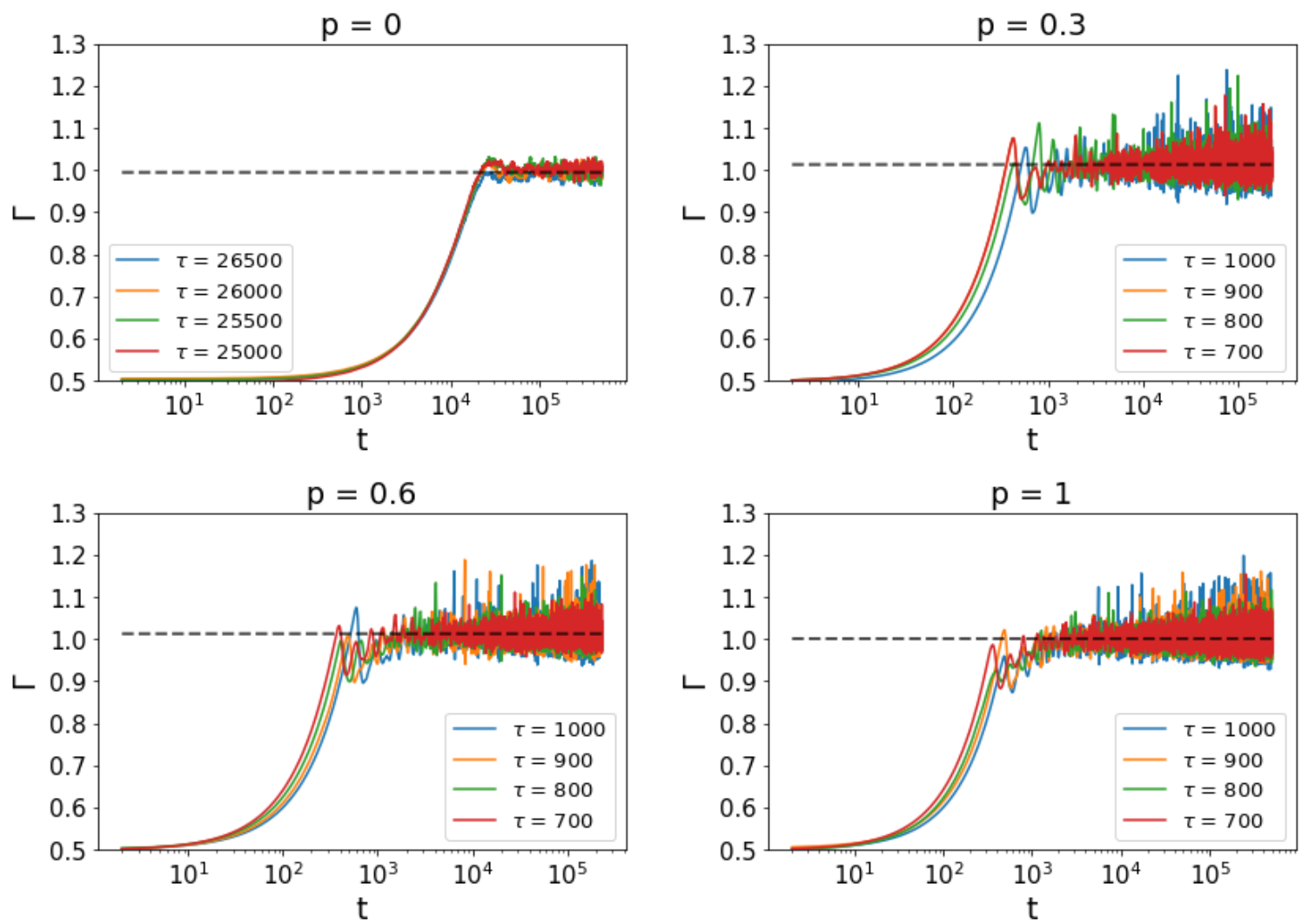

(a) Quenched
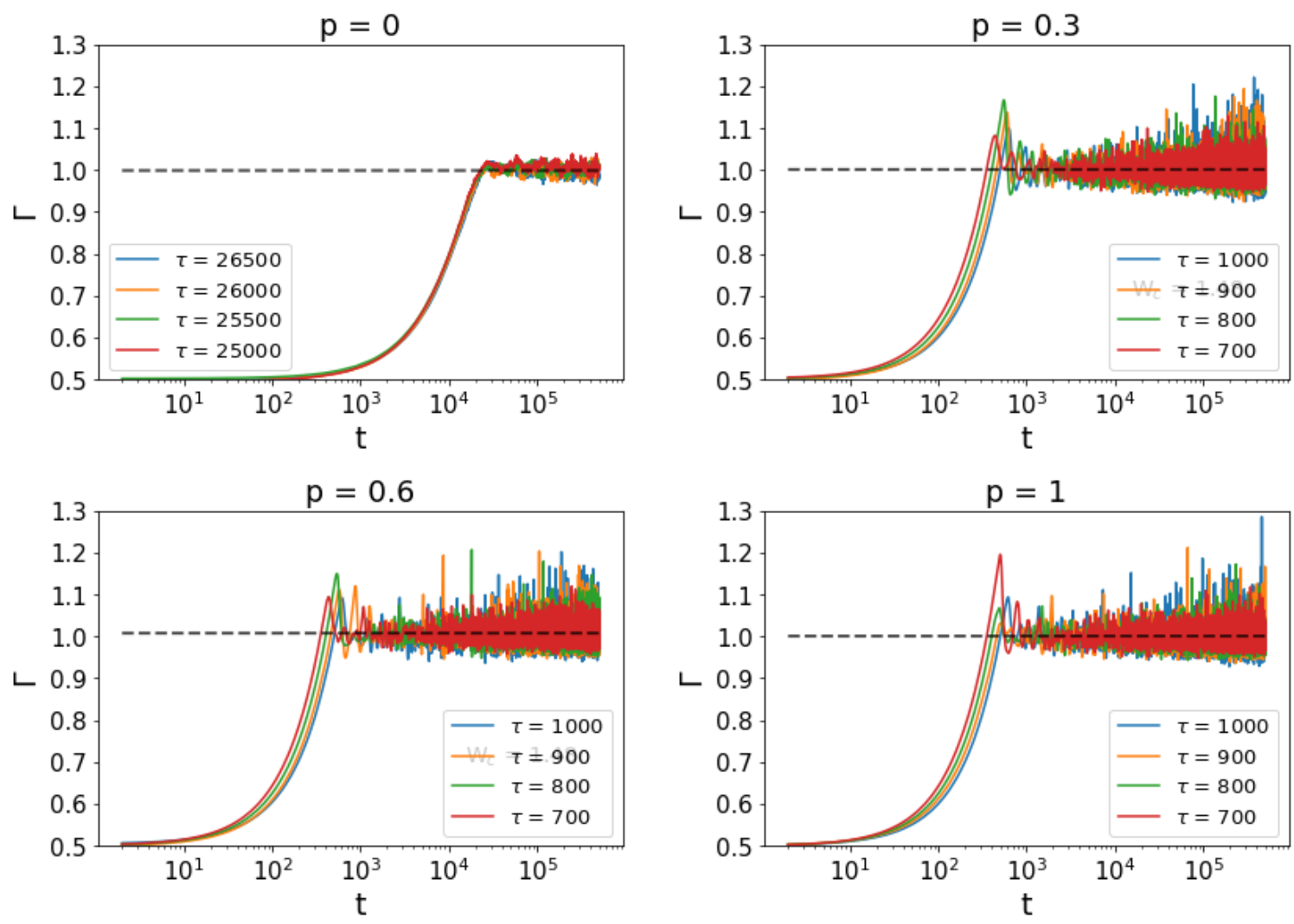

(b) Annealed

Figura 4.11: Auto-organização com ganhos neuronais dinâmicos. Parâmetros: $W_{c}=W_{c}(p)$ da Tabela 4.2, $\theta=0, K=4, \mu=0, I=0, u=0,1$ e $\tau$ variável. Para diferentes valores de $p$. (a) Simulação de rede do tipo quenched. (b) Simulação de rede do tipo annealed. 
annealed.

Neste caso temos algumas considerações a respeito da auto-organização para que o evento pudesse ser observado. Primeiramente, quanto ao campo externo temos que:

$$
h=I-\theta \text {. }
$$

Como utilizamos um campo externo $(h=0)$ para o caso estático, decidimos manter essas configurações para poder comparar com o caso dinâmico. Portanto, na Figura 4.12 é mostrado o caso $I=0$ e observa-se que o valor de $\theta$ se auto-organiza em aproximadamente zero.

O valor de $\Gamma$ foi fixado em 1 . No entanto, nota-se que os valores de $W$ utilizados para se ajustar o sistema são diferentes daqueles utilizados na seção anterior com o mecanismo proposto no parâmetro $\Gamma$, no entanto os valores de $W_{c}$ utilizados se encontram dentro do intervalo de valores considerando o desvio padrão da Tabela 4.2.

No entanto para os casos de $p=0,3$ e $p=0,6$ do caso annealed usamos um valor um pouco acima dos valores da Tabela 4.2 e vemos que temos maiores flutuações e a rede se encontra um pouco acima de $\theta_{c}=0$ que pode ser visto nas demais figuras, o que corresponde a uma rede com características supercríticas para a escolha do $W_{c}$ utilizado.

Vale ressaltar que fizemos as figuras com variações do parâmetro $\tau$. Para a maior parte das simulações a flutuação é mínima, como pode-se ver na Figura.

\subsubsection{Auto-organização com pesos sinápticos dinâmicos}

Por fim, como nosso último mecanismo homeostático estudado temos o peso sináptico $\left(W_{i j}\right)$. A equação utilizada para esse mecanismo foi apresentada na seção anterior, ver Eq. 3.8. Temos os parâmetros $\tau$ e $u$ novamente e iremos fazer um estudo a respeito de como o comportamento da rede muda à medida que variamos $\tau$ (Figura 4.13).

A princípio vemos um comportamento semelhante ao observado nos ganhos neuronais para o caso com $p=0$, que demanda muito mais tempo para que ocorra a autoorganização e também necessário um valor de $\tau$ consideravelmente maior do que para os casos com $p>0$. Vemos que para 500.000 passos de tempo tau ainda não auto-organizou. Dado que as simulações de $W_{i j}$ são computacionalmente muito custosas, já que o valor do peso de cada sinapse é atualizado a cada passo de tempo, é difícil a realização de simulações muito longas. Esse é um ponto que importante, que implica em uma grande vantagem de se estudar, sempre que possível, mecanismos biologicamente plausíveis de adaptação no valor de variáveis referentes a cada neurônio (o que corresponde a $N$ atualizações por passo de tempo) ao invés de a cada sinapse (o que leva a $N K$ equações para cada instante $t$ ). 

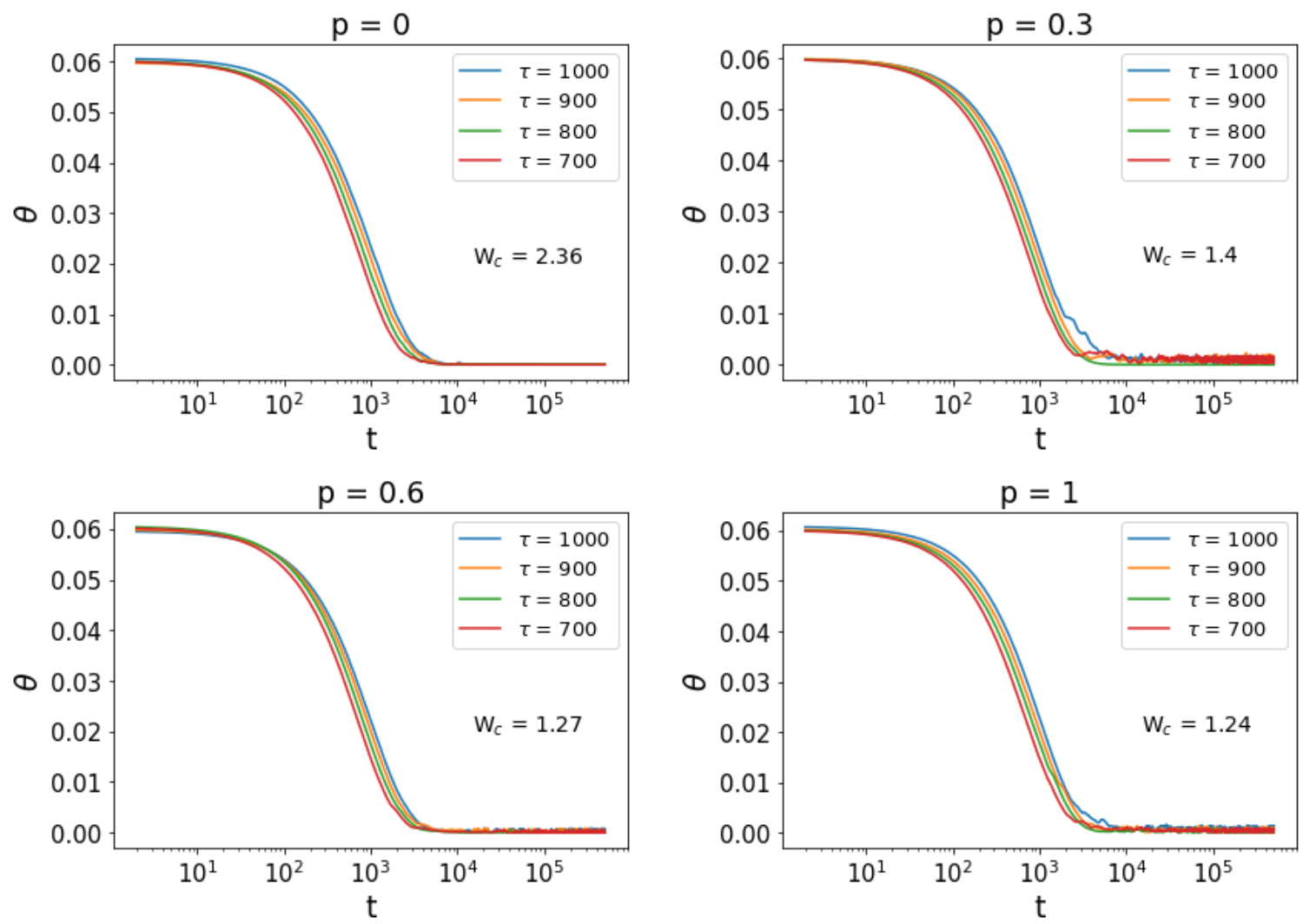

(a) Quenched
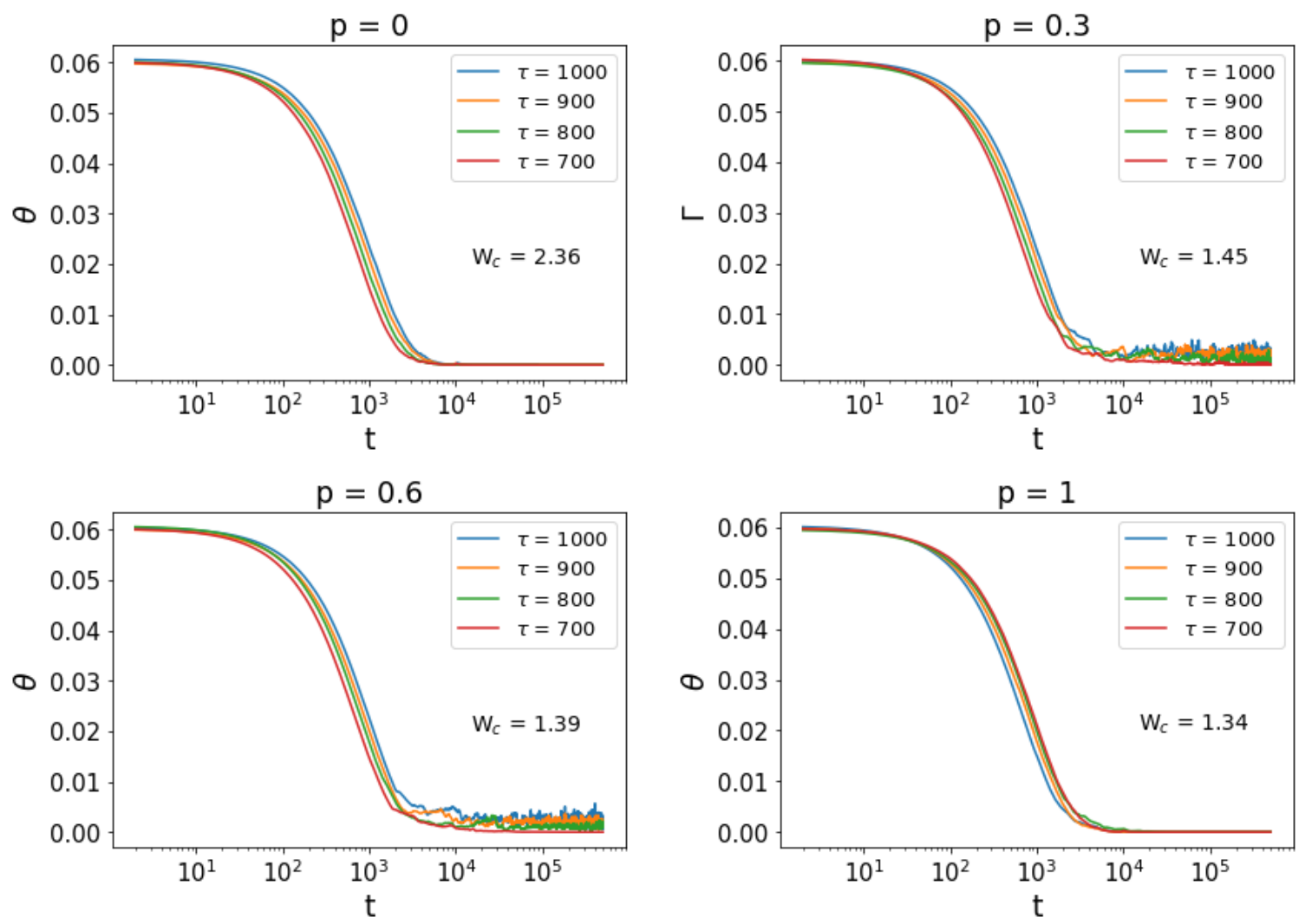

(b) Annealed

Figura 4.12: Auto-organização com limiar de disparo dinâmicos. Parâmetros: $W_{c}=W_{c}(p), \Gamma=1, K=4, \mu=0, I=0, u=0,1$ e $\tau$ variável. Para diferentes valores de $p$. (a) Simulação de rede do tipo quenched. (b) Simulação de rede do tipo annealed. 


\begin{tabular}{|l|l|}
\hline \multicolumn{2}{|c|}{ Annealed } \\
\hline & $W^{*} \rho^{*}$ \\
\hline$p=0,0$ & \\
\hline$p=0,3$ & 0,0134 \\
\hline$p=0,6$ & 0,0137 \\
\hline$p=1,0$ & \\
\hline
\end{tabular}

\begin{tabular}{|c|c|}
\hline \multicolumn{2}{|c|}{ Quenched } \\
\hline & $W^{*} \rho^{*}$ \\
\hline$p=0.0$ & \\
\hline$p=0,3$ & 0,0134 \\
\hline$p=0,6$ & 0,0136 \\
\hline$p=1,0$ & 0,0138 \\
\hline
\end{tabular}

Os valores analíticos previstos para o campo médico com a dinâmica proposta para a adaptação de $w$ leva ao resultado já apresentado na Eq. 3.4: $W^{*} \rho^{*}=\frac{1}{\tau_{w} u_{w}}$.

Dessa forma, os valores de $W^{*}$ e $\rho^{*}$ foram obtidos no intervalo de $t=100.000$ a 500.000 passos de tempo de simulação. E ficam próximos do valor analítico particularmente para valores maiores de $p$, que se aproximam mais da situação de campo médio. Os valores de $W^{*}$ estão destacados com uma linha tracejada na Figura 4.13.

A curva tracejada foi obtida pela media de todas as curvas e o valor encontrado pode ser visualizado na legenda das figuras, para o caso $p=1$ temos a impressão da media das curvas estar localizada um pouco acima da curva, no entanto vale ressaltar que o transiente não foi desconsiderado para o calculo da media das curvas.

Desconsiderando os casos com $p=0$, nos quais não foi possível atingir a autoorganização no intervalo simulado, observa-se que a amplitude das oscilações diminui para maiores valores de $p$, principalmente para o caso annealed. 

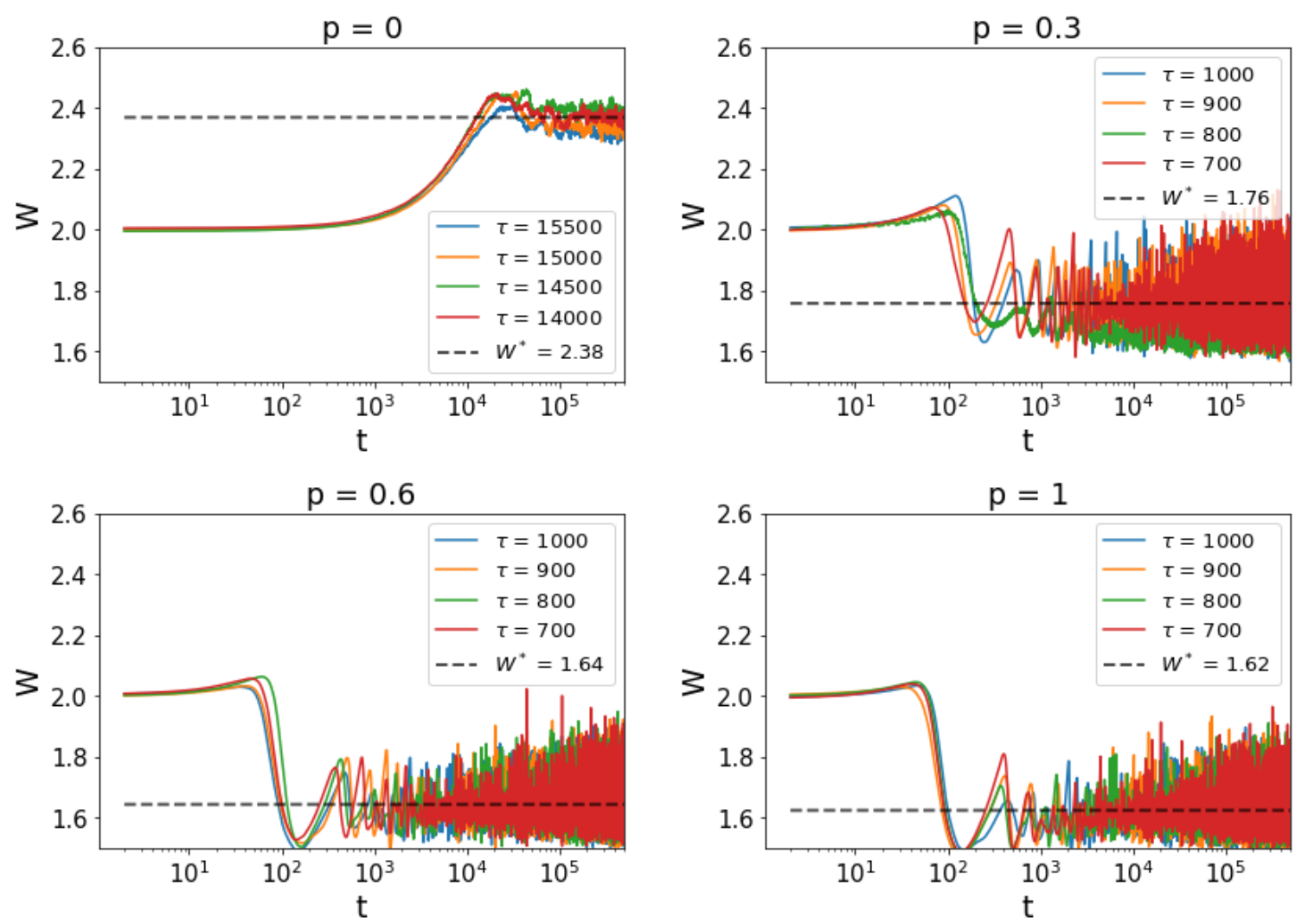

(a) Quenched
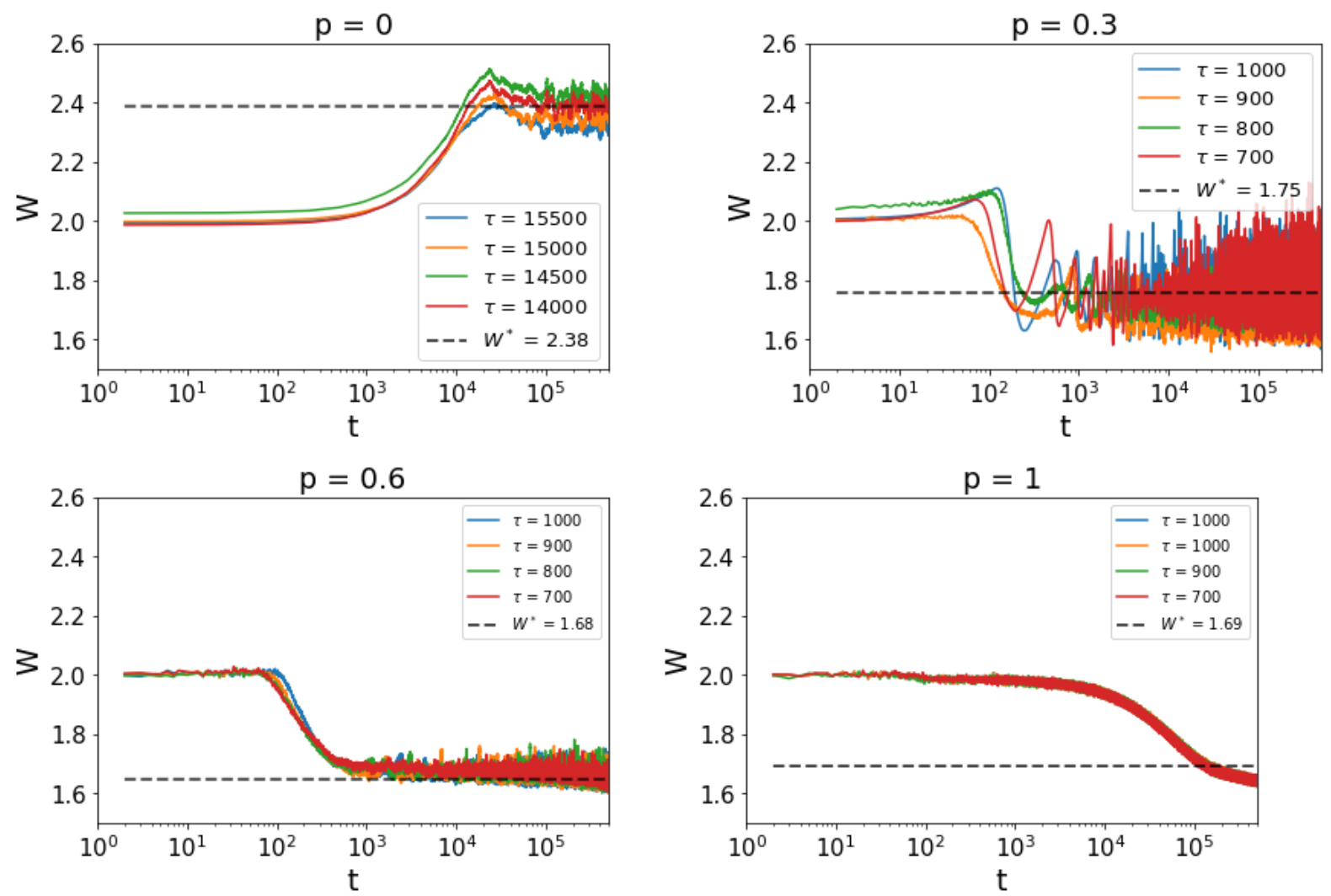

(b) Annealed

Figura 4.13: Auto-organização com peso-sináptico dinâmicos. Parâmetros: $\theta=0, \Gamma=1, K=4, \mu=0, I=0, u=0,1$ e $\tau$ variável. Para diferentes valores de $p$. (a) Simulação de rede do tipo quenched. (b) Simulação de rede do tipo annealed. 


\section{CONCLUSÕES E PERSPECTIVAS}

No presente trabalho, foram realizadas simulações computacionais de um modelo neuronal utilizando uma topologia de rede mundo pequeno tipo Watts-Strogatz. O modelo estudado foi uma adaptação de tempo discreto do modelo GGL (Gerstner-Galves-Löcherbach), que é um modelo integra-e-dispara estocástico. Para uma melhor compreensão a respeito dos assuntos tratados nas simulações computacionais estudadas, foi realizada inicialmente uma revisão de literatura abrangendo conceitos sobre o sistema nervoso e sobre Mecânica Estatística.

Para compararmos com os resultados das simulações, fizemos cálculos analíticos de campo médio. Pelas simulações vimos que o modelo apresenta transições de fase de segunda ordem e o ponto crítico das transições foi estudado para diferentes conjuntos de parâmetros. Com os pontos criticos conseguimos encontrar os expoentes críticos do sistema e assim constatar que pertence à classe de universalidade de percolação direcionada. Alguns estudos já haviam sido feitos com relação à classe de universalidade para outras redes usando modelos neuronais semelhantes. Assim, uma das novidades de nosso trabalho foi confirmar esse resultado para redes do tipo Watts-Strogatz.

Estudamos diferentes probabilidades de reconexão da rede WS e um resultado interessante foi que para $p=0$ (rede fechada com conexões apenas entre os $K$ vizinhos mais próximos de cada neurônio) o expoente crítico corresponde ao da dimensão $d=1$ da classe PD, enquanto para redes com $p>0$ temos $d=4$, condizente com campo médio. A rede unidimensional é de "mundo grande" e encontramos certas peculiaridades para este caso. O estado ativo da rede perdura por mais interações e consequentemente suas avalanches são maiores e sua lei de potência possui um expoente diferente.

Quando incluímos conexões de longa distância na rede $(p>0)$ temos redes que se aproximam dos resultados de campo médio. Lembremos, porém, que nossa rede é esparsa $(K<<N)$ : dado isso, o ponto crítico depende de $K$, ou seja, $W_{c}(K)$. Vale ressaltar que o ponto critico da rede para diferentes valores de $p$ também apresentou diferenças quantitativas, observamos também que as transições de fase dependem do termo de vazamento $(\mu)$.

Considerando trabalho futuros, é possível realizar estudos mais aprofundados a respeito dos pesos sinápticos $W_{i j}[t]$ adaptativos, bem como de combinações de mecanismos. As diferenças entre os casos quenched e annealed desse sistema podem ser também mais exploradas, medindo-se cuidadosamente as diferenças quantitativas existentes e estudandose a propagação da atividade na rede e as correlações no percurso. Outra possibilidade é a inclusão de sinapses inibitórias no modelo, o que demanda novas considerações e novos ajustes. 


\section{Trabalhos resultantes dessa dissertação}

\section{Artigos publicados}

KINOUCHI, O. ; PAZZINI, R. L. ; COPELLI, M. . Mechanisms of self-organized quasicriticality in neuronal networks models. Frontiers in Physics, 2020.

PAZZINI, R. ; KINOUCHI, O. ; COSTA, A. A. . Neuronal avalanches in WattsStrogatz networks of stochastic spiking neurons. PHYSICAL REVIEW E, v. 104, p. 014137, 2021.

\section{Apresentação em congressos}

PAZZINI, R. L.. Phase transitions in stochastic neuron networks with small world topology. In: XLIII Reunião Anual da SBNeC - Online, 2020. Neurocienciaa Teórica, Computacional e Neurotecnologias (interfaces neurobóticas,nanotecnologia, etc.), 2020.

PAZZINI, R. ; KINOUCHI, O. ; COSTA, A. A. . NEURONAL AVALANCHES AND CRITICALITY IN SMALL-WORLD NETWORKS OF STOCHASTIC SPIKING NEURONS. In: Encontro de Outono da SBF 2021 - Online, 2020. Critical Phenomena and Phase Transitions, 2021. 


\section{REFERÊNCIAS}

[1] Osame Kinouchi, Renata Pazzini, and Copelli. Mechanisms of self-organized quasicriticality in neuronal networks models. Front. Phys., 8, 2020.

[2] Dale Purves, George J Augustine, David Fitzpatrick, William C Hall, McNamara JO, and Williams SM Neuroscience. Sinauer associates. Inc, , 3(5):24, 2004.

[3] Eric Kandel, James Schwartz, Thomas Jessell, Steven Siegelbaum, and AJ Hudspeth. Princípios de Neurociências-5. AMGH Editora, 2014.

[4] Mark Bear, Barry Connors, and Michael Paradiso. Neuroscience: Exploring the brain: Fourth edition. Wolters Kluwer, 2015.

[5] Harry Eugene Stanley and Guenter Ahlers. Introduction to phase transitions and critical phenomena. Phys Today, 26:71, 1973.

[6] Joaquin Marro and Ronald Dickman. Nonequilibrium Phase Transitions in Lattice Models. Collection Alea-Saclay: Monographs and Texts in Statistical Physics. Cambridge University Press, 1999.

[7] Henkel Malte, Hinrichsen Haye, and Lübeck Sven. Non-Equilibrium Phase Transitions. Springer Netherlands, 2008.

[8] Duncan J. Watts and Steven H. Strogatz. Collective dynamics of 'small-world' networks. Nature, 393(4):440-442, 1998.

[9] Mark EJ Newman, Cristopher Moore, and Duncan J Watts. Mean-field solution of the small-world network model. Physical Review Letters, 84(14):3201, 2000.

[10] Emilio Salinas and Terrence J Sejnowski. Correlated neuronal activity and the flow of neural information. Nature reviews neuroscience, 2(8):539-550, 2001.

[11] Emilio Salinas and Terrence J Sejnowski. Impact of correlated synaptic input on output firing rate and variability in simple neuronal models. Journal of neuroscience, 20(16):6193-6209, 2000.

[12] Wulfram Gerstner and Werner M Kistler. Spiking Neuron Models: Single Neurons, Populations, Plasticity. Cambridge Univ. Press, 2002.

[13] Panayiota Poirazi, Terrence Brannon, and Bartlett W Mel. Pyramidal neuron as two-layer neural network. Neuron, 37(6):989-999, 2003.

[14] Santiago Ramon y Cajal. Nueva concepta de la histologia de los centros nervosos. Annals of Surgery, 18:122, 1893. 
[15] Sabrina Bezerra. Reservoir Computing com Hierarquia para Previsão de Vazões Médias Diárias. PhD thesis, Universidade de Pernambuco, 2016.

[16] Guy Major, Matthew E Larkum, and Jackie Schiller. Active properties of neocortical pyramidal neuron dendrites. Annual review of neuroscience, 36:1-24, 2013.

[17] Nelson Spruston. Pyramidal neurons: dendritic structure and synaptic integration. Nature Reviews Neuroscience, 9(3):206-221, 2008.

[18] Elenice A. de Moraes Ferrari, Margarete Satie S. Toyoda, Luciane Faleiros, and Suzete Maria Cerutti. Plasticidade neural: relação com o comportamento e abordagens experimentais. Psicologia: Teoria e Pesquisa, 17:187 - 194, 2001.

[19] Robert C Malenka. Synaptic plasticity. 2001.

[20] Mikhail I. Rabinovich, Pablo Varona, Allen I. Selverston, and Henry D. I. Abarbanel. Dynamical principles in neuroscience. Rev. Mod. Phys., 78:1213-1265, Nov 2006.

[21] Claudia Dechichi, Juliene Ferreira, and Lazara Cristina Silva. Inclusão Educacional e Educação Especial : Múltiplos olhares e deveras contribuições. EDUFU, 2013.

[22] Nicola B Hamilton and David Attwell. Do astrocytes really exocytose neurotransmitters? Nature Reviews Neuroscience, 11(4):227-238, 2010.

[23] Graeme W Davis and Corey S Goodman. Synapse-specific control of synaptic efficacy at the terminals of a single neuron. Nature, 392(6671):82, 1998.

[24] Larry F. Abbott. Theoretical neuroscience rising. Neuron, 60(3):489-495, 2008.

[25] Peter Dayan and Larry F. Abbott. Theoretical Neuroscience. MIT Press, Cambridge, MA, 2001.

[26] Misha Rabinovich, Ramon Huerta, and Gilles Laurent. Transient dynamics for neural processing. Science, 321(5885):48-50, 2008.

[27] Larry F. Abbott and Thomas B Kepler. Model neurons: from hodgkin-huxley to hopfield. In Statistical mechanics of neural networks, pages 5-18. Springer, 1990.

[28] Ariadne A Costa, Mauro Copelli, and Osame Kinouchi. Can dynamical synapses produce true self-organized criticality? J. Stat. Mech., 2015(6):P06004, 2015.

[29] Mauricio Girardi-Schappo, MHR Tragtenberg, and Osame Kinouchi. A brief history of excitable map-based neurons and neural networks. J. Neurosci. Methods, 220(2):116-130, 2013. 
[30] Bruno Cessac. A discrete time neural network model with spiking neurons. J. Math. Biol., 56(3):311-345, 2008.

[31] Eugene M Izhikevich. Simple model of spiking neurons. IEEE Transactions on Neural Networks, 14(6):1569-1572, 2003.

[32] Wulfram Gerstner and J L van Hemmen. Associative memory in a network of 'spiking' neurons. Netw. Comput. Neural Syst., 3(2), 1992.

[33] Antonio Galves and E Löcherbach. Infinite systems of interacting chains with memory of variable length - a stochastic model for biological neural nets. J. Stat. Phys., 151(5), 2013.

[34] Ludmil Brochini, Ariadne de Andrade Costa, Miguel Abadi, Jorge Roque, Antônio C.and Stolfi, and Osame Kinouchi. Phase transitions and self-organized criticality in networks of stochastic spiking neurons. Scientific Reports, 6:440-442, 2016.

[35] Ariadne Costa, Ludmila Brochini, and Osame Kinouchi. Self-organized supercriticality and oscillations in networks of stochastic spiking neurons. Entropy, 19, 2017.

[36] Osame Kinouchi, Ludmila Brochini, Ariadne A Costa, João G F Campos, and Mauro Copelli. Stochastic oscillations and dragon king avalanches in self-organized quasicritical systems. Sci. Rep., 9:3874, 2019.

[37] Mauricio Girardi-Schappo, Ludmila Brochini, Ariadne A Costa, Tawan TA Carvalho, and Osame Kinouchi. Self-organized critical balanced networks: a unified framework. arXiv preprint arXiv:1906.05624, 2019.

[38] Mark Newman. Networks: an introduction. Oxford university press, 2010.

[39] Stanley Milgram. The small world problem. Psychology today, 2(1):60 - 67, 1967.

[40] Danielle Smith Bassett and Ed Bullmore. Small-world brain networks. The Neuroscientist, 12(6):512-523, 2006. PMID: 17079517.

[41] Lei Gu, Hui Lin Huang, and Xiao Dong Zhang. The clustering coefficient and the diameter of small-world networks. Acta Mathematica Sinica, English Series, 29(1):199$208,2013$.

[42] Cornelis J Stam, BF Jones, G Nolte, M Breakspear, and Ph Scheltens. SmallWorld Networks and Functional Connectivity in Alzheimer's Disease. Cerebral Cortex, 17(1):92-99, 022006.

[43] Mark EJ Newman. Models of the small world. Journal of Statistical Physics, 101(3):819-841, 2000. 
[44] Duncan J Watts. Networks, dynamics, and the small-world phenomenon. American Journal of sociology, 105(2):493-527, 1999.

[45] Xiao Fan Wang and Guanrong Chen. Complex networks: small-world, scale-free and beyond. IEEE Circuits and Systems Magazine, 3(1):6-20, 2003.

[46] Danielle Smith Bassett and Ed Bullmore. Small-world brain networks. The Neuroscientist, 12(6):512-523, 2006. PMID: 17079517.

[47] Yong Liu, Meng Liang, Yuan Zhou, Yong He, Yihui Hao, Ming Song, Chunshui Yu, Haihong Liu, Zhening Liu, and Tianzi Jiang. Disrupted small-world networks in schizophrenia. Brain, 131(4):945-961, 2008.

[48] Edward T. Bullmore, S. Frangou, and R.M. Murray. The dysplastic net hypothesis: an integration of developmental and dysconnectivity theories of schizophrenia. Schizophrenia Research, 28(2):143 - 156, 1997.

[49] Malte Henkel, Haye Hinrichsen, Sven Lübeck, and Michel Pleimling. Non-equilibrium phase transitions, volume 1. Springer, 2008.

[50] Herbert B Callen. Thermodynamics and an Introduction to Thermostatistics. AAPT, 1998.

[51] Haye Hinrichsen. Non-equilibrium critical phenomena and phase transitions into absorbing states. Advances in Physics, 49(7):815-958, 2000.

[52] John M Beggs and Dietmar Plenz. Neuronal avalanches in neocortical circuits. J. Neurosci., 23(35):11167-11177, 2003.

[53] Gerald Hahn, Thomas Petermann, Martha N. Havenith, Shan Yu, Wolf Singer, Dietmar Plenz, and Danko Nikolić. Neuronal avalanches in spontaneous activity in vivo. Journal of Neurophysiology, 104(6):3312-3322, 2010. PMID: 20631221.

[54] Dante R Chialvo. Emergent complex neural dynamics. Nature Phys., 6(10), 2010.

[55] Alan M Turing. Computing machinery and intelligence. Mind, 59:433-460, 1950.

[56] Per Bak, Chao Tang, and Kurt Wiesenfeld. Self-organized criticality: An explanation of the 1/f noise. Phys. Rev. Lett., 59(4):381, 1987.

[57] Thomas Petermann, Tara C. Thiagarajan, Mikhail A. Lebedev, Miguel A. L. Nicolelis, Dante R. Chialvo, and Dietmar Plenz. Spontaneous cortical activity in awake monkeys composed of neuronal avalanches. Proceedings of the National Academy of Sciences, 106(37):15921 - 15926, 2009. 
[58] Oren Shriki, Jeff Alstott, Frederick Carver, Tom Holroyd, Richard NA Henson, Marie L Smith, Richard Coppola, Edward Bullmore, and Dietmar Plenz. Neuronal avalanches in the resting meg of the human brain. Journal of Neuroscience, 33(16):7079$7090,2013$.

[59] Osame Kinouchi and Mauro Copelli. Optimal dynamical range of excitable networks at criticality. Nature Physics, 2(5):348 - 351, 2006.

[60] Woodrow L Shew, Hongdian Yang, Thomas Petermann, Rajarshi Roy, and Dietmar Plenz. Neuronal avalanches imply maximum dynamic range in cortical networks at criticality. J. Neurosci., 29(49):15595-15600, 2009.

[61] Shree H. Gautam, Thanh T Hoang, Kylie McClanahan, Stephen K Grady, and Woodrow L Shew. Maximizing sensory dynamic range by tuning the cortical state to criticality. PLoS Comput. Biol., 11(12):e1004576, 2015.

[62] Lucilla de Arcangelis, Carla Perrone-Capano, and Hans J Herrmann. Self-organized criticality model for brain plasticity. Phys. Rev. Lett., 96(2):028107, 2006.

[63] Thiago S Mosqueiro and Leonardo P Maia. Optimal channel efficiency in a sensory network. Phys. Rev. E, 88(1):012712, 2013.

[64] Nicolas Brunel. Dynamics of sparsely connected networks of excitatory and inhibitory spiking neurons. J. Comput. Neurosci., 8(3):183-208, 2000.

[65] Per Bak and Chao Tang. Earthquakes as a self-organized critical phenomenon. Journal of Geophysical Research: Solid Earth, 94(B11):15635-15637, 1989.

[66] Robert Burridge and Leon Knopoff. Model and theoretical seismicity. Bulletin of the seismological society of america, 57(3):341-371, 1967.

[67] Norma B Crosby, Markus J Aschwanden, and Brian R Dennis. Frequency distributions and correlations of solar x-ray flare parameters. Solar Physics, 143(2):275-299, 1993.

[68] Kan Chen, Per Bak, and Mogens H Jensen. A deterministic critical forest fire model. Physics Letters A, 149(4):207-210, 1990.

[69] Siegfried Clar, Barbara Drossel, and Franz Schwabl. Scaling laws and simulation results for the self-organized critical forest-fire model. Physical Review E, 50(2):1009, 1994.

[70] Henrik Jeldtoft Jensen. Self-organized criticality: Emergent Complex Behavior in Physical and Biological Systems. Cambridge Univ. Press, Cambridge, UK, 1998. 
[71] Jonathan Touboul and Alain Destexhe. Power-law statistics and universal scaling in the absence of criticality. Physical Review E, 95(1):012413, 2017.

[72] Jonathan Touboul and Alain Destexhe. Power-law statistics and universal scaling in the absence of criticality. Physical Review E, 95(1):012413, 2017.

[73] Jens Wilting and Viola Priesemann. 25 years of criticality in neuroscience - established results, open controversies, novel concepts. Current Opinion in Neurobiology, 58:105-111, 2019. Computational Neuroscience.

[74] Juan A Bonachela and Miguel A Muñoz. Self-organization without conservation: true or just apparent scale-invariance? J. Stat. Mech., 2009(09):P09009, 2009.

[75] Gunnar Pruessner. Self-organised Criticality: Theory, Models and Characterisation. Cambridge Univ. Press, Cambridge, UK, 2012.

[76] Lorenzo Palmieri and Henrik Jeldtoft Jensen. The emergence of weak criticality in soc systems. EPL (Europhysics Letters), 123(2):20002, 2018.

[77] Lorenzo Palmieri and Henrik Jeldtoft Jensen. The forest fire model: The subtleties of criticality and scale invariance. Frontiers in Physics, 8:257, 2020.

[78] Victor Buendia, Serena di Santo, Juan A. Bonachela, and Miguel A. Muñoz. Feedback mechanisms for self-organization to the edge of a phase transition. Frontiers in Physics, 8:333, 2020.

[79] Ronald Dickman, Miguel A Muñoz, Alessandro Vespignani, and Stefano Zapperi. Paths to self-organized criticality. Braz. J. Phys., 30(1):27-41, 2000.

[80] Juan A Bonachela, Sebastiano de Franciscis, Joaquín J Torres, and Miguel A Muñoz. Self-organization without conservation: are neuronal avalanches generically critical? J. Stat. Mech., 2010(02):P02015, 2010.

[81] Mauricio Girardi-Schappo, Brochini Ludmina, A Ariadne Costa, T Tawan A Carvalho, and O Kinouchi. Synaptic balance due to homeostatically self-organized quasicritical dynamics. Phys. Rev. Res., 2:012042, 2020.

[82] Kiyoshi Kawai, Toru Suzuki, and Masaharu Oguni. Low-temperature glass transitions of quenched and annealed bovine serum albumin aqueous solutions. Biophysical journal, 90(10):3732-3738, 2006.

[83] Abdul N. Malmi-Kakkada, Oriol T. Valls, and Chandan Dasgupta. Ising model on a random network with annealed or quenched disorder. Phys. Rev. B, 90:024202, Jul 2014. 
[84] Dietrich Stauffer and Muhammad Sahimi. Diffusion in scale-free networks with annealed disorder. Physical Review E, 72(4):046128, 2005.

[85] Eugene Izhikevich. Dynamical systems in neuroscience. MIT Press, page 111, 2007.

[86] Ariadne A Costa, Ludmila Brochini, and O Kinouchi. Self-organized supercriticality and oscillations in networks of stochastic spiking neurons. Entropy, 19(8):399, 2017.

[87] Johanna M.H. Levelt Sengers. From van der waals' equation to the scaling laws. Physica, 73(1):73-106, 1974.

[88] Mario N Berberan-Santos, Evgeny N Bodunov, and Lionello Pogliani. The van der waals equation: analytical and approximate solutions. Journal of mathematical chemistry, 43(4):1437-1457, 2008.

[89] Nicolas Gast and Benny Van Houdt. A refined mean field approximation. Proceedings of the ACM on Measurement and Analysis of Computing Systems, 1(2):1-28, 2017.

[90] Toshiyuki Tanaka. A theory of mean field approximation. Advances in Neural Information Processing Systems, pages 351-360, 1999.

[91] Édouard Brézin and J. Zinn-Justin. Finite size effects in phase transitions. Nuclear Physics B, 257:867-893, 1985.

[92] Gina G Turrigiano and Sacha B Nelson. Hebb and homeostasis in neuronal plasticity. Curr Opin Neurobiol, 10(3):358-364, 2000.

[93] Bard Ermentrout, Ma Pascal, and B Gutkin. The effects of spike frequency adaptation and negative feedback on the synchronization of neural oscillators. Neural Comput., 13(6):1285-1310, 2001.

[94] Jan Benda and Andreas VM Herz. A universal model for spike-frequency adaptation. Neural computation, 15(11):2523-2564, 2003.

[95] Ludmila Brochini, A Ariadne Costa, M Abadi, A C Roque, J Stolfi, and O Kinouchi. Phase transitions and self-organized criticality in networks of stochastic spiking neurons. Sci. Rep., 6, 2016.

[96] Joaquin Marro, JL Lebowitz, H Spohn, and M Ho Kalos. Nonequilibrium phase transition in stochastic lattice gases: Simulation of a three-dimensional system. Journal of Statistical Physics, 38(3-4):725-733, 1985.

[97] James P Sethna, Karin A Dahmen, and Christopher R Myers. Crackling noise. Nature, 410(6825):242-250, 2001. 
[98] Miguel A Munoz, Ronald Dickman, Alessandro Vespignani, and Stefano Zapperi. Avalanche and spreading exponents in systems with absorbing states. Phys. Rev. E, 59(5):6175, 1999.

[99] Anna Levina, J Michael Herrmann, and Theo Geisel. Dynamical synapses causing self-organized criticality in neural networks. Nature Phys., 3(12):857-860, 2007. 